Differentielle Genexpression während Ischämie und Reperfusion im Modell der extrakorporalen Dünndarmperfusion am Schwein

\author{
DISSERTATION \\ zur Erlangung des Doktorgrades \\ der Mathematisch-Naturwissenschaftlichen Fakultäten \\ der Georg-August-Universität zu Göttingen
}

vorgelegt von

Dipl.-Biol. Seyed Mehdi Hosseini

aus Teheran/Iran

Göttingen 2002 
D7

Referent:

Professor Dr. Hardeland

Korreferent:

Professor Dr. Engel

Tag der mündlichen Prüfung:

30.10 .2002 
Verwendete Abkürzungen III

Universeller genetischer Code $\quad$ VI

Abkürzungen von Restriktionsendonukleasen VII

1 EINLEITUNG 1

1.1. Allgemeine Vorbemerkungen 1

1.2. Ischämie-Reperfusionsschaden 2

1.2.1. Ischämie-Reperfusionsschaden des Dünndarms 5

1.3. Aufgabenstellung und Ziel der Arbeit 10

2 MATERIAL 11

2.1. Verwendete Lösungen und Puffer 11

2.2. Nährmedien 16

2.3. Chemikalien 17

2.4. Enzyme 18

2.5. Nukleinsäuren, Radiochemikalien 18

2.6. Bakterienstamm 19

2.7. Geräte 19

2.8. Fotomaterialien 20

3 METHODEN 21

3.1. Versuchstiere und Extrakorporale Dünndarmperfusion 21

3.2. Molekularbiologische Methoden 22

3.2.1. RNA-Arbeiten 22

3.2.1.1. Isolation von Gesamt-RNA aus Gewebe 23

3.2.1.2. Reinigung der Proben mit DNase 23

3.2.1.3. Reverse Transkription $\quad 24$

3.2.2. Oligonukleotid Primer für die RT-PCR 25

3.2.3. PCR-Reaktionen 25

3.2.4. Quantitative Polymerasekettenreaktion 26

3.2.5. RACE-PCR 27

3.2.6. RNA-Gelelektrophorese 28

3.2.7. Markierungen von DNA und RNA 29

3.2.7.1. Nicht-radioaktive Markierung von DNA mit Digoxygenin 29

3.2.7.2. Nicht-radioaktive Markierung von RNA mit Digoxygenin 29

3.2.8. Dot-Blot 30

3.2.9. Slot-Blot 30

3.2.10. Northern-Blot 31

3.2.11. Hybridisierung membrangebundener Nukleinsäuren mit markierten Sonden 31

3.2.12. In-situ-Hybridisierung der Gewebeschnitte 32

3.2.12.1. Nachweis der digoxygeninmarkierten Sonde mit
alkalischer Phosphatase

3.2.12.2. Meerrettichperoxidase-Nachweis digoxygeninmarkierter Sonden 34 
3.2.13. mRNA-Differential Display-Technik (DD-RT-PCR) 34

3.2.13.1. Downstream Primer und upstream Primer 36

3.2.13.2. Reverse Transkription von mRNA für differentielles RNA-Display

36

3.2.13.3. PCR im differentiellen RNA-Display 36

3.2.13.4. Polyacrylamidgel-Elektrophorese (PAGE) von Nukleinsäuren

3.2.13.5. Darstellen von Nukleinsäuren in Polyacrylamidgelen mittels Silberfärbung

3.2.13.6. Reamplifikation von PCR-Produkten 38

3.2.13.7. Native-Agarose-Gelelektrophorese 39

3.2.13.8. Isolierung von DNA-Fragmenten aus präparativen Gelen 39

3.2.14. Molekulare Klonierungstechniken 40

3.2.14.1. Klonierung der PCR-Produkte mit dem TA-Verfahren 40

3.2.14.2. Verdauung von DNA mit Restriktionsendonukleasen 41

3.2.14.3. Auffüllen von 3'-zurückliegenden Enden 41

3.2.14.4. Dephosphorylierung linearisierter DNA mit alkalischer Phosphatase

3.2.14.5. Ligation

3.2.15. DNA-Isolierungstechniken 43

3.2.15.1 Analyse von Plasmidklonen 43

3.2.15.2. Präparation von Plasmid-DNA aus E. coli 43

3.2.15.2.1. Mini-Präparation 43

3.2.15.2.2. Midi-Präparation 44

3.2.16. Konzentrations- und Reinheitsbestimmung isolierter DNA 45

3.2.17. Sequenzierung von DNA 45

3.2.18. Datenbankrecherche 46

$\begin{array}{lll}4 & \text { ERGEBNISSE } & 47\end{array}$

4.1. Hämodynamische Veränderungen und mukosale Schädigung 47

4.2. Proinflammatorische Mediatoren $\quad 47$

4.2.1. Interleukin $6 \quad 47$

4.2.2. Interleukin 2

4.2.3. Hitze-Schock-Protein 70 (HSP70) 52

4.2.4. Interferon-gamma (IFN $\gamma$ ) 55

4.2.5. E-Selektin 56

4.3. mRNA-Differential Display 59

$5 \quad$ DISKUSSION 69

$\begin{array}{ll}\text { 5.1. Proinflammatorische Mediatoren } & 70\end{array}$

5.2. mRNA-Differential Display 76

5.3. Schlussfolgerung 84

6 ZUSAMMENFASSUNG 86

7 LITERATURVERZEICHNIS 90 


\section{Verwendete Abkürzungen}

\begin{tabular}{|c|c|}
\hline alpha-NAC & Nascent-Polypeptide-Associated Comlex \\
\hline$A m p^{r}$ & Ampicillinresistenz \\
\hline AMPS & Ammoniumperoxodisulfat \\
\hline AP & Alkalische Phosphatase \\
\hline AS & Aminosäure(n) \\
\hline BCIP & 5-Bromo-4-chloro-3-indolyl-phosphat \\
\hline bp & Basenpaar(e) \\
\hline BSA & Rinderserumalbumin (bovine serum albumin) \\
\hline cc & zirkulär geschlossen (closed circular) \\
\hline \multirow[t]{2}{*}{ CIP } & alkalische Phosphatase aus Kälberdarm \\
\hline & (calf intestinal alkaline phosphatase) \\
\hline cDNA & komplementäre DNA \\
\hline \multirow[t]{3}{*}{ CSPD $®$} & Disodium 3-(4-methoxyspiro $\left\{1,2-\right.$-Dioxetane-3,2 $-\left(5^{\prime}\right.$ - \\
\hline & Chloro) Tricyclo[3.3.1.13,7] Decan\}-4-yl) \\
\hline & Phenylphosphat \\
\hline d & $\operatorname{Tag}(\mathrm{e})$ (days) \\
\hline $\mathrm{Da}$ & Dalton \\
\hline DEPC & Diethyl-Pyrocarbonat \\
\hline (d)ATP & (2'-Desoxy)adenosin-5'-Triphosphat \\
\hline (d)CTP & (2'-Desoxy)cytidin-5'-Triphosphat \\
\hline dd & bidestilliertes Wasser \\
\hline DDEF1 & Development and Differentiation Enhancing Factor 1 \\
\hline ddNTP & $2^{\prime}, 3^{\prime}$-Didesoxynukleosid-5'-Triphosphat \\
\hline DD-RT & Differential Display-Reverse Transkriptase \\
\hline (d)GTP & (2'-Desoxy)guanosin-5'-Triphosphat \\
\hline DIG & Digoxygenin \\
\hline DMSO & Dimethylsulfoxyd \\
\hline DNA & Desoxyribonukleinsäure (deoxyribonucleic acid) \\
\hline DNase & Desoxyribonuklease \\
\hline dNTP & 2'-Desoxynukleosid-5'-Triphosphat \\
\hline ds DNA & doppelsträngige DNA (double-stranded DNA) \\
\hline DTT & Dithiothreitol \\
\hline
\end{tabular}




\begin{tabular}{|c|c|}
\hline E.coli & Escherichia coli \\
\hline EDTA & Ethylendiamintetraacetat (Natriumsalz) \\
\hline et al. & und andere (et alteri) \\
\hline $\mathrm{EtOH}$ & Ethanol \\
\hline g & Gramm \\
\hline Gal & Galactose \\
\hline GUCY1B3 & Guanylat-Cyclase 1B3 \\
\hline $\mathrm{h}$ & Stunde(n) (hours) \\
\hline HAC & Essigsäure \\
\hline $\mathrm{H}_{2} \mathrm{O}_{\mathrm{dd}}$ & doppelt destilliertes Wasser \\
\hline HSE & Hitze-Schock-Element \\
\hline HSF & Hitze-Schock-Faktor \\
\hline HSP70 & Hitze-Schock Protein 70 \\
\hline HTK & Histidin-Tryptophan-Ketoglutarat \\
\hline $\mathrm{IFN} \gamma$ & Interferon-gamma \\
\hline IL- & Interleukin- \\
\hline $\mathrm{ISH}$ & In-situ-Hybridisierung \\
\hline $\mathrm{kDa}$ & Kilodalton \\
\hline $\mathrm{Kg}$ & Kilogramm \\
\hline $\mathrm{KIZ}$ & kalte Ischämiezeit \\
\hline M & Molar \\
\hline $\mathrm{mA}$ & Milliampere \\
\hline MAB & Maleinsäure-Puffer \\
\hline MCS & Multi cloning site \\
\hline $\min$ & Minute(n) \\
\hline $\mathrm{mM}$ & Millimolar \\
\hline $\mathrm{mmHg}$ & Druckeinheit \\
\hline MMLV & Murine-Moloney Leukemia Virus \\
\hline MYO 5B & Myosin 5B \\
\hline$N$ & Stickstoff \\
\hline $\mathrm{n}$ & normal \\
\hline NBT & Nitroblautetrazoliumchlorid \\
\hline NTD & N-terminale Domäne \\
\hline OD & optische Dichte \\
\hline
\end{tabular}




$\begin{array}{ll}\text { ORF } & \text { offener Leserahmen (open reading frame) } \\ \text { PAA } & \text { Polyacrylamid } \\ \text { PCR } & \text { Polymerase-Kettenreaktion (polymerase chain reaction) } \\ \text { PEG } & \text { Polyethylenglykol } \\ \text { Perf. } & \text { Perfusion } \\ \text { pH } & \text { negativer dekadischer Logarithmus der } \\ & \text { Protonenkonzentration } \\ \text { RNase A } & \text { Ribonuklease A } \\ \text { RNase H } & \text { Ribonuklease H } \\ \text { rpm } & \text { Umdrehungen pro Minute (revolutions per minute) } \\ \text { rRNA } & \text { ribosomale Ribonukleinsäure } \\ \text { RPL3 } & \text { Ribosomal Protein L3 } \\ \text { RT } & \text { Reverse Transkription } \\ \text { sec } & \text { Sekunde(n) } \\ \text { SDS } & \text { Natriumdodecylsulfat (sodium dodecyl sulphate) } \\ \text { SNAP23 } & \text { Synaptosomal-Associated Protein 23 } \\ \text { ss DNA } & \text { einzelsträngige DNA (single-stranded DNA) } \\ \text { STK12 } & \text { Serin/Threonin kinase 12 } \\ \text { TCF7 } & \text { Transkriptionsfaktor 7 (Transcription Factor 7) } \\ \text { Tris } & \text { a,a,a-Tris-(hydroxymethyl)-Methylamin } \\ \text { U } & \text { Unit(s)=Enzymeinheit(en) } \\ \text { UHRF1 } & \text { Ubiquitin-Like Containing PHD and RING Finger } \\ \text { UpM } & \text { Domains 1 } \\ \text { ü.N. } & \text { Umderehungen pro Minute } \\ \text { UV-Licht } & \text { über Nacht } \\ \text { V } & \text { ultraviolettes Licht } \\ \text { (v/v) } & \text { Volt } \\ \text { (w/v) } & \text { Volumen pro Volumen } \\ & \text { Gewicht pro Volumen } \\ & \end{array}$




\section{Universeller genetischer Code}

\begin{tabular}{|c|c|c|c|}
\hline$A$ & Ala & Alanin & GCA GCC GCGGCT \\
\hline C & Cys & Cystein & TGC TGT \\
\hline D & Asp & Asparaginsäure & GAC GAT \\
\hline$E$ & Glu & Glutaminsäure & GAA GAG \\
\hline $\mathrm{F}$ & Phe & Phenylalanin & TTC TTT \\
\hline G & Gly & Glycin & GGA GGC GGG GGT \\
\hline $\mathrm{H}$ & His & Histidin & CAC CAT \\
\hline I & lle & Isoleucin & ATA ATC ATT \\
\hline K & Lys & Lysin & AAA AAG \\
\hline $\mathrm{L}$ & Leu & Leucin & TTA TTG CTA CTC CTG CTT \\
\hline M & Met & Methionin & ATG \\
\hline $\mathrm{N}$ & Asn & Asparagin & AAC AAT \\
\hline$P$ & Pro & Prolin & CCA CCC CCG CCT \\
\hline Q & GIn & Glutamin & CAA CAG \\
\hline $\mathrm{R}$ & Arg & Arginin & AGA AGG CGA CGC CGG CGT \\
\hline S & Ser & Serin & AGC AGT TCA TCC TCG TCT \\
\hline $\mathrm{T}$ & Thr & Threonin & ACA ACC ACG ACT \\
\hline V & Val & Valin & GTA GTC GTG GTT \\
\hline W & Trp & Tryptophan & TGG \\
\hline \multirow[t]{2}{*}{$\mathrm{Y}$} & Tyr & Tyrosin & TAC TAT \\
\hline & & Stop-Codon & TAA TAG TGA \\
\hline
\end{tabular}


Abkürzungen von Restriktionsendonukleasen

$\begin{array}{ll}\text { Ag } & \text { Agel } \\ \text { B } & \text { BamHI } \\ \text { b } & \text { Bgll } \\ \text { Bs } & \text { BsrGl } \\ \text { Bst } & \text { BstEll } \\ \text { E } & \text { EcoRI } \\ \text { EV } & \text { EcoRV } \\ \text { H } & \text { HindlII } \\ \text { M } & \text { Mlul } \\ \mathrm{N} & \text { Nhel } \\ \text { Nc } & \text { Ncol } \\ \text { No } & \text { Notl } \\ \text { P } & \text { Pstl } \\ \text { S } & \text { Sall } \\ \text { Se } & \text { Spel } \\ \text { X } & \text { Xbal } \\ \text { Xo } & \text { Xhol }\end{array}$




\section{EINLEITUNG}

\subsection{Allgemeine Vorbemerkungen}

Die Transplantation solider Organe ist eine etablierte Therapie bei akuten oder chronischen Erkrankungen, die zum irreversiblen Verlust der Organfunktion führen. Die Entnahmeoperation findet bei der postmortalen Organspende meist örtlich getrennt von der Empfängeroperation statt, so dass die Spenderorgane zum Empfänger-Krankenhaus transportiert werden müssen. Die Entwicklung geeigneter Konservierungslösungen und die Kühlung der Transplantate erlaubt eine Konservierung der Spenderorgane für mehrere Stunden. Die zeitlichen Grenzen für die kalte Konservierung liegen bei der Niere bei 36, bei der Leber bei 12 und beim Herzen bei 6 Stunden. Die kalten Konservierungslösungen enthalten protektive Substanzen, welche die Organfunktion nach Reperfusion des Transplantates erhalten sollen und somit den Transport der Spenderorgane erlauben.

Neben den logistischen Voraussetzungen, die eine kalte Konservierung der Spenderorgane erfordern, werden die Transplantate notwendigerweise unterschiedlichen Schädigungen ausgesetzt. Die Organe werden im hirntoten Spender durch Aufrechterhaltung der Hämostase weiter mit Blut perfundiert. Das Spenderalter, die Todesursache, eine eventuelle Reanimation und die intensivmedizinische Therapie beeinflussen hierbei die Spenderorgane. Während der Spenderoperation werden die Organe der operativen Manipulation ausgesetzt. Die Perfusion der Spenderorgane mit einer $4^{\circ} \mathrm{C}$ kalten Konservierungslösung stellt den Beginn der kalten Ischämiezeit dar. Die Organe werden bis zur Reperfusion im Empfänger in der kalten Konservierungslösung gelagert. Unmittelbar vor der Reperfusion werden die Organe einer kurzen warmen Ischämiephase ausgesetzt, die zur Fertigstellung der Gefäßanastomosen benötigt wird. Die resultierende Schädigung des Transplantates als Folge der Exposition gegenüber Phasen der warmen und kalten Ischämie sowie der Reperfusion mit Blut im Empfänger wird als Ischämie-Reperfusionsschaden bezeichnet. Ein ausgeprägter IschämieReperfusionsschaden kann eine Transplantatnichtfunktion oder Transplantatdysfunktion zur Folge haben. 


\subsection{Ischämie-Reperfusionsschaden}

Im Rahmen von akuten Durchblutungsstörungen, jedoch auch bei der Organtransplantation sowie bei interventionellen Maßnahmen kommt es zu Ischämie von Organen und nachfolgend während der Phase der Reperfusion zur Schädigung des Organs. Die Organschädigung durch Ischämie-Reperfusion führt zu einem teilweisen Verlust der Organfunktion und ist damit für die Transplantation von entscheidender Bedeutung. Neben immunologischen Mechanismen spielt die Ischämie-Reperfusion eine wesentliche Rolle beim akuten und chronischen Organversagen. Eine immer genauere Erforschung der zellulären Mechanismen bei Ischämie-Reperfusion ist daher von Bedeutung, da nur so ein kausaler Ansatz bei der Suche nach neuen Interventionsstrategien möglich ist.

Die Ischämie-Reperfusion ist ein komplexer pathophysiologischer Prozess. Anhand von Tierexperimenten ist deutlich geworden, dass Ischämie-Reperfusion eine kurzzeitige und eine langfristige Modulation zahlreicher Zellfunktionen auslöst, die eine induzierte zelluläre Dysfunktion und mikrozirkuläre Minderperfusion im Transplantat induziert und zum akuten oder verzögerten Zelltod führen kann. Verschiedene Mechanismen scheinen am Ischämie-Reperfusionsschaden beteiligt zu sein. Hierzu gehören Azidose, ATP-Verbrauch, Sauerstoffmangel, Störung der Ionen-Pumpen und Transporterfunktion für Glucose und Lactat, Auftreten von freien Radikalen, mitochondriale Dysfunktion, Freisetzung von immunologischen Faktoren und inflammatorischen Zytokinen.

Für den Ischämie-Reperfusionsschaden ist zum größten Teil die Hypothermie während der Konservierung verantwortlich. Das Absenken der Organtemperatur reduziert die zelluläre metabolische Aktivität. Für die Niere konnte bereits Ende der fünfziger Jahre gezeigt werden, dass der Metabolismus weiter aktiv ist (Levy 1959). Dies bedeutet, dass es während der Hypothermie zu einem Substrat- und ATPVerlust kommt. Die ablaufenden Stoffwechselprozesse verbrauchen mehr Energie als synthetisiert werden kann (Harvey et al.1988). Bei der Ischämie führt der Sauerstoff- und Glucose-Mangel zu einem intrazellulären Energieverbrauch, der den Erhalt des zellulären Membranpotentials beeinträchtigt. Besonders rasch ist die $\mathrm{Na}^{+} / \mathrm{K}^{+}$-ATPase betroffen, die einen Großteil des durch oxidative Phosphorylierung bereitgestellten ATPs für den energieabhängigen $\mathrm{Na}^{+} / \mathrm{K}^{+}$-Antiport benötigt (Silver $\mathrm{u}$. Erecinska 1994). Die Aktivierung spannungsabhängiger lonenkanäle an Membranen bewirkt einen Einstrom von $\mathrm{Na}^{+}-, \mathrm{Ca}^{2+}$ - und $\mathrm{Cl}^{-}$-Ionen. $\mathrm{Cl}^{-}$strömt in die Zelle, während 
sich $\mathrm{K}^{+}$aus der Zelle hinausbewegt. Diese lonenverschiebungen führen zu einem Wassereinstrom mit Ausbildung eines intrazellulärem Ödems, dessen Ausmaß von der Hypothermiesensitivität der $\mathrm{Na}^{+} / \mathrm{K}^{+}$-ATPase abhängig ist (Martin et al. 1972).

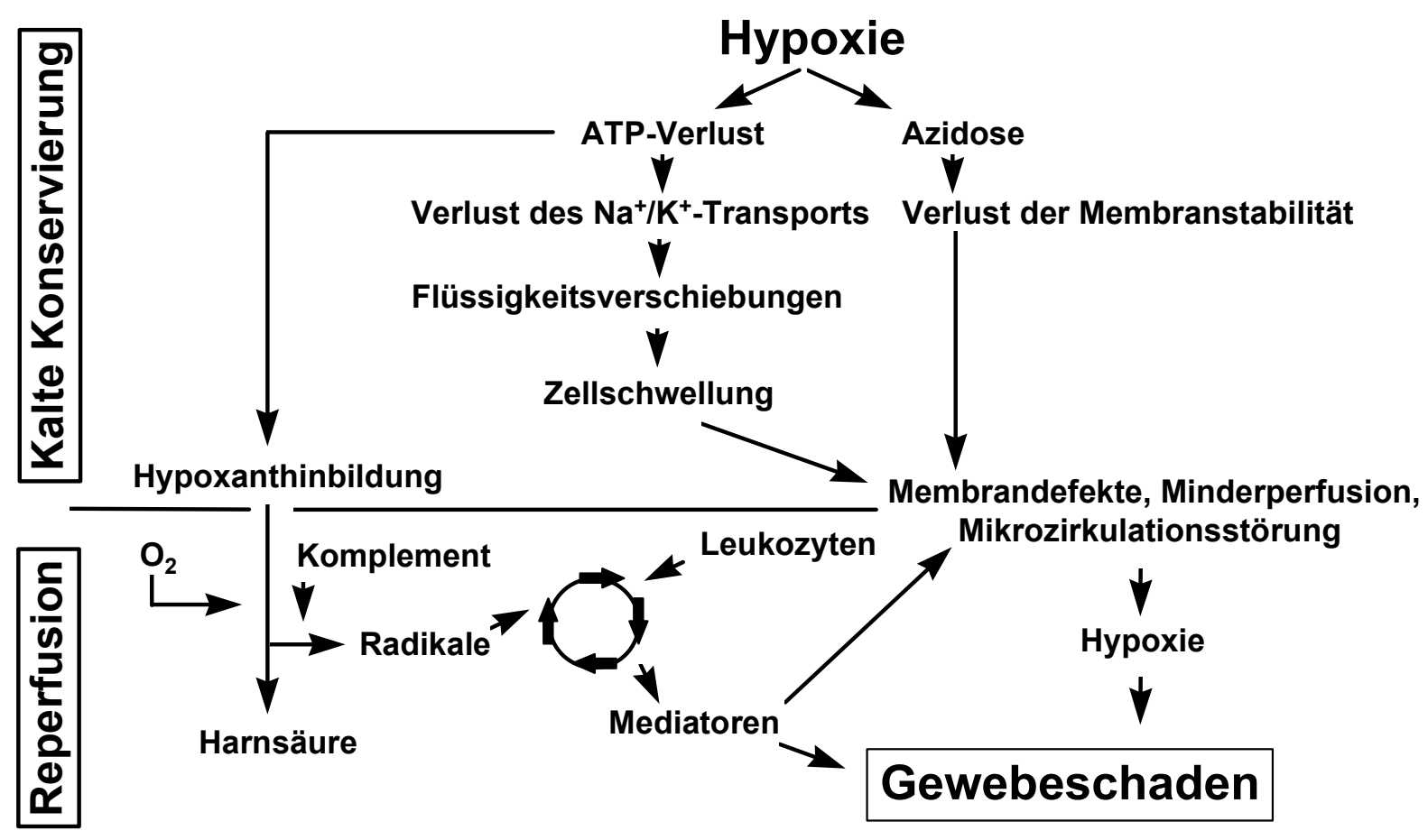

Abbildung 1:

Vereinfaches Schema der Pathophysiologie des Ischämie-Reperfusionsschadens (modifiziert nach Post et al. 1996).

Eine Bereitstellung von intrazellulärer Energie in Form von ATP kann nur über anaerobe Glykolyse erfolgen, was zu einer intrazellulären Azidose führt. Die Hypoxie bedingte Azidose führt zu einem Verlust der Membranpermeabilität. Gleichzeitig erfolgt in saurem Milieu die Konversion der Xanthinhydrogenase in ihre oxidierende Form, die Xanthinoxidase (Waud u. Rajagopalan 1976). Die Hypothermie verlangsamt diese Reaktion erheblich, aber nach Reperfusion des Organs mit sauerstoffreichem Blut kommt es zur Bildung von Sauerstoffradikalen, welche die Entzündungskaskade auslöst (Abb. 1).

Reperfusion und Reoxygenierung nach längerer Ischämie oder Hypoxie sind mit einem Anstieg der $\mathrm{Ca}^{2+}-$ Konzentration verbunden. Die erhöhte $\mathrm{Ca}^{2+}-$ Konzentration führt zu einer Kalziumüberladung der Mitochondrien. Hinzu kommt die Anhäufung freier Fettsäuren als Folge der PLA2-Aktivierung, die zur mitochondrialen Dysfunktion und Schädigung des oxidativen Stoffwechsels beiträgt (Siesjö 1991). Die Folge ist eine Entkoppelung der oxidativen Phosphorylierung von der Atmungskette und 
Störung des ATP/ADP Transports. Die Mitochondrien sind unter hypoxischischämischem Energiemangel („oxidativer Stress“) dilatiert, das mitochondriale transmembranale Potential verringert sich und, sie produzieren durch den fortlaufenden Elektronentransport bei reduzierter Atmungskette zusätzliche reaktive Sauerstoffderivate wie $\mathrm{O}_{2}^{-}$und $\mathrm{H}_{2} \mathrm{O}_{2}$. Vor allem Komplex I (NADH-UbichinonOxidoreduktase) der Atmungskette wird durch reaktive Sauerstoffderivate geschädigt mit der Folge eines weiteren Energiemangels durch die verminderte mitochondriale ATP-Produktion. Dies erhöht die zelluläre Empfindlichkeit für weitere Schäden (Davis et al. 1997). Die Öffnung einer Protonenpore in der inneren Mitochondrienmembran führt zum Zusammenbruch des elektrochemischen Gradienten von $\mathrm{H}^{+}$und zum Sistieren der ATP-Produktion (Kristian u. Siesjö 1998).

Beim Ischämie-Reperfusionsschaden spielt das Endothel eine wesentliche Rolle. Im gesunden Organ sind die Endothelzellen für die Regulation der Permeabilität, die Adhäsion von Leukozyten und Thrombozyten sowie für die Bildung und Sekretion von vasodilatierenden und antiadhäsiven Substanzen wie NO, Prostaglandine usw. verantwortlich. Diese Funktionen werden durch Ischämie wesentlich beeinträchtigt. Eine Schädigung der Gefäßendothelien führt zu einer Aktivierung des Komplementsystems, das seinerseits eine weitere Aktivierung zirkulierender neutrophiler Granulozyten zu Folge hat. Die Endothelzellschicht ist für die Hämostase der Gefäßwand sehr wichtig und wird als erste von den Auswirkungen der Ischämie und der Reperfusion betroffen. Durch die progressive endotheliale Dysfunktion kommt es zu einer Erhöhung der mikrovaskulären Permeabilität mit konsekutiver Transsudation in das Interstitium und Bildung von Mikrothromben, so dass eine Gewebeischämie auftreten kann (Van Griensven et al. 1999, Barie u. Mullins 1988, Seekamp u. Ward 1993, Stephens et al. 1988, Sigurdsson et al. 1992). Durch das in den Gefässendothelzellen vorkommende Enzym Xanthinoxidase werden aus den während der Ischämie entstandenen Adeninnukleotiden gewebsschädigende Sauerstoffradikale gebildet, die ihrerseits $\mathrm{zu}$ einem Gefässendothelschaden führen. Kommt es zu einer Wiederherstellung der Durchblutung, kann durch Sauerstoffradikale und die Induktion von Hitze-SchockProteinen in dem Ischämiegebiet ein Reperfusionsschaden entstehen (Cipolle et al. 1993, Rinaldo et al. 1990). Die entstandene Ischämie führt erst bei einer Reperfusion durch Einschwemmen von Proteasen, Iysosomalen Enzymen, Sauerstoffradikalen, 
Arachidonsäuremetaboliten und aktivierten neutrophilen Granulozyten zu sekundären Organschäden.

\subsubsection{Ischämie-Reperfusionsschaden des Dünndarms}

Im Darm kommt es direkt nach Reperfusion durch Desquamation des Epithels zur Zerstörung der Darmschleimhaut (Kong et al. 1998). An dieser Gewebeschädigung scheinen Sauerstoffradikale ursächlich beteiligt zu sein (Kong et al.1998, Weixiong et al. 1994, Arthur 1988). Durch Interaktionen mit Desoxyribonukleinsäuren können Sauerstoffradikale DNA-Strangbrüche hervorrufen (Bielski u. Shiue 1979, Burger et al. 1980). Die hochreaktiven Radikale und Intermediate können durch direkte Reaktion mit Lipiden und Proteinen der Zellmembranen den Gewebeschaden induzieren, indirekt durch Vasokonstriktion und Thrombozytenaktivierung zu Mikrozirkulationsstörungen beitragen oder aber durch Aktivierung von Leukozyten zur Ausdehnung der Inflammation führen (Tribble et al.1987, Jung et al. 2000). Die Granulozyten wandern über einen speziellen Mechanismus ein. Endothelzellen setzen Zytokine wie Interleukin-1 $\beta$, Interleukin-6, Interleukin-8 und TNF $\alpha$ frei, die proinflammatorisch die Infiltration mit neutrophilen Granulozyten fördern.

Die Aktivierung der polymorphnukleären Neutrophilen unterliegt einer Signalkaskade, an deren Ende u. a. die Expression von Adhäsionsmolekülen am Gefässendothel steht (Nüssler et al. 1999). Diese Aktivierung von Leukozyten bzw. polymorphnukleären Neutrophilen (PMN) ist das Kennzeichen der späteren Phase der Gewebeschädigung (Kong et al. 1998, Moore et al. 1994). Pulmonale Schäden wurden nach Ischämie-Reperfusion der Extremitäten (Belkin et al.1989, Seekamp et al. 1994, Siebert et al. 1993) und der Leber (Dubayo u. Carlson 1988) beschrieben. Ursächlich hierfür sind neutrophile Granulozyten und reaktive Sauerstoffradikale (Belkin et al. 1989, Goldman et al. 1992, Kazui et al. 1994, Klausner et al. 1988, Seibert et al. 1993), welche zum Teil in den neutrophilen Granulozyten gebildet werden oder bei den chemischen Reaktionen entstehen, welche in dem reperfundierten Areal ablaufen (Korthuis et al. 1989, Parks u. Granger 1986). Eine gesteigerte Biosynthese von Adhäsionsmolekülen, welche die Leukozyten-Endothel Adhäsion vermittelt, resultiert als Folge des Ischämie-Reperfusionsschadens (Carden u. Granger 2000). In einem Rattendünndarm Transplantationsmodell zeigten Cicalese et al., dass die Zahl neutrophiler Granulozyten in der Mukosa nach Reperfusion zunimmt (Cicalese et al. 1996). Die polymorphnukleären Neutrophilen 
(PMN) werden als Ursache der lokalen Schädigung während intestinaler Ischämie und Reperfusion diskutiert. Die Blockierung der Adhäsion von PMN nach kompletter intestinaler Ischämie-Reperfusion resultiert in einer geringeren Schädigung nachgeschalteter Organe, jedoch nicht in einer geringeren lokalen Dünndarmschädigung. Simpson et al. vermuteten hierauf, dass PMN und deren Produkte während des Ischämie-Reperfusionsschadens hauptsächlich zu einer Schädigung der Lunge, teilweise der Leber aber nicht lokal am Dünndarm führen (Simpson et al. 1993). In einem Rattenmodell führte eine warme Ischämie des Dünndarms von $30 \mathrm{~min}$ und anschließende Reperfusion über 1 Stunde zur Verminderung der Durchblutung im gesamten Dünndarm. Interaktionen zwischen Leukozyten und Gefäßwänden wurden hingegen nur in der Submukosa beobachtet. Beuk et al. kamen zu der Schlussfolgerung, dass die initiale Entzündungsreaktion nach Ischämie-Reperfusion auf die Submukosa beschränkt ist und dass beide mikrovaskulären Effekte zur mukosalen Schädigung beitragen (Beuk et al. 2000). Die Interaktionen zwischen Leukozyten und Endothel werden durch Selektine vermittelt. E-Selektin initiiert das Rollen der Leukozyten und deren anschließende Adhäsion an das Endothel. In einem Ischämie-Reperfusionsmodell des Mäuse-dünndarms konnte gezeigt werden, dass die Gabe eines E-Selektin spezifischen monoklonalen Antikörpers zu einer Reduktion des Ischämie-Reperfusionsschadens führt (Russell et al. 2000). Sauerstoffradikale aus aktivierten Leukozyten/PMN sind nicht nur maßgeblich am Gewebeschaden während der Reperfusionsphase in den vorher ischämischen Organabschnitten beteiligt, sondern spielen auch eine entscheidende Rolle bei der Dissemination des Ischämie-Reperfusionsschaden, wenngleich die exakten Mechanismen noch ungeklärt sind (Kong et al. 1998, Poggetti et al. 1992, Moore et al.1994).

Die Mukosa des Dünndarms ist besonders empfindlich gegenüber dem IschämieReperfusionsschaden. Die morphologischen Auswirkungen des IschämieReperfusionsschadens auf die Mukosa wurden bereits 1970 von Chiu et al. in einem Ratenmodell beschrieben. Der charakteristische Verlauf der mukosalen Schädigung zeigt zu Anfang eine Ablösung des mukosalen Epithels, welche histologisch als Grünhagen'sche Spalten imponieren. Die Destruktion der mukosalen Villi erfolgt anschließend apikobasal und endet in einer Desintegration der Mukosa mit Denudation der Villi und Hämorrhagien (Chiu et al. 1970). Takeyoshi et al. konnten in einem Hundedünndarm-Transplantationsmodell zeigen, dass eine kalte 
Konservierung von 24 Stunden nur zu einer minimalen Schädigung der Mukosa führt (Takeyoshi et al. 2001). Im Darm wurde während der Ischämie eine Schädigung der Mukosa und Lamina propria mit Einschränkung der mukosalen Barrierefunktion beobachtet (Haglund 1994, Kong et al. 1998, Illyés u. Hammar 1992). Eine mukosale Schädigung kann jedoch frühzeitig nach Reperfusion beobachtet werden. In einem Perfusionsmodell des Rattendünndarms konnte bereits 2 Stunden nach Reperfusion eine deutliche Schädigung der Mukosa gezeigt werden (Brown et al. 1990). Bereits 1 Stunde nach Reperfusion wurde eine erhebliche mukosale Schädigung bei humanen Dünndärmen nachgewiesen (Sisley et al. 1994).

Die Mukosa des Dünndarms ist von besonderer Bedeutung, da das intestinale Lumen direkten Kontakt zur Außenwelt besitzt. Der Dünndarm ist besiedelt von Mikroorganismen. Durch Störungen der Mikrozirkulation kann es zur Beeinträchtigung der mukosalen und vaskulären Integrität und zum Übertritt von Bakterien und Toxinen vom Darmlumen in den Blutkreislauf kommen (Wenzel 1993) und eine schwere Infektion und Entzündungsreaktion auslösen. Dort werden die Mikroorganismen lysiert und als Zellwandbestandteil grammnegativer Bakterien werden Endotoxine, Lipopolysaccharid (LPS), freigesetzt (Bahrami et al. 1998). Endotoxin selbst stimuliert wiederum humorale und zelluläre Systeme, die inflammatorische Mediatoren wie Zytokine und Stickoxid (NO) synthetisieren. Als Zielzellen für Endotoxin treten Thrombozyten, Erythrozyten, Granulozyten/Makrophagen, Lymphozyten und Endothelzellen auf. Bereits eine geringe Konzentration von Endotoxin bewirkt eine Vorstimulierung der Granulozyten für nachfolgende chemische Faktoren mit erhöhter Freisetzung von Proteasen und toxischen Sauerstoffradikalen, die für die Granulozyten- Endothelzellen- Interaktion mitverantwortlich sind.

Die neutrophilen Granulozyten als wichtiger Bestandteil des unspezifischen zellulären Immunsystems (Griswold u. Maier 1988) werden durch Chemotaxis auf die mikrobiellen Organismen aufmerksam gemacht. Die Adhäsion und Migration der neutrophilen Granulozyten durch das Endothel wird durch mehrere Phasen (Rolling, Attachement und Diapedesis) gekennzeichnet. Die Migration verläuft über einen chemotaktischen Gradienten, wobei die mikrobiellen Organismen phagozytiert und lysiert werden. Bei der Lyse körperfremder Stoffe spielen die in der Granula (Peroxidase positive- und negative- Granula) enthaltenen Substanzen wie Myeloperoxidase, Elastase, Lysozym, alkalische Phosphatase usw. eine wichtige 
Rolle (Ackerman 1971, Bainton u. Farquhar 1966). Beim IschämieReperfusionsschaden nehmen auch diese lysosomalen Produkte eine wichtige Funktion ein, so dass die neutrophilen Granulozyten zu den Schlüsselzellen des Ischämie-Reperfusionsschadens zählen (Fujishima u. Aikawa 1995, Vedder et al. 1989, Korithuis et al 1988). Ausgelöst wird der Pathomechanismus durch Chemotaxine, chemische Stimuli, die die Wanderungsrichtung phagozytierender Zellen in Abhängigkeit von einem Konzentrationsgradienten der reizauslösenden Substanz bestimmen und welche nicht obligat ein mikrobieller Organismus sein müssen (Ward u. Mulligan 1991). Zu den potenten Chemotaxinen gehören IL-1, IL-6, TNF $\alpha$, Endotoxin, Sauerstoffradikale, die Komplementfaktoren C3 und C5, und der Plättchenaktivierende Faktor (Kindt et al. 1991, Warren et al. 1989). Ein großer Teil wird direkt im Gewebe nach Ischämie in der Reperfusionsphase von Endothelzellen und Gewebsmakrophagen gebildet. Weitere Aktivatoren sind neutrophile Granulozyten, Immunkomplexe, Gerinnungsfaktoren, Prostaglandine und Fragmente des geschädigten Organs (Jonas et al. 1991, Cerasoli et al. 1990). Diese Aktivierung führt zu einer Hochregulation der Adhäsionsmoleküle, und die neutrophilen Granulozyten adhärieren am kapillaren Endothel. Es kommt zu einer vermehrten Produktion und Freisetzung der oben genannten lysosomalen Produkte und Sauerstoffradikale, die morphologisch eine Ausbreitung der Endothelzelle verursachen, was eine verminderte Verformbarkeit der Zelle zur Folge hat (Hoover et al. 1987). Dies führt zu einer Erhöhung der endothelialen Permeabilität und somit können die schädigenden Mediatoren und Zellen einfacher die Endothelbarriere passieren. Eine Endothelpermeabilitätserhöhung kann auch von inflammatorischen Mediatoren wie IL-6 verursacht werden (Maruo et al. 1992, van Griensven et al. 1999). Verschiedene Zelltypen wurden als physiologische Produzenten der IL-6 Expression beschrieben, einschließlich Monozyten, Granulozyten, T- und BLymphozyten.

Während der kalten Konservierung stellt die Hypoxie des Gewebes einen potentiellen Reiz für die Regulation von Genen dar. Eine Aktivierung des IL-6 Gens während Hypoxie und Reoxygenierung wird in der Pathogenese des IschämieReperfusionsschadens diskutiert. Muraoka et al. zeigten in vitro, dass die Aktivierung von NF-kB durch die Hypoxie jedoch nicht durch die Reoxygenierung induziert wird. Die Hypoxie-vermittelte Aktivierung von NF-kB resultiert in einer $\kappa B$-vermittelten Aktivierung der IL-6 Transkription (Muraoka et al. 1997). 
Neben IL-6 sind IL-2 und IFN $\gamma$ weitere Mediatoren, die in der Pathogenese des Ischämie-Reperfusionsschadens diskutiert werden. Die immunregulatorischen Zytokine IFN $\gamma$ und IL-2 sind Produkte von T-Zellen, die an vielen Geweben wirken. Die Gesamtzahl der IFN $\gamma$ induzierten Gene wird auf mindestens 400 geschätzt (Wan et al. 1996, Früh et al. 1997). Die Fähigkeit von IFN $\gamma$, die Transkription und Expression von MHC Molekülen zu induzieren, war eine der ersten beschriebenen biologischen Effekte (Rosa et al. 1986). IL-2 besitzt eine zentrale Rolle bei intestinalen Entzündungsreaktionen. IL-2 und der IL-2 Rezeptor werden während Entzündungsprozessen hoch reguliert, und die Hemmung IL-2 produzierender Zellen hat einen günstigen Einfluss auf die intestinale Entzündungsreaktion (Fiocchi et al. 1996).

In den letzten Jahren wurden zunehmend Erkenntnisse über die molekularen Mechanismen des Ischämie-Reperfusionsschadens gewonnen. NF-kB und AP-1 sind Transkriptionsfaktoren, die bei unterschiedlichsten Entzündungsprozessen nachgewiesen wurden. Insbesondere wird die Aktivierung von „immediate early genes" (IEG) wie c-fos, c-jun und egr-1 in der Pathogenese des IschämieReperfusionsschadens diskutiert (Itoh et al. 2000, Pujic et al. 1996). 


\subsection{Aufgabenstellung und Ziel der Arbeit}

Der intestinale Ischämie-Reperfusionsschaden ist ein komplexer pathophysiologischer Prozess, dessen molekulare Mechanismen bislang nur annähernd bekannt sind. Als Versuchsmodell der Ischämie-Reperfusions-schädigung diente die isolierte extrakorporale Perfusion am Schweinemodell, welche in der Klinik für Transplantationschirurgie der Universität Göttingen entwickelt und standardisiert wurde.

Die Ziele der Dissertationsarbeit waren:

1. Nachweis von bekannten Mediatoren der Entzündungsreaktion, die in der Pathogenese des intestinalen Ischämie-Reperfusionsschadens diskutiert werden. Hierzu sollte die Genexpression von IL-6, IL-2, HSP70, IFN $\gamma$ und ESelektin während der Ischämie- und Reperfusionsphase quantitativ untersucht und mittels In-situ-Hybridisierung lokalisiert werden.

2. Zur Identifikation und Lokalisation von Genen, die an molekularen Mechanismen während der Ischämie- und Reperfusionsphase beteiligt sind, sollten geeignete Methoden aufgebaut werden. Interessant erscheinende Gene sollten weitergehend untersucht werden. Hierzu wurde ein Vergleich der Genexpression zwischen intaktem Dünndarmgewebe und IschämieReperfusions geschädigtem Gewebe angestrebt.

Um bessere Einblicke in den molekularen und genetischen Ablauf des Ischämie-Reperfusionsschadens im Dünndarm zugewinnen, wurde das Verfahren des mRNA-Differential Displays eingesetzt, mit welchem man differentiell regulierte Gene identifizieren kann. 


\section{MATERIAL}

\subsection{Verwendete Lösungen und Puffer}

Folgende Lösungen und Puffer wurden im Rahmen der Dissertation eingesetzt:

\begin{tabular}{|c|c|c|c|}
\hline \multicolumn{4}{|l|}{ AEC-Substrat } \\
\hline Lösung I & $13,6 \%$ & $(w / v)$ & $\mathrm{Na}-$ Acetat-Trihydrat auf $10 \mathrm{ml}$ mit $\mathrm{H}_{2} \mathrm{O}_{\mathrm{dd}}$ \\
\hline Lösung II & $5,49 \%$ & $(v / v)$ & Eisessig auf $10 \mathrm{ml} \mathrm{mit} \mathrm{H}_{2} \mathrm{O}_{\mathrm{dd}}$ \\
\hline Lösung III & $0,4 \%$ & $(w / v)$ & $\begin{array}{l}3 \text { Amino-9 Ethylcarbazol ad. } 100 \mathrm{ml} \\
\text { Dimethylformamid }\end{array}$ \\
\hline \multirow[t]{2}{*}{ Alkali-SDS-Puffer } & 200 & $\mathrm{mM}$ & $\mathrm{NaOH}$ \\
\hline & $1 \%$ & $(w / v)$ & SDS \\
\hline Ampicillin-Stocklösung & 2 & $\mathrm{mg}$ & Ampicillin/ml $\mathrm{H}_{2} \mathrm{O}_{\mathrm{dd}}$ \\
\hline AMPS-Lösung & $10 \%$ & $(w / v)$ & Amoniumperoxidsulfat in $\mathrm{H}_{2} \mathrm{O}_{d d}$ \\
\hline \multirow[t]{5}{*}{ Breaking-Puffer-A } & $200 \mu$ & $0.5 \mathrm{M}$ & Tris/HCl \\
\hline & $1 \mathrm{ml}$ & $1 \mathrm{M}$ & $\mathrm{NaCl}$ \\
\hline & $40 \mu \mathrm{l}$ & 0.25 & EDTA \\
\hline & 0,1 & M & SDS \\
\hline & 0,2 & $\mathrm{~g}$ & Triton X-100 pH 8.0 ad. $10 \mathrm{ml} \mathrm{H} \mathrm{O}_{2} \mathrm{dd}$ \\
\hline \multirow[t]{3}{*}{ Breaking-Puffer-B } & 50 & $\mathrm{mM}$ & Tris/HCl \\
\hline & 20 & $\mathrm{mM}$ & EDTA \\
\hline & $1 \%$ & $(w / v)$ & SDS pH 7,5 \\
\hline \multirow[t]{4}{*}{ BX-Farbmarkerlösung } & $0,125 \%$ & $(w / v)$ & Bromphenolblau \\
\hline & $0,125 \%$ & $(w / v)$ & Xylencyanol \\
\hline & $20 \%$ & $(v / v)$ & Ficoll \\
\hline & 10 & $\mathrm{mM}$ & $\mathrm{ZnCl}_{2} \mathrm{pH} 8,3$ \\
\hline Dephosphorylierungs- & 10 & $\mathrm{mM}$ & Tris/HCl \\
\hline Puffer & 0,1 & $\mathrm{mM}$ & EDTA \\
\hline Entwicklerlösung für & $2,5 \%$ & $(w / v)$ & Natriumcarbonat \\
\hline \multirow[t]{2}{*}{ Silberfärbung } & $0,02 \%$ & $(w / v)$ & Natriumthiosulfat \\
\hline & $0,37 \%$ & $(v / v)$ & Formaldehyd \\
\hline
\end{tabular}




\begin{tabular}{|c|c|c|c|}
\hline \multirow[t]{3}{*}{ E1-Puffer } & 100 & $\mathrm{mg}$ & RNase A/ml Puffer \\
\hline & 50 & $\mathrm{mM}$ & Tris/HCl \\
\hline & 10 & $\mathrm{mM}$ & EDTA pH 8,0 \\
\hline \multirow[t]{2}{*}{ E2-Puffer } & 200 & $\mathrm{mM}$ & $\mathrm{NaOH}$ \\
\hline & $1 \%$ & $(w / v)$ & SDS \\
\hline E3-Puffer & 3,2 & M & Kaliumacetat pH 5,5 \\
\hline \multirow[t]{3}{*}{ E4-Puffer } & 600 & $\mathrm{mM}$ & $\mathrm{NaCl}$ \\
\hline & 100 & $\mathrm{mM}$ & Natriumacetat \\
\hline & 0,15 & $(v / v)$ & Triton $\mathrm{X}-100 \mathrm{pH} 5,0$ \\
\hline \multirow[t]{2}{*}{ E5-Puffer } & 800 & $\mathrm{mM}$ & $\mathrm{NaCl}$ \\
\hline & 100 & $\mathrm{mM}$ & Natriumacetat pH 5,0 \\
\hline \multirow[t]{2}{*}{ E6-Puffer } & 1,25 & M & $\mathrm{NaCl}$ \\
\hline & 100 & $\mathrm{mM}$ & Tris/HCl pH 8,5 \\
\hline Ethidiumbromid- & 10 & $\mathrm{mg}$ & Ethidiumbromid/ml \\
\hline Stammlösung & & & 0,5 M EDTA \\
\hline Fixier-Lösung & $3 \%$ & $(w / v)$ & Benzensulphon-Säure \\
\hline (5fach konzentriert) & $24 \%$ & $(\mathrm{v} / \mathrm{v})$ & Ethanol \\
\hline \multirow[t]{5}{*}{ Hybridisierungs-Puffer } & $50 \%$ & $(v / v)$ & deionisierte Formamid \\
\hline & $5 x$ & $(\mathrm{v} / \mathrm{v})$ & SSC-Puffer \\
\hline & $2 \%$ & $(w / v)$ & Blockierungsreagens \\
\hline & $0,1 \%$ & $(w / v)$ & N-Laurylsarkosin \\
\hline & $0,02 \%$ & $(w / v)$ & SDS \\
\hline \multirow[t]{4}{*}{ Ligations-Puffer } & 66 & $\mathrm{mM}$ & Tris/HCl \\
\hline & 5 & $\mathrm{mM}$ & $\mathrm{MgCl}_{2}$ \\
\hline & 10 & $\mathrm{mM}$ & DTT \\
\hline & 1 & $\mathrm{mM}$ & ATP $\mathrm{pH} 7,5$ \\
\hline Lysozym-Stammlösung & 10 & $\mathrm{mg}$ & Lysozym/ml Suspensions-Puffer \\
\hline \multirow[t]{3}{*}{ Lytic-Mix } & 120 & $\mathrm{mM}$ & Tris/HCl \\
\hline & 30 & $\mathrm{mM}$ & EDTA \\
\hline & $1 \%$ & $(w / v)$ & TritonX-100 pH 8,0 \\
\hline MAB-Puffer & $2,32 \%$ & $(w / v)$ & Maleinsäure \\
\hline (2fach konzentriert) & $1,75 \%$ & $(w / v)$ & $\mathrm{NaCl}$ pH 7,5 mit $\mathrm{NaOH}$ \\
\hline
\end{tabular}




$\begin{array}{llll}\text { Markierungs-Mix } & 7,5 & \mu \mathrm{M} & \text { 7-deaza-dGTP } \\ & 7,5 & \mu \mathrm{M} & \text { dCTP } \\ & 7,5 & \mu \mathrm{M} & \text { dTTP } \\ \text { MOPS-Puffer } & 2,5 \% & (\mathrm{w} / \mathrm{v}) & \text { Natriumcarbonat } \\ \text { (10fach konzentriert) } & 0,02 \% & (\mathrm{w} / \mathrm{v}) & \text { Natriumthiosulfat } \\ & 0,37 \% & (\mathrm{v} / \mathrm{v}) & \text { Formaldehyd } \\ \text { NTMT-Puffer } & 0,1 & \mathrm{M} & \mathrm{NaCl} \\ & 0,1 & \mathrm{M} & \mathrm{Tris} / \mathrm{HCl} \\ & 25 & \mathrm{mM} & \mathrm{MgCl}_{2} \\ & 0,1 \% & (\mathrm{v} / \mathrm{v}) & \mathrm{Tween}^{20} \mathrm{ad} .100 \mathrm{ml} \mathrm{H}_{2} \mathrm{O}_{\mathrm{dd}}\end{array}$

Orange G-Stopp-Mix $\quad 50 \% \quad(\mathrm{w} / \mathrm{v}) \quad$ Saccharose

$1 \% \quad(w / v) \quad$ SDS

$0,2 \% \quad(w / v) \quad$ Orange $G$

Puffer $1 \quad 0,1 \quad M \quad$ Maleinsäure

$0,15 \quad \mathrm{M} \quad \mathrm{NaCl}$ pH 7,5 mit $\mathrm{NaOH}$

$\begin{array}{llll}\text { Puffer } 2 & 1 \% & (\mathrm{w} / \mathrm{v}) & \text { Blockierungslösung in Puffer } 1\end{array}$

$\begin{array}{llll}\text { Puffer } 3 & 0,1 & \mathrm{M} & \text { Tris } / \mathrm{HCl}\end{array}$

$0,1 \quad \mathrm{M} \quad \mathrm{NaCl}$

$50 \quad \mathrm{mM} \quad \mathrm{MgCl}_{2} \mathrm{pH} \mathrm{9,5}$

P1-Puffer $\quad 100 \quad \mathrm{mg} \quad$ RNase A/ml Puffer

$10 \quad \mathrm{mM}$ EDTA

$50 \quad \mathrm{mM} \quad$ Tris/HCl pH 8,0

P2-Puffer $\quad 200 \quad \mathrm{mM} \quad \mathrm{NaOH}$

P3-Puffer $\quad 3 \quad$ M Kaliumacetat $\mathrm{pH}$ 5,5

$\begin{array}{llll}\text { PBS-Puffer } & 3 & \mathrm{mM} & \mathrm{KCl}\end{array}$

$2 \quad \mathrm{mM} \quad \mathrm{KH}_{2} \mathrm{PO}_{4}$

$150 \quad \mathrm{mM} \quad \mathrm{NaCl}$

$8 \quad \mathrm{mM} \quad \mathrm{Na}_{2} \mathrm{HPO}_{4} \mathrm{pH} 7,4$

$\mathrm{PCl}$

Phenol:Chloroform:Isoamylalkohol 25:24:1

PEG-Lösung A zur $30 \%$ (w/v) PEG 6000

DNA-Präzipitation $\quad 1,5 \quad M \quad \mathrm{NaCl}$ 


\begin{tabular}{|c|c|c|c|}
\hline Plasmid- & 400 & $\mathrm{mM}$ & Tris/HCl \\
\hline \multirow[t]{2}{*}{ Reaktionspuffer } & 100 & $\mathrm{mM}$ & $\mathrm{MgCl}_{2}$ \\
\hline & 250 & $\mathrm{mM}$ & $\mathrm{NaCl} \mathrm{pH} \mathrm{7,5}$ \\
\hline Plasmid- & 10 & $\mathrm{mM}$ & Tris/HCl \\
\hline Denaturierungs- & 1 & $\mathrm{mM}$ & EDTA \\
\hline \multirow[t]{2}{*}{ reagenz } & $50 \%$ & $(w / v)$ & Glycerin \\
\hline & $50 \%$ & $(w / v)$ & Ethylenglycol pH 7,5 \\
\hline \multirow[t]{4}{*}{ QBT-Puffer } & 750 & $\mathrm{mM}$ & $\mathrm{NaCl}$ \\
\hline & 50 & $\mathrm{mM}$ & MOPS \\
\hline & $15 \%$ & $(\mathrm{v} / \mathrm{v})$ & EtOH \\
\hline & $0,15 \%$ & $(\mathrm{v} / \mathrm{v})$ & Triton $\mathrm{X}-100 \mathrm{pH} 7,0$ \\
\hline \multirow[t]{3}{*}{ QC-Puffer } & 1 & M & $\mathrm{NaCl}$ \\
\hline & 50 & $\mathrm{mM}$ & MOPS \\
\hline & $15 \%$ & $(\mathrm{v} / \mathrm{v})$ & $\mathrm{EtOH} \mathrm{pH} 7,0$ \\
\hline \multirow[t]{3}{*}{ QF-Puffer } & 1,25 & M & $\mathrm{NaCl}$ \\
\hline & 50 & $\mathrm{mM}$ & MOPS \\
\hline & $15 \%$ & $(v / v)$ & EtOH pH 8,5 \\
\hline Restriktions-Puffer 1 & 100 & $\mathrm{mM}$ & Tris/HCl \\
\hline \multirow[t]{2}{*}{ (10fach konzentriert) } & 100 & $\mathrm{mM}$ & $\mathrm{MgCl}_{2}$ \\
\hline & 10 & $\mathrm{mM}$ & DTT pH 7,0 \\
\hline Restriktions-Puffer 2 & 100 & $\mathrm{mM}$ & Tris/HCl \\
\hline \multirow[t]{3}{*}{ (10fach konzentriert) } & 100 & $\mathrm{mM}$ & $\mathrm{MgCl}_{2}$ \\
\hline & 10 & $\mathrm{mM}$ & DTT pH 7,0 \\
\hline & 500 & $\mathrm{mM}$ & $\mathrm{NaCl}$ pH 7,9 \\
\hline Restriktions-Puffer 3 & 500 & $\mathrm{mM}$ & Tris/HCl \\
\hline \multirow[t]{3}{*}{ (10fach konzentriert) } & 100 & $\mathrm{mM}$ & $\mathrm{MgCl}_{2}$ \\
\hline & 10 & $\mathrm{mM}$ & DTT pH 7,0 \\
\hline & 1 & $\mathrm{mM}$ & $\mathrm{NaCl} \mathrm{pH} 7,9$ \\
\hline Restriktions-Puffer 4 & 200 & $\mathrm{mM}$ & Tris/Hac \\
\hline \multirow[t]{3}{*}{ (10fach konzentriert) } & 100 & $\mathrm{mM}$ & Magnesiumacetat \\
\hline & 500 & $\mathrm{mM}$ & Kaliumacetat \\
\hline & 10 & $\mathrm{mM}$ & DTT pH 7,9 \\
\hline
\end{tabular}




\begin{tabular}{|c|c|c|c|}
\hline \multirow[t]{6}{*}{ RF I-Puffer } & 100 & $\mathrm{mM}$ & $\mathrm{RbCl}$ \\
\hline & 50 & $\mathrm{mM}$ & $\mathrm{MnCl}_{2}$ \\
\hline & 30 & $\mathrm{mM}$ & Kaliumacetat \\
\hline & 10 & $\mathrm{mM}$ & $\mathrm{CaCl}_{2}$ \\
\hline & $15 \%$ & $(w / v)$ & Glycerin $\mathrm{pH}$ 5,8 mit Hac ad. 100 ml \\
\hline & & & $\mathrm{H}_{2} \mathrm{Odd}$ \\
\hline \multirow[t]{4}{*}{ RF II-Puffer } & 10 & $\mathrm{mM}$ & MOPS \\
\hline & 10 & $\mathrm{mM}$ & $\mathrm{RbCl}$ \\
\hline & 75 & $\mathrm{mM}$ & $\mathrm{CaCl}_{2}$ \\
\hline & $15 \%$ & $(w / v)$ & $\begin{array}{l}\text { Glycerin } \mathrm{pH} 6,8 \text { mit } \mathrm{NaOH} \text { ad. } 100 \mathrm{ml} \\
\mathrm{H}_{2} \mathrm{O}_{\mathrm{dd}}\end{array}$ \\
\hline RNase-Stammlösung & $1 \%$ & $(w / v)$ & RNase A \\
\hline \multirow[t]{3}{*}{ Silbernitrat-Lösung } & $0,2 \%$ & $(w / v)$ & Sibernitrat \\
\hline & $0,07 \%$ & $(w / v)$ & Benzensulphonic Säure ad. $100 \mathrm{ml}$ \\
\hline & & & $\mathrm{H}_{2} \mathrm{O} d d$ \\
\hline \multirow[t]{2}{*}{ 20x SSC-Puffer } & 3 & M & $\mathrm{NaCl}$ \\
\hline & 0,3 & M & Natriumcitrat $\mathrm{pH} 7,0$ \\
\hline \multirow[t]{4}{*}{ STET } & $8 \%$ & $(w / v)$ & Saccharose \\
\hline & $5 \%$ & $(w / v)$ & Triton-X-100 \\
\hline & 50 & $\mathrm{mM}$ & EDTA \\
\hline & 50 & $\mathrm{mM}$ & Tris/HCl pH 8,0 \\
\hline \multirow[t]{4}{*}{ Stopp-Lösung } & $95 \%$ & $(v / v)$ & Formamid \\
\hline & 20 & $\mathrm{mM}$ & EDTA \\
\hline & $0,05 \%$ & $(w / v)$ & Bromphenolblau \\
\hline & $0,05 \%$ & $(w / v)$ & Xylencyanol FF \\
\hline \multirow[t]{2}{*}{ Suspensions-Puffer } & $10 \%$ & $(w / v)$ & Saccharose \\
\hline & 12 & $\mathrm{mM}$ & Tris/HCl pH 8,0 \\
\hline \multirow[t]{3}{*}{ TAE-Puffer } & 40 & $\mathrm{mM}$ & Tris/Hac \\
\hline & 20 & $\mathrm{mM}$ & Natriumacetat \\
\hline & 1 & $\mathrm{mM}$ & EDTA pH 8,2 \\
\hline \multirow[t]{3}{*}{ TBE-Puffer } & 60 & $\mathrm{mM}$ & Tris/Borsäure \\
\hline & 60 & $\mathrm{mM}$ & Borsäure \\
\hline & 1 & $\mathrm{mM}$ & EDTA pH 8,3 \\
\hline
\end{tabular}


TBS-Puffer

$50 \quad \mathrm{mM} \quad$ Tris/ $\mathrm{HCl}$

$\begin{array}{llll} & 0,9 \% & (\mathrm{w} / \mathrm{v}) & \mathrm{Na} / \mathrm{Cl} \\ & 50 & \mathrm{mM} & \text { Tris/HCl pH 7,5 } \\ \text { TE-Puffer } & 10 & \mathrm{mM} & \text { Tris/HCl } \\ & 1 & \mathrm{mM} & \text { EDTA pH 8,0 } \\ \begin{array}{lll}\text { Tryptophan- } \\ \text { Stammlösung }\end{array} & 10 & \mathrm{mg} & \text { L-Tryptophan } / \mathrm{ml} \mathrm{H}_{2} \mathrm{O}_{\mathrm{dd}} \\ \begin{array}{l}\text { TTE-Puffer } \\ \text { (20fach konzentriert) }\end{array} & 0,57 & \mathrm{M} & \text { Taurin } \\ & 10 & \mathrm{mM} & \text { EDTA pH 9,0 }\end{array}$

\subsection{Nährmedien}

Folgende Nährmedien wurden im Rahmen der Experimenten verwendet:

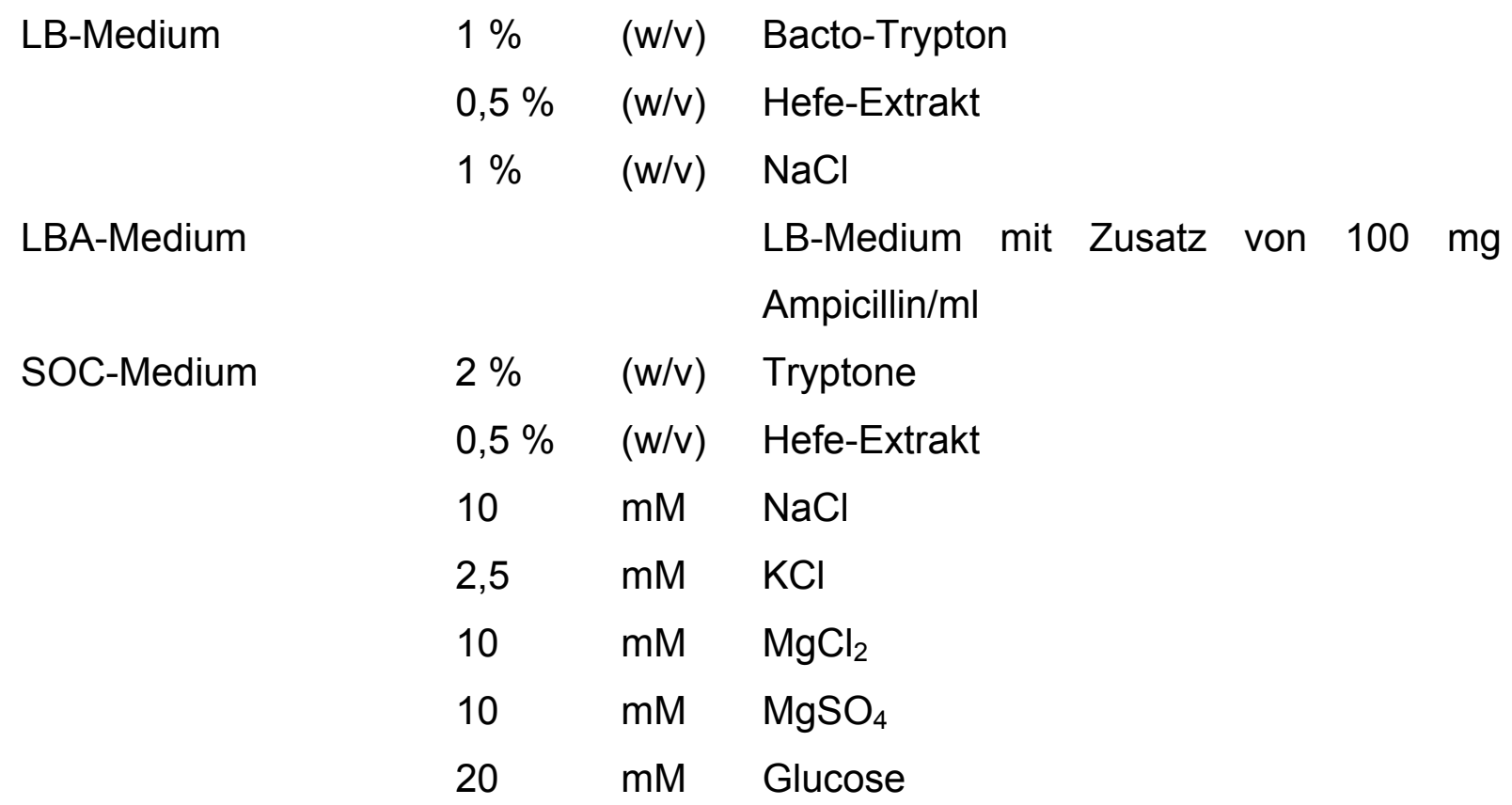




\subsection{Chemikalien}

Folgende Chemikalien wurden zur Durchführung der Experimenten eingesetzt:

\section{Substanz}

Ammonium Persulfat (AMPS)

ATP (Dinatriumsalz)

Ampicillin (Natriumsalz)

Bacto-Agar

Bacto-Pepton

Bacto-Trypton

Bacto-Hefe-Extrakt

Bacto-Hefe Nitrogen Base

ß-Mercaptoethanol

Bromphenolblau

Dextran-Sulfat

D-(+)-Glucose

D-(+)-Galactose

DNA aus Heringssperma

DNA-Molekulargewichtsstandard

Ethidiumbromid

Harnstoff

Jetstar Plasmid Kit

Lysozym

MOPS

Polyacrylamid

Qiagen Plasmid Kit

Rinderserumalbumin, Fraktion $\mathrm{V}$

SDS

Xylencyanol

\section{Hersteller}

Merck, Darmstadt

Boehringer Mannheim, Mannheim

Merck, Darmstadt

Difco, Detroit; USA

Difco, Detroit; USA

Difco, Detroit; USA

Difco, Detroit; USA

Difco, Detroit; USA

Fluka, Buchs; Schweiz

Merck, Darmstadt

Sigma, München

Merck, Darmstadt

Merck, Darmstadt

Boehringer Mannheim, Mannheim

MBI Fermentas, St. Leon-Rot

Gibco BRL, Eggenstein

Merck, Darmstadt

Gibco-BRL, Eggenstein

Genomed, Bad Oeynhausen

Boehringer Mannheim, Mannheim

Sigma, München

Merck, Darmstadt

Diagen, Hilden

Biomol, Ilvesheim

Merck, Darmstadt

Merck, Darmstadt

Die organischen Lösungsmittel lieferten die Firmen Sigma (München) sowie Merck (Darmstadt). Nicht aufgeführte Substanzen wurden, ebenfalls in p.a.-Qualität, von den Firmen Merck (Darmstadt), Fluka (Buchs, Schweiz), Boehringer Mannheim 
(Mannheim) und Sigma (München) bezogen. Der mRNA-Differential Display Kit wurde von der Firma WAK-Chemie Medical GmbH (Bad Soden), der PCR DIG Probe Synthesis Kit sowie der DIG RNA Labeling Kit (SP6/T7) von der Firma Boehringer Mannheim (Mannheim), der MARATHON RACE Kit von der Firma Clontech (Heidelberg) und der Clean Gel DNA Analysis Kit sowie der DNA Silver Staining Kit von der Firma Amersham Pharmacia Biotech (Freiburg) bezogen.

\subsection{Enzyme}

Folgende Enzyme wurden für die molekularbiologischen Techniken eingesetzt:

\section{Enzym}

Anti Digoxygenin Alkalische Phosphatase

Anti Digoxygenin -POD

Envision; Ziege Anti-Kaninchen/HRP

DNA-Polymerase (AmpliTaq)

DNase I

DNA-Polymerase I

Kaninchen-Anti-DIG-HRP

Proteinase $\mathrm{K}$

Restriktionsendonukleasen

RNase A (Rinderpankreas)

T4-DNA-Ligase

T4-Polynukleotid-Kinase

Lysozym (Muramidase)

\section{Hersteller}

Boehringer Mannheim, Mannheim

Boehringer Mannheim, Mannheim

DAKO, Carpinteria; USA

Perkin Elmer, Langen

Amersham Pharmacia Biotech, Freiburg

Boehringer Mannheim, Mannheim

DAKO, Carpinteria; USA

DAKO, Carpinteria; USA

MBI Fermentas, St. Leon-Rot

Boehringer Mannheim, Mannheim

MBI Fermentas, St. Leon-Rot

MBI Fermentas,St. Leon-Rot

Boehringer Mannheim, Mannheim

Folgende Restriktionsendonukleasen wurden verwendet: Agel, BamHI, Bglll, EcoRI, Hindlll, Ncol, Notl, Pstl, Sall, Xbal, Eco RV und Xhol.

\subsection{Nukleinsäuren, Radiochemikalien}

Der DNA-Längenstandard (100 bp DNA Ladder) wurde von MBI Fermentas (St. Leon-Rot) und Gibo BRL (Eggenstein) bezogen. Die RNA-Längenstandards I und III, Digoxygenin markiert sowie CSPD ${ }^{\circledR}$ wurden von Boehringer Mannheim (Mannheim) bezogen. 


\subsection{Bakterienstamm}

E.coli TOP10F': $\quad \mathrm{F}^{\prime}\{l a c l q \quad$ Tn10 $\quad$ (TetR) $\} \quad$ mcrA $\quad \Delta$ (-mrr-hsdRMS-mcrBC)

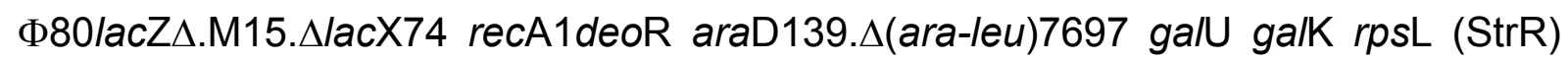
endA1 nup

\subsection{Geräte}

Folgende Geräte wurden zur Durchführung der Methoden verwendet:

\section{Gerät}

Autoklav

Elektrophoresekammern

Elektrophoresekammern

für Differential Display

Fluoreszenzmikroskop

Filter-set

Inkubatoren

Light Cycler ${ }^{R}$

Mikroskopleuchte

Netzgerät

pH-Meter

Rotoren

Festwinkelrotoren

Sequenzierer

Spektralphotometer

Sterilbank

Thermocycler

UV-Crosslinker

UV-Transilluminator

Vakuumpumpe

Vakuumzentrifuge

Waagen

\section{Hersteller}

HAST 32/25 (Zirbus, Bad Grund)

Sub-Cell ( GT (Bio-Rad, München) für Agarose Gel

Multiphor-II (Pharmacia, Freiburg)

Standard FM (Zeiss, Oberkochem)

Emissionsfilter 02 und 09 (Zeiss,Oberkochem)

MS1 Minishaker (IKA-Works, Wilmington USA);

Eppendorf Thermomixer compact (Schütt, Göttingen);

Hybridisierunsinkubator APT Leine (Biometra,Göttingen);

Schüttelwasserbad 1083 (GFL, Burgwedel)

Roche Diagnostics (Mannheim)

HBO 50 (Zeiss, Oberkochem)

PowerPac 3000 (Bio Rad, München)

WTW pH 526 (Schütt, Göttingen)

Ausschwingrotoren SW25.2, SW40 und SW65-L

SS-34, GSA und GS-3 (Dupont, Bad Nauheim)

LI-COR 4000 (MWG-Biotech, Ebersberg)

Ultrospec 2000 (Amersham Pharmacia Biotech, Freiburg)

Heraeus HS 18/2 (Heraeus, Hanau)

Trioblock (Biometra, Göttingen)

UV Stratalinker ${ }^{\circledR} 1800$ (Stratagene, Amsterdam)

Mini-Transilluminator (Bio-Rad, München)

Vacuubrand RD4 (Brand, Wertheim)

Speed Vac Concentrator (Savant, Hicksville, USA)

BP 610 Sartorius (W. Krannich, Göttingen) 
Zentrifugen

Laborzentrifugen Labofuge 400 R (Schütt, Göttingen);

Sorvall RC2-B und RC-5 (Dupont, Bad Nauheim) und J2-

MC (Beckman, Fullerton, USA); Kühlzentrifuge Heraeus

Function Line (Schütt, Göttingen)

\subsection{Fotomaterialien}

An Filmmaterialien wurden Polaroid Schwarzweiss-Filme 667 (Polaroid Corporation, Cambridge, USA), Lumi-Filme 18 × 24 cm (Boehringer Mannheim, Mannheim) und Elite chrome 100 ASA Filme (Kodak $\mathrm{GmbH}$, Stuttgart) verwendet. 


\section{METHODEN}

\subsection{Versuchstiere und extrakorporale Dünndarmperfusion}

Als Versuchstiere wurden weibliche Schweine (Deutsche Landrasse, Versuchsgut Relliehausen, Deutschland) mit einem Gewicht von 23-30 kg verwendet. Die abdominellen Organe wurden mit 4 Litern kalter Histidin-Tryptophan-Ketoglutarat (HTK)-Lösung (Custodiol, Dr-Franz-Köhler-Chemie, Alsbach-Haehnlein, Deutschland) perfundiert und anschließend bei $4^{\circ} \mathrm{C}$ in HTK-Lösung bis zur extrakorporalen Reperfusion konserviert. Die kalte Ischämiezeit betrug bei je fünf Dünndärmen 2 beziehungsweise 20 Stunden. Die Tötung von Versuchstieren zum Zwecke der Organentnahme wurde von der Bezirksregierung Braunschweig genehmigt (AZ 604.42502/01-0-05-96).

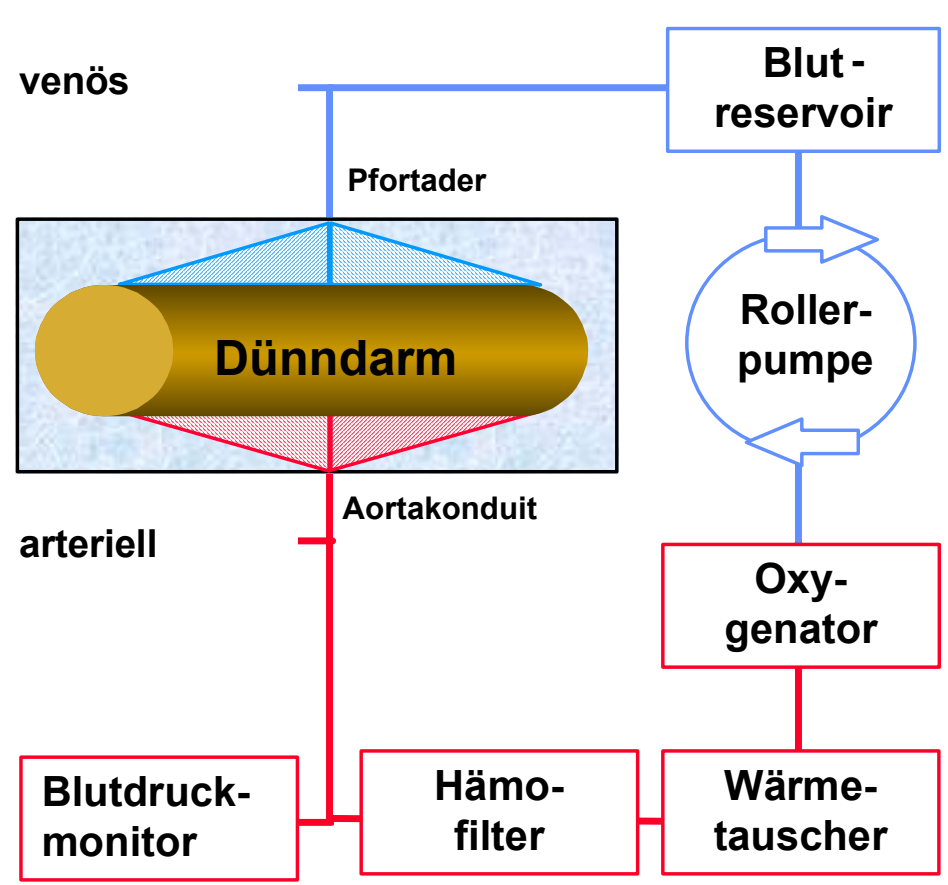

Abbildung 2:

Schematische Darstellung des geschlossenen rezirkulierenden Systems zur isolierten extrakorporalen Dünndarmperfusion (modifiziert nach Braun et al. 1998).

Die explantierten Dünndärme wurden mit heparinisiertem Schweinevollblut in einem standardisierten geschlossenen rezirkulierenden Perfusionssystem nach Ende der kalten Ischämiezeit reperfundiert. Die Perfusionseinheit bestand aus einem Perfusionsbecken, einer Rollerpumpe, einem Blutreservoir, einer Perfusionskammer, einem Oxygenator und einem Wärmetauscher (Braun et al., 1998: (Abb. 2)). Nach einer Stabilisierungsphase wurde die Volumenstromstärke auf einen Bereich von 
200-450 ml/min eingestellt. Die Reperfusion endete sobald der arterielle Druck 180 $\mathrm{mmHg}$ überstieg.

Die Gewebeproben wurden vor HTK-Perfusion, nach HTK-Perfusion, am Ende der kalten Ischämiezeit und stündlich nach Reperfusion gewonnen (Abb. 3). Als Gewebeproben dienten Dünndarmsegmentresektate von $3-5 \mathrm{~cm}$ Länge, die am terminalen lleum genommen wurden. Ein Teil der Gewebeproben wurde längs

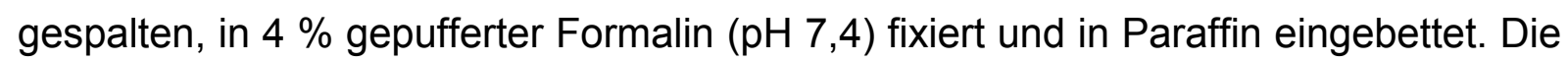
Reste der Gewebeproben wurden sofort in ein $1,5 \mathrm{ml}$ Eppendorfgefäß aufgenommen, in flüssigem Stickstoff schockgefroren und bis zur weiteren Verwendung bei $-70^{\circ} \mathrm{C}$ gelagert.

Gewebe-/Blutproben

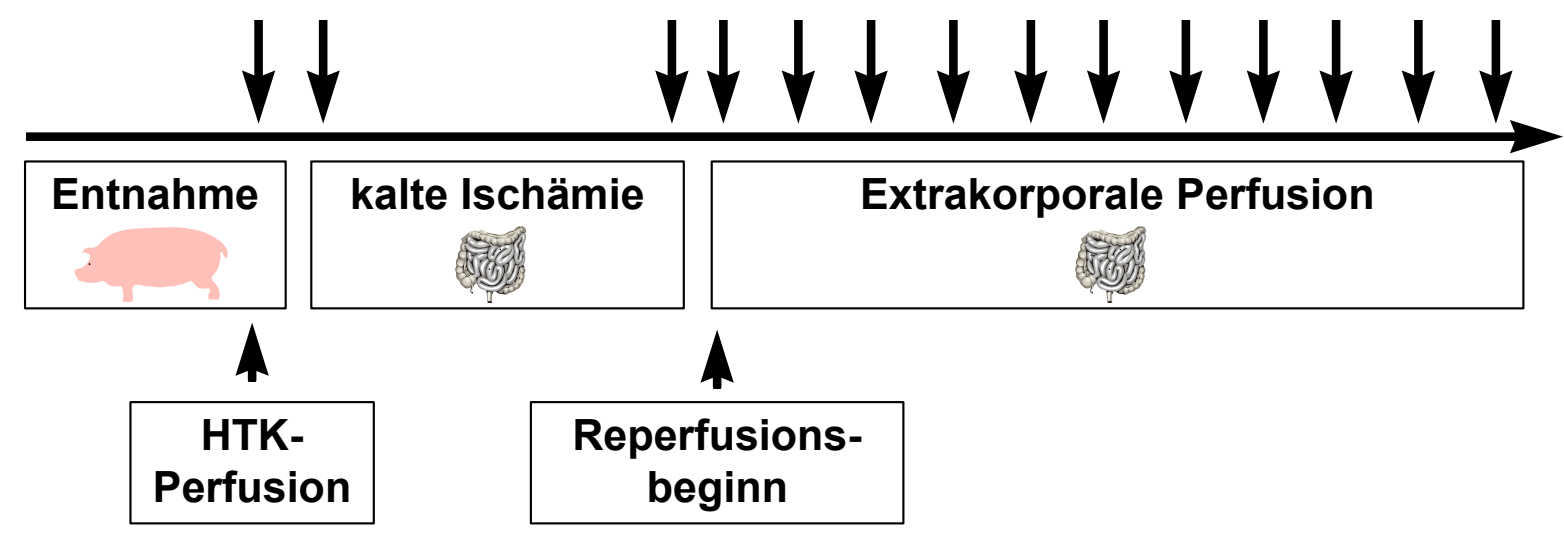

Abbildung 3:

Schematische Übersicht des Versuchsaufbaus und Zeitpunkte der Gewinnung von Gewebe- und Blutproben.

\subsection{Molekularbiologische Methoden}

Sämtliche bei molekularbiologischen Arbeiten eingesetzte Glas- und Kunststoffmaterialien sowie Lösungen wurden durch Autoklavieren oder Erhitzen $\left(180^{\circ} \mathrm{C}, 3\right.$ Stunden) sterilisiert. Hitzelabile Substanzen wurden durch Sterilfiltration entkeimt.

\subsubsection{RNA-Arbeiten}

Beim Arbeiten mit RNA ist besondere Vorsicht geboten, da RNasen überall präsent und kaum inhibierbar sind. Alle RNA-Arbeiten wurden deshalb mit Handschuhen durchgeführt, um eine Kontamination durch RNasen der Haut zu verhindern. Alle Glasgegenstände wurden für 6 Stunden bei $240^{\circ} \mathrm{C}$ sterilisiert. Diese Erhitzung ist in 
Hinblick auf inaktivierte RNasen und DNA/RNA Restbestandteile der Autoklavierung überlegen. Das verwendete Wasser wurde mit 0,1 \% DEPC (Diethyl-Pyrocarbonat, Sigma) versetzt. DEPC-haltige Lösungen stellen die wirksamsten, nicht proteinartigen RNase Inaktivatoren dar (Sambroook et al. 1989). Die DEPC haltigen Lösungen wurden für 24 Stunden bei $37^{\circ} \mathrm{C}$ inkubiert und anschließend noch einmal für $20 \mathrm{~min}$ bei 1,3 bar feuchter Hitze $\left(120^{\circ} \mathrm{C}\right)$ autoklaviert, um DEPC möglichst komplett zu hydrolysieren. Alle Puffer und Lösungen wurden autoklaviert und DEPC behandelt. Die verwendeten Gefäße und Gelkammern wurden zusätzlich mit 0,3\% $\mathrm{H}_{2} \mathrm{O}_{2}$ behandelt und anschließend mit EtOH und RNase freiem Wasser gespült.

\subsubsection{Isolation von Gesamt-RNA aus Gewebe}

Die Extraktion der Gesamt-RNA aus Gewebeproben wurde mit einem kommerziell erhältlichen Kit (RNeasy, Fa. Qiagen) durchgeführt. Das gewogene, frische oder gefrorene Gewebe wurde sofort in flüssigen Stickstoff gegeben und mit Mörser und Stößel unter flüssigem Stickstoff zerkleinert. Das zertrümmerte Gewebe wurde mit 3,8 $\mathrm{ml}$ Lysispuffer RLT lysiert und homogenisiert. Zur vollständigen Aufschließung des Gewebes wurde das Lysat mit einem QIAshredder 3 min kalt bei $4500 \mathrm{rpm}$ zentrifugiert. Das Eluat wurde mit 3,6 ml EtOH $70 \%$ gemischt und auf RNeasySäulen aufgetragen. Nach kurzer Zentrifugation bei $4500 \mathrm{rpm}$ wurden die Säulen zunächst mit 3,8 ml RW1-Puffer versetzt, bei $45000 \mathrm{rpm}$ für $5 \mathrm{~min}$ zentrifugiert und zweimal mit 2,5 ml RPE-Puffer gewaschen. Die Elution der RNA in ein neues Röhrchen erfolgte mit $150 \mu \mathrm{l}$ RNase freiem Wasser über einen weiteren Zentrifugationsschritt (3 min, $4500 \mathrm{rpm}$ ).

\subsubsection{Reinigung der Proben mit DNase}

Die eluierten Proben wurden mit $2 \mu \mathrm{l}$ RNase freier DNase I (Pharmacia) versetzt und inkubiert (30 $\mathrm{min}, 37^{\circ} \mathrm{C}$ ), um eine Kontamination durch Rest-DNA zu vermeiden. Der Reaktionsansatz bestand aus $3 \mu \mathrm{l} 10 \times$ Reaktionspuffer, $2 \mu \mathrm{l}$ DNase I und $30 \mu \mathrm{l}$ RNA. Zur Inaktivierung bzw. Entfernung der DNase wurden die Proben mit $70 \mu \mathrm{l}$ RNase freiem Wasser aufgefüllt, mit $350 \mu \mathrm{l}$ RLT-Puffer und 250 $\mu \mathrm{l}$ absolutem Ethanol gemischt, auf Säulen aufgetragen und zentrifugiert (15 s, 10000 rpm). Nach zwei Waschschritten mit $500 \mu \mathrm{l}$ RPE-Puffer wurden die Säulen in neue Röhrchen überführt und mit $30 \mu \mathrm{l}$ RNase freiem Wasser eluiert. Es folgte die Gelelektrophorese von $4 \mu \mathrm{l}$ der RNA-Lösung analog dem Protokoll der RNA- 
Gelelektrophorese, welches unter 3.2.6 beschrieben wird, um die Reinheit, Integrität und Menge der RNA beurteilen zu können. Intakte RNA zeigt klare $28 \mathrm{~S}$ und $18 \mathrm{~S}$ ribosomale RNA-(rRNA) Banden, wobei die 28 S-Bande ungefähr doppelt so intensiv wie die 18 S-Bande imponiert. Kontamination der RNA mit genomischer DNA erscheint als hochmolekularer undeutlicher Fleck oder als eine Bande, größer als die 28 S rRNA-Bande. Der Rest der RNA-Lösung wurde in $10 \mu \mathrm{l}$ Aliquots sofort weiterverarbeitet oder bei $-70^{\circ} \mathrm{C}$ aufbewahrt.

\subsubsection{Reverse Transkription}

Bei der reversen Transkription macht man sich die charakteristische Eigenschaft von Retroviren zunutze, ihre genetische Information, die in Form von RNA vorliegt, nach Infektion von eukaryonten Zellen durch Synthese von DNA-RNA-Hybriden in komplementäre DNA (cDNA) umzuschreiben. Dieser Schritt wird von der RTase in vitro von einem Oligo-dT-Starter ausgehend katalysiert. Für molekularbiologische Zwecke wird die klonierte Mäuse-Leukämie-Virus- Reverse-Transkriptase (MMLVRT) verwendet. Die intrinsische RNase H-Aktivität der MMLV-RTase ist ausreichend, die nach der cDNA-Synthese verbleibenden intakten mRNAMoleküle zu degradieren, die sonst mit der cDNA als Schablone konkurrierend die PCR stören.

Zur cDNA-Synthese wurden $4 \mu \mathrm{l}$ RNA-Lösung eingesetzt. Für das Priming wurden $4 \mu$ Oligo $\mathrm{dT}_{12-18}$ (Fa. BRL) Primer und 18,8 $\mu$ I DEPC- $\mathrm{H}_{2} \mathrm{O}$ zugegeben, inkubiert (5 $\min , 65^{\circ} \mathrm{C}$ ) und abgekühlt, um die Anlagerung des Oligo-dT-Primers an das PolyA-Ende zu ermöglichen, welches mRNA-Molelüle auszeichnet. Durch Zusatz von $8 \mu \mathrm{l} 5 \mathrm{x}$ Erststrangpuffer, 3,2 $\mu \mathrm{l}$ dNTP's $250 \mu \mathrm{M}$, und $2 \mu \mathrm{l}$ RTase (BRL) ergab sich ein Gesamtvolumen von $40 \mu \mathrm{l}$, welches bei Inkubation ( 1 Stunde, $37^{\circ} \mathrm{C}$ ) zur Erststrangsynthese führt. Zur Inaktivierung der MMLV-RTase wurden die Proben anschließend aufgeheizt $\left(5 \mathrm{~min}, 75^{\circ} \mathrm{C}\right)$, ohne den mRNA/cDNA-Komplex zu denaturieren. Die cDNA-Lösungen wurden weiter aufgearbeitet oder bei $-20^{\circ} \mathrm{C}$ gelagert. 


\subsubsection{Oligonukleotid Primer für die RT-PCR}

Spezifische Primer für IL-6, IFN $\gamma$, IL-2, HSP70, E-Selektin, $\beta$-Actin und GAPDH wurden ausgewählt und von der Firma NAPS (Göttingen) synthetisch hergestellt.

\begin{tabular}{|c|c|c|c|}
\hline Gen & Primersequenz & $\begin{array}{l}\text { PCR- } \\
\text { Produkt } \\
\text { bp }\end{array}$ & $\begin{array}{l}\text { Gen } \\
\text { Bank } \\
\text { Accession }\end{array}$ \\
\hline \multirow[t]{2}{*}{ IL-6 } & 5'-CTATGAАСТСССТСТССАСАА-3' & 710 & M80258 \\
\hline & 5'-TGCCCAGTGGACAGTTTTCT-3' & & \\
\hline \multirow[t]{2}{*}{ IL-2 } & 5'-GCACCTACTTCAAGCTCTAC-3' & 387 & X56750 \\
\hline & 5'-GATGCTTTGACAAAAGGTAATC3' & & \\
\hline \multirow[t]{2}{*}{$\mathrm{IFN} \gamma$} & 5'-ATTTTGAAGAATTGGAAAGAGG-3' & 365 & X53085 \\
\hline & 5'-AAATTCAAATATTGCAGGCAGG-3' & & \\
\hline \multirow[t]{2}{*}{ HSP70 } & 5'-AGGCCTAGTTCCTTCTCTCT-3' & 239 & M69100 \\
\hline & 5'-TGGCAGTGTTGATTACAGGG-3' & & \\
\hline \multirow[t]{2}{*}{ E-Selektin } & 5'-TGACCCCAGAGGCCACCAAT-3' & 417 & U08350 \\
\hline & 5'-CCGTCCCAGCTCCCAGATGA-3' & & \\
\hline \multirow[t]{2}{*}{$\beta$-Actin } & 5'-TGACCCAGATCATGTTTGAGA-3' & 456 & $\mathrm{X} 00351$ \\
\hline & 5'-ACTCCATGCCCAGGAAGG-3' & & \\
\hline \multirow[t]{2}{*}{ GAPDH } & 5' -CTCCAGGCGGCAGGTCAGAT-3' & 592 & U48832 \\
\hline & 5'-CTCCAGGCGGCAGGTCAGAT-3 & & \\
\hline
\end{tabular}

\subsubsection{PCR-Reaktionen}

Die PCR-Methodik wurde ursprünglich von Saiki, Erlich und Mullis bei Cetus in Kalifornien entwickelt (Mullis u. Faloona 1987) und dient der in-vivo-Amplifikation bestimmter DNA-Abschnitte. Die Methode ahmt den in vivo DNA-Replikationsprozeß in sofern nach, als die Zahl der generierten DNA-Moleküle nach jedem Zyklus verdoppelt wird. Durch die PCR-Analyse können Nukleotidsequenzen in vitro enzymatisch exponentiell amplifiziert werden. Für diese Kettenreaktion wird eine Matrix benötigt, deren Sequenz am 5 '-und am 3'-Ende annähernd bekannt ist, damit zwei Oligonukleotide (Primer) abgeleitet werden können.

Der semiquantitative RT-PCR-Ansatz bestand aus $1 \mu \mathrm{l}$ cDNA 1:10 verdünnt, $10 \mu \mathrm{l}$ 10-fach konzentrierter PCR-Puffer $(100 \mathrm{mM}$ Tris/ $\mathrm{HCl}(\mathrm{pH} 8,8)$ mit $500 \mathrm{mM} \mathrm{KCl}$ und 
0,8 \% Nonidet P40 mit MgCl 25 mM, $4 \mu \mathrm{l} 4$ dNTP's (je 2,5 mM), je $1 \mu$ l Oligos $(0,1$ nM), 0,5 $\mu$ l Taq-Polymerase (4 U/ml) und $\mathrm{H}_{2} \mathrm{O}_{\text {dd }}$ ad. $100 \mu$ l. Der Ansatz wurde mit 100 $\mu$ l Mineralöl als Verdunstungsschutz überschichtet. Der Ansatz wurde in die PCRApparatur (Thermocycler) gegeben und die RT-PCR Analyse mit folgendem Programm durchgeführt:

$\begin{array}{llll}\text { PCR-Programm: } & 2 \min & \text { Denaturierung } & \text { bei } 95{ }^{\circ} \mathrm{C} \\ & 1 \mathrm{~min} & \text { Annealing } & \text { bei } 55^{\circ} \mathrm{C} \text { oder } 58^{\circ} \mathrm{C} \text { oder } 62{ }^{\circ} \mathrm{C} \\ 2 \mathrm{~min} & \text { Elongation } & \text { bei } 72{ }^{\circ} \mathrm{C} \text { (Polymerisation) } \\ & 30 \text { Zyklen } & & \\ 8 \mathrm{~min} & \text { Abschluss } & \text { bei } 72{ }^{\circ} \mathrm{C}\end{array}$

Nach dem Durchlaufen der 30 Zyklen und Abschluss wurde der Reaktionsmix langsam abgekühlt und das Mineralöl entfernt. Die Reaktion wurde mit $2 \mu$ StoppLösung versetzt und $15 \mu$ der Probe auf ein Agarose-Gel aufgetragen.

\subsubsection{Quantitative Polymerasekettenreaktion}

Für die quantitative RT-PCR wurde der Light Cycler ${ }^{R}$ (Roche Diagnostics, Mannheim) verwendet. Eine externe Standardreihe mit bekannten Konzentrationen des Gens, dessen Expression untersucht werden sollte, wurde angefertigt. Dabei wurde der Logarithmus des Fluoreszenzsignales gegen die Zykluszahl zum ersten Zyklus über dem Rauschen extrapoliert. Für die Genexpression von IL-6, HSP70 und E-Selektin wurde der Elongationsfaktor-2 (EF-2) als Referenzgen benutzt. Pro Lauf wurden $20 \mu \mathrm{l}$ Light Cycler DNA-Master-SYBR-Green-I, 1,25 pmol Oligonukleotidprimer und $1 \mu \mathrm{l}$ cDNA eingesetzt.

Die Standardkurve aus dsDNA für IL-6, HSP70 und E-Selektin wurde aus einem Bereich von 2000 bis 2000000 Kopien und für EF-2 von 2000 bis 4000000 Kopien angelegt. Spezifische Oligonukleotidprimer, welche als spezifisch für Sus scrofa ESelektin (GenBank Acc. No. U08350, Position 799-818 for. Und 1001-982 rev.), für Pig HSP70 (GenBank Acc. No. M69100, Position 2412-2431 for. Und 2631-2612 rev.), für Sus scrofa IL-6 (GenBank Acc. No. M80258, Position 101-118 for. Und 343323 rev.) und für Homo sapiens EF-2 (GenBank Acc. No. XM_009189, Position 1990-2010 for. Und 2207-2188 rev.) gelten, wurden im Auftrag synthetisiert (MWGBiotech, Ebersberg, Deutschland). 
Die Genexpression wurde als Quotient der cDNA- Kopien des entsprechenden Gens zu den cDNA-Kopien des Referenzgenes EF-2 ausgedrückt (cDNA- Kopien Gen/ cDNA- Kopien EF-2). Der Lingt Cycler wurde mit folgendem Programm durchgeführt (Tab. 1):

\begin{tabular}{|c|c|c|c|}
\hline Arbeitsschritt & Temperat & & Zeit (sek) \\
\hline Initiale Denaturierung & 95 & & 1 \\
\hline 35 Zyklen Denaturation & 95 & & 1 \\
\hline 35 Zyklen Annealing & 57 & & 5 \\
\hline 35 Zyklen Elongation & 72 & & 10 \\
\hline Messung & $\begin{array}{l}\text { E-Selektin } \\
\text { HSP70 } \\
\text { IL-6 } \\
\text { EF-2 }\end{array}$ & $\begin{array}{l}85 \\
80 \\
83 \\
87\end{array}$ & 1 \\
\hline
\end{tabular}

Tabelle 1:

Bedingungen für die quantitative RT-PCR.

\subsubsection{RACE-PCR}

Mit der Methode der RACE- (Rapid Amplification of cDNA Ends) PCR ist es möglich, die noch unbekannten 5'- Enden (5'- RACE) oder 3'- Enden (3'- RACE) von cDNAFragmenten zu identifizieren. Die gesamte Länge der cDNA eines unbekannten Gens wird so amplifiziert und kann isoliert und kloniert werden (Frohmann 1994). Da die aus dem mRNA-Differential Display Gel isolierten Fragmente das 3' -Ende der jeweiligen mRNA repräsentieren, musste zur Identifizierung der vollen Länge eine 5' -RACE durchgeführt werden.

Dazu wurde der "MARATHON RACE Kit" von Clontech verwendet. Die Reaktionen wurden nach dem Protokoll des Herstellers durchgeführt.

Die Erststrang-Synthese der cDNA wurde aus Gesamt-RNA mit einem genspezifischen Primer ESP und Moloney Murine Leukemia Virus Reverse Transkriptase (M-MLV-RT) durchgeführt. Anschließend wurde die Zweitstrangsynthese mit dem Zweitstrang-Enzym-Cocktail (RNase H, E. coli DNA Polymerase I, E. coli DNA Ligase) für 2 Stunden bei $16{ }^{\circ} \mathrm{C}$ durchgeführt. Die Enden der doppelsträngigen cDNA wurden dann mit $5 \cup$ T4-DNA-Polymerase aufgefüllt, die Reaktion mit Phenol/Chloroform extrahiert und gefällt. Das Pellet wurde in $\mathrm{H}_{2} \mathrm{O}$ aufgenommen und auf einem 1,5\%igen Agarosegel getestet. $5 \mu$ davon wurden in 
einer Ligationsreaktion eingesetzt, in der MARATHON cDNA Adapter (Linker) an die Enden der cDNA angefügt wurden. Das 5' -RACE-PCR-Produkt nach der Amplifikation wurde mit einem "nested" genspezifischen Primer und AP1 bzw. AP2 Primer über einem Agarosegel gereinigt und in einem $\mathrm{pCR}{ }^{\circledR}$ II-TOPO-Vektor kloniert und sequenziert.

\subsubsection{RNA-Gelelektrophorese}

Nukleinsäuren können bei geeignetem pH-Wert als geladene Makromoleküle durch Anlegen eines elektrischen Feldes in einer Agarose-Gelmatrix nach ihrem Molekulargewicht aufgetrennt werden. RNA und DNA sind im pH Bereich des Puffers $(\mathrm{pH} 8,0)$ aufgrund ihres Phosphatrests negativ geladen und wandern daher zur Anode.

Zuerst wurden 3-5 $\mu \mathrm{g}$ isolierte Gesamt-RNA und $100 \mathrm{ng}$ Digoxygenin-markierter RNA-Längenstandard (Boehringer Mannheim) in einem 1-1,5-\%igen denaturierenden Agarose-Formaldehydgel elektrophoretisch aufgetrennt (SHIFMAN u. Stein 1995). In einem Gefäß wurden 1,5 bis 2,3 g Agarose abgewogen und diese in 108 ml DEPCWasser und $15 \mathrm{ml}$ 10x MOPS-Puffer unter Erhitzen vollständig geschmolzen. Nach Abkühlen auf ca. $60^{\circ} \mathrm{C}$ wurden noch $36 \mathrm{ml}$ Formaldehyd $37 \%(2,2 \mathrm{M})$ zugegeben, in eine Gelschale gegossen und bis zum Erstarren stehen gelassen. 3-5 $\mu \mathrm{g}$ der RNA wurden vor dem Auftragen mit dem gleichen Volumen RNA-Laufpuffer gemischt, denaturiert $\left(10 \mathrm{~min}, 65^{\circ} \mathrm{C}\right)$ und auf Eis abgekühlt. Der Laufpuffer bestand aus $250 \mu \mathrm{l}$ deionisiertem Formamid, $83 \mu \mathrm{l} 37$ \% Formaldehyd, $50 \mu \mathrm{l}$ 10x MOPS-Puffer, $17 \mu \mathrm{l}$ DEPC- $\mathrm{H}_{2} \mathrm{O}$ und 0,035 $\mathrm{g}$ Bromphenolblau. In einer bis zum Gelrand mit $1 \mathrm{x}$ MOPSPuffer gefüllten Kammer wurde die Auftrennung der RNA durch Elektrophorese (5 min, 150 V) gestartet und nach Auffüllen der Kammern mit 1x MOPS-Puffer bis ca. 5 $\mathrm{mm}$ über den Gelrand durch einen zweiten Elektrophoreseschritt (3h, $80 \mathrm{~V})$ aufgetrennt. Anschließend wurde das Gel in DEPC-Wasser auf einem Schüttler 30 min gewässert, um das Formaldehyd aus dem Gel herauszuwaschen. Zur Anfärbung der RNA wurde das Gel in Ethidiumbromidlösung gegeben. 


\subsubsection{Markierungen von DNA und RNA}

\subsubsection{Nicht-radioaktive Markierung von DNA mit Digoxygenin}

Als Alternative zur Hybridisierung von radioaktiv markierter Nukleinsäure kann eine Digoxygenin-markierte Sonde verwendet werden. Die Detektion erfolgt durch mit Peroxidase- oder alkalischer Phosphatase- gekoppelten Antikörpern und anschließender Chemilumineszenzreaktion. Zur nicht-radioaktiven Markierung von DNA wurde der "PCR DIG Probe Synthesis Kit" (Boehringer Mannheim) benutzt. Zur Entwicklung von DNA-Sonden erfolgte die Überprüfung der Expression amplifizierter DNA-Fragmente mittels der DIG-Labelling-PCR. Das zugesetzte OligonukleotidGemisch enthält zusätzlich eine alkalilabile DIG-11-dUTP Form. Die DNA-Sonden wurden in einer PCR-Reaktion mit Digoxygenin-11-dUTP markiert. Die PCRProdukte $(15 \mu \mathrm{l})$ wurden mit einer 1,5\%-Agarose-Gelelektrophorese nach Ethidiumbromidfärbung überprüft. Anschließend wurde die PCR mit DIG-11-dUTP wiederholt. Dabei wurde die Nukleotidlösung durch eine Lösung mit je 2 mM dATP, dCTP, dGTP, 1,3 mM dTTP und 0,7 mM DIG-11-dUTP (alkalilabil, pH 7,0) ersetzt. Nach 10 Zyklen wurde die Elongationszeit für weitere 20 Zyklen um 20 s pro Zyklus verlängert. Die Annealing-Temperatur wurde aufgrund des großvolumigen DIG-11dUTP-Nukleotids um $3^{\circ} \mathrm{C}$ erniedrigt, um den Digoxygenineinbau zu erleichtern. Im Vergleich zum PCR-Produkt aus der PCR ohne DIG-11-dUTP ergibt sich ein sogenannter „band-shift“. Die Bande des DIG-markierten PCR-Produkts liegt im Gel nicht auf derselben Höhe wie ihr unmarkiertes Pendant. Digoxygenin hemmt durch sein großes Volumen die Wanderung des PCR-Fragments im Agarose-Gel. Der „band-shift“ ist ein wichtiges Indiz für den gelungenen Einbau von DIG-11-dUTP in die DNA. Die fertige Sonde wurde direkt für Northern-Blot bzw. Slot-Blot-Analysen eingesetzt oder bei -20 C gelagert.

\subsubsection{Nicht-radioaktive Markierung von RNA mit Digoxygenin}

Bei dieser Methode wird die DNA durch Anwesenheit von RNA-Polymerase in vitro transkribiert und anwesende DIG-dUTPs zufällig in die gebildete RNA eingebaut (Feinberg u. Vogelstein 1983). Zur Markierung von RNA-Fragmenten wurde der "DIG RNA Labeling Kit Sp6/T7" (Boehringer Mannheim) benutzt. Zur Herstellung von RNASonden wurde das entsprechende DNA-Fragment in einen pCR ${ }^{\circledR}$ II-TOPO-Vektor oder pBlueskript II SK kloniert und das entstandene Plasmid anschließend mit 
Restriktionsendonukleasen am 3'- bzw. 5'-Ende des Inserts linearisiert. Das linearisierte und aufgereinigte Plasmid-DNA $(1 \mu \mathrm{g})$ wurde mit $2 \mu \mathrm{L}$ 10x dNTPs (10mM), $2 \mu \mathrm{L}$ 10x Transkriptionspuffer, $1 \mu \mathrm{L}$ RNase-Inhibitor $(20 \mathrm{U} / \mu \mathrm{L})$ und $2 \mu \mathrm{L}$ RNA-Polymerase (T3, SP6 oder T7) versetzt. Der Ansatz wurde mit Wasser auf 20 $\mu \mathrm{L}$ aufgefüllt und inkubiert (2 Stunden, $37^{\circ} \mathrm{C}$ ). Anschließend wurden $2 \mu \mathrm{L}$ RNase-freie DNase $(10 \mathrm{U} / \mu \mathrm{L})$ zugefügt und inkubiert $\left(10 \mathrm{~min}, 37^{\circ} \mathrm{C}\right)$, um die DNA zu hydrolysieren. Die Inhibition der DNase erfolgte mit $2 \mu \mathrm{L}$ EDTA $(0,5 \mathrm{M}, \mathrm{pH} 8,0)$. Nach Zugabe von $2,5 \mu \mathrm{L} \mathrm{LiCl}(4 \mathrm{M})$ und $75 \mu \mathrm{L}$ EtOH erfolgte die Präzipitation der RNA (30 min, $-70^{\circ} \mathrm{C}$ ). Es folgte ein Waschgang mit $70 \% \mathrm{EtOH}$, Trocknen der RNA und Resuspension in $50 \mu \mathrm{L} \mathrm{H}_{2} \mathrm{O}$. Die hergestellten Sonden wurden unmittelbar für Northern-Blot, Slot-Blot oder In-situ-Hybridisierung eingesetzt oder bei $-70^{\circ} \mathrm{C}$ gelagert.

\subsubsection{Dot-Blot}

Die Dot-Blot-Analyse wird zur Abschätzung der Markierungseffizienz verwendet. Hierbei wird eine Verdünnungsreihe der markierten Sonde direkt auf eine Hybond $\mathrm{N}^{+}$Nylonmembran (Amersham Pharmacia) aufgetragen. Die DIG-markierten Proben werden vorher für $10 \mathrm{~min}$ bei $100^{\circ} \mathrm{C}$ denaturiert und rasch auf Eis abgekühlt. Nach dem Auftragen wurden die Membranen beidseitig auf einem "UV-Crosslinker" (Stratagen, Amsterdam, Niederlande) für $3 \mathrm{~min}$ bei $254 \mathrm{~nm}$ bestrahlt, um die Nukleinsäuren durch UV-Quervernetzung zu fixieren. Die Effizienz der DIGMarkierung wurde mit Anti-DIG-AP-Konjugat und CSPD ${ }^{\circledR}$-Lösung sichtbar gemacht.

\subsubsection{Slot-Blot}

Beim Slot-Blot wurden RNA-Proben mit einer Vakuumapparatur "Slot-Blotter" schlitzförmig aufgetragen. Der verwendete Slot-Blotter PR648 (Amersham Pharmacia) ermöglicht das Auftragen von 48 Proben auf die Hybond $\mathrm{N}^{+}-$ Nylonmembran (Amersham-Pharmacia). Nach dem Durchsaugen der Proben wurden je $100 \mu \mathrm{l} 2 x$ SSC-Puffer in die Probenvertiefung gegeben und durchgesaugt. Die aufgetragenen Nukleinsäuren wurden durch UV-Quervernetzung (2x 3min) auf der Membran fixiert und verbliebene Reste durch anschließendes Waschen mit 2x SSC und $\mathrm{H}_{2} \mathrm{O}$ entfernt. 


\subsubsection{Northern-Blot}

Der Northern-Blot basiert auf kapillarem RNA-Transfer unter neutralen Bedingungen von einem denaturierenden Formaldehydgel auf eine $\mathrm{N}^{+}$-Nylonmembran (Maniatis et al. 1989). Das unter dem UV-Transilluminator fotographierte Gel wurde zum RNATransfer auf der $\mathrm{N}^{+}$-Nylonmembran (Amersham Pharmacia) 2x 10min in $\mathrm{H}_{2} \mathrm{O}$ gespült, um die Hintergrundfärbung des Ethidiumbromids zu entfernen. Der eigentliche Transfer erfolgte mittels Kapillarblotting. Hierzu wurde 20x SSC-getränktes Whatmanpapier auf eine Glasplatte gelegt, so dass die Ränder überstanden und in eine mit 20x SSC gefüllte Schale reichten. Das RNA-Gel wurde mit nach unten zeigenden Taschen darauf gelegt. Auf das Gel wurde luftblasenfrei eine 20x SSCbefeuchtete $\mathrm{N}^{+}$-Nylonmembran gelegt, die von zwei ebenfalls angefeuchteten und vier trockenen Whatman-Papieren bedeckt wurde. Das Sandwich wurde mit einem Stapel saugfähigem Papier bedeckt, mit Gewichten beschwert und für mindestens 12 Stunden gelagert. Nach abgeschlossenem RNA-Transfer wurde die Membran für 30 min in 2x SSC und kurz in $\mathrm{H}_{2} \mathrm{O}$ gewaschen, an der Luft getrocknet und im UVCrosslinker fixiert.

\subsubsection{Hybridisierung membrangebundener Nukleinsäuren mit markierten Sonden}

Die Membranen wurden in RNase-freien Hybridisierröhren mit je $20 \mathrm{ml}$ Hybridisierungslösung pro $100 \mathrm{~cm}^{2}$ Filterfläche unter Schütteln prähybridisiert (1 Stunde, $65^{\circ} \mathrm{C}$ ) (Trayhurn et al. 1994). Die DNA-Sonde (20 ng) bzw. RNA-Sonde (100 ng) pro $\mathrm{ml}$ Hybridisierungslösung wurde denaturiert $\left(10 \mathrm{~min}, 100^{\circ} \mathrm{C}\right)$, nach Erhitzen umgehend mit gleichem Volumen entionisiertem Formamid versetzt und auf Eis gestellt, um erneutes Zusammenlagern der DNA-Stränge vor der Hybridisierung zu unterbinden. Die Membranen wurden in $2,5 \mathrm{ml} 50$ \% Formamid-HybridisierungsLösung pro $100 \mathrm{~cm}^{2}$ (ü.N, $65^{\circ} \mathrm{C}$ ) unter Schütteln inkubiert. Die Filter wurden je $2 x$ $5 \mathrm{~min}$ in $2 x$ SSC, $0,1 \%$ SDS bei Raumtemperatur, $2 \times 0,1$ SSC, $0,1 \%$ SDS bei $65^{\circ} \mathrm{C}$ gewaschen. Nach Hybridisierung der DIG-markierten RNA- bzw. DNA-Sonden an die Ziel-Nukleinsäuren wurden die Hybride durch EIA (Enzym-Immuno-Assay) unter Verwendung eines anti-DIG-AP-Konjugats nachgewiesen. Die folgenden Inkubationen wurden ausschließlich der CSPD ${ }^{\circledR}$-Lösung bei Raumtemperatur unter kontinuierlicher Durchmischung durchgeführt. Die Volumenangaben der Inkubationsmedien beziehen sich auf eine Filterfläche von $100 \mathrm{~cm}^{2}$. Nach kurzem 
Waschen der Filter in Puffer 1 und Inkubation (30 min) mit $100 \mathrm{ml}$ Puffer 2 wurden die Filter für 30 min mit $20 \mathrm{ml}$ Puffer 2 inkubiert, der $75 \mathrm{mU} / \mathrm{ml}$ 1:10000 verdünntes anti-DIG-AP-Konjugats enthielt. Ungebundene Antikörper-Konjugate wurden durch zweimaliges Waschen (je $15 \mathrm{~min}$ ) in $100 \mathrm{ml}$ Puffer 1 entfernt. Anschließend wurden die Membranen für $5 \mathrm{~min}$ mit $20 \mathrm{ml}$ Puffer 3 äquilibriert und mit 1,5 ml CSPD ${ }^{\circledR}$ Lösung (15 $\mu \mathrm{l} \mathrm{CSPD}{ }^{\circledR} / 1,5 \mathrm{ml}$ Puffer 3 ) in einem verschweißten Hybridisierungsbeutel inkubiert. Nach der Inkubation wurde die CSPD ${ }^{\circledR}$-Lösung aus dem Beutel gepresst, der Beutel verschweißt und die Membranen zur Darstellung der ChemilumineszenzReaktion auf einem Röntgenfilm exponiert. Um eine erneute Hybridisierung der Membranen zu ermöglichen, wurden gebundene DIG-markierte Sonden durch zweimaliges Waschen mit kochendem 0,1\% SDS-Puffer (je $10 \mathrm{~min}$ ) unter Schwenken entfernt.

\subsubsection{In-situ-Hybridisierung der Gewebeschnitte}

Die Technik der In-situ-Hybridisierung (ISH) wurde Ende der sechziger Jahre von zwei Arbeitsgruppen unabhängig voneinander entwickelt (Pardue und Gall 1969, John et al. 1969). ISH ermöglicht spezifische Nukleinsäuresequenzen in Metaphasenchromosomen, Interphasekernen und Zellen von Gewebeschnitten zu detektieren.

Für die Lokalisation zellulärer RNA wurden Gewebeschnitte verwendet. Aus Parafinblöcken wurden Frontalschnitte mit einer Schnittdicke von $5 \mu \mathrm{m}$ hergestellt. Diese wurden auf Poly-L-Lysin-beschichtete Objektträger aufgezogen und bei $40^{\circ} \mathrm{C}$ für 1 min erwärmt, damit sich die Schnitte ausbreiten konnten. Die Schnitte wurden in Xylol entparafinisiert $(2 \times 10 \mathrm{~min})$ und in einer abnehmenden Ethanolreihe rehydriert. Die Fixation der zellulären Proteinmatrix mit $4 \%$ Paraformaldehyd bewahrt den RNAGehalt im Gewebe, jedoch vermindert dies die Zugänglichkeit zur komplementären Sonde. Um diese zu verbessern wurde das Gewebe vor der Hybridisierung mit Proteinase $\mathrm{K}$ verdaut.

Die Acetylierung neutralisiert positiv geladene Moleküle, z.B. basische Proteine, und verhindert eine unspezifische Bindung der Sonde an Poly-L-Lysin beschichtete Objektträger. Daher wurden die Schnitte in 0,1 M Triethanolamin/HCL-Lösung (pH 8) unter leichtem Rühren inkubiert (10 min) und mit 1x PBS gewaschen. Für die Detektion mit anti-DIG-PO-Konjugat wurden die Schnitte mit 0,6 \% $\mathrm{H}_{2} \mathrm{O}_{2}$ inkubiert, um die endogene Peroxidase zu blockieren. Im Anschluss wurden die Präparate in 
einer Ethanolreihe dehydriert und an der Luft getrocknet, damit die Sonde nicht mit Resten der Prähybridisierungslösung verdünnt wird. Um alle unspezifischen Bindungsstellen zu Blockieren, wurden die Objektträger mit je $250 \mu \mathrm{l}$ Prähybridisierungslösung bedeckt und in einer feuchten Hybridisierungskammer inkubiert ( 1 Stunde, $65^{\circ} \mathrm{C}$ ). Die Hybridisierungslösung enthielt $50 \%$ entionisiertes Formamid, um eine spezifische Hybridisierung der Probe zu ermöglichen und die Zellmorphologie zu erhalten. Zur Herstellung der Hybridisierungslösung wurden 25 ng DIG-markierte cRNA ("antisens") mit $30 \mu \mathrm{l}$ Prähybridisierungslösung je Objektträger verdünnt. Die Hybridisierung erfolgte in einer feuchten Hybridisierungskammer (ü.N, $65^{\circ} \mathrm{C}$ ). Die Objektträger wurden in einer absteigenden SSC-Konzentration $(6 x ; 2 x ; 0,2 x)$, die $50 \%$ entionisierte Formamid enthielt, je zweimal für $30 \mathrm{~min}$ bei $65^{\circ} \mathrm{C}$ gewaschen, um überschüssige und unspezifisch gebundene Sonde zu entfernen.

\subsubsection{Nachweis der digoxygeninmarkierten Sonde mit alkalischer Phosphatase}

Bei AP-Nachweisreaktionen lässt sich die höchste Sensitivität mit dem Substrat BCIP/NBT erreichen. Die Objektträger wurden für $10 \mathrm{~min}$ in 1x MAB-Puffer gewaschen und für 1 Stunde mit Blockierungs-Lösung (2\% Blockierungsreagenz; 20 $\%$ FCS in 1x MAB-Puffer) inkubiert. Der anti-DIG-AP-Ak wurde 1:500 mit Blockierungspuffer verdünnt und je $100 \mu \mathrm{l}$ pro Objektträger hinzugegeben. Nach 1 Stunde wurden die Schnitte in 1x MAB-Puffer je 3x 5 min gewaschen, für $5 \mathrm{~min}$ in NTMT-Puffer mit $5 \mathrm{mM}$ Levamisol inkubiert und schließlich in der Hybridisierungskammer mit je $100 \mu \mathrm{l}$ des chromogenen Substrates (NBT/BCIP) bei Raumtemperatur ü.N. im Dunkeln inkubiert. Die Farbreaktion wurden mit $1 \mathrm{x}$ Tris/EDTA-Puffer gestoppt, mit bidestilliertem Wasser gespült, gegengefärbt und mit einem Deckglas versehen. Die Auswertung der Ergebnisse erfolgte lichtmikroskopisch. Als Kontrollen wurden Schnitte ohne DIG-markierte Probe und ohne anti-DIG-AP-Ak behandelt. 


\subsubsection{Meerrettichperoxidase-Nachweis digoxygeninmarkierter Sonde}

Meerrettichperoxidase (HRP) ist gewöhnlich an einen sekundären Antikörper gebunden. Als Substrat diente AEC (3-Amino-9-Ethylcarbazol). Die Objektträger wurden für 10 min in 1x MAB-Puffer gewaschen und für 1 Stunde mit BlockierungsLösung inkubiert. Der Kaninchen anti-DIG-HRP-Ak (DAKO, Carpinteria) wurde 1 zu 100 in Blockierungs-Puffer verdünnt und je $50 \mu \mathrm{l}$ davon pro Objektträger hinzugegeben. Nach 1 Stunde wurden die Schnitte in 1x MAB-Puffer für je 2x 5 min gewaschen und mit einem zweiten Ziege anti-Kaninchen-HRP-Ak (Envision; DAKO, Carpinteria) für 30 min bei Raumtemepratur inkubiert. Nach dreimaligem Waschen mit 1x MAB-Puffer wurden die Schnitte für 10 bis 30 min mit Entwicklungsreagenz (AEC-Substrat, 0,3\% $\mathrm{H}_{2} \mathrm{O}_{2}$ ) unter leichtem Schütteln inkubiert. Die Farbreaktion wurde unter $\mathrm{H}_{2} \mathrm{O}_{\text {bidest }}$ gestoppt, mit Hämalaun gegengefärbt, erneut mit $\mathrm{H}_{2} \mathrm{O}_{\mathrm{dd}}$ gewaschen und mit Aqua Maunt eingedeckelt. Die Auswertung der Ergebnisse erfolgte lichtmikroskopisch. Die gefärbten Schnitte wurde mit einer automatischen Kamera (Zeiss, Jena) auf Kodak Elite chrome 100-Film dokumentiert.

\subsubsection{3. mRNA-Differential Display}

Die Technik des mRNA-Differential Displays (DD-RT-PCR) basiert auf der Überlegung, dass jedes mRNA Molekül durch RT-PCR Amplifikation mit unterschiedlichen Primern dargestellt werden kann (Liang u. Pardee, 1992).

Mittels mRNA-Differential Display kann die Genexpression zu unterschiedlichen Zeitpunkten partiell verglichen werden. Hierzu wählten wir „nicht geschädigtes“ Dünndarmgewebe (d. h. vor HTK-Perfusion gewonnenes Gewebe) und „geschädigtes“(d. h. 3 Stunden nach Reperfusion gewonnenes Material) aus. Die Präparation der RNA wurde unter 3.2.1.1 beschrieben. Die präparierte RNA wurde einer reversen Transkription unterworfen. Von der Gesamt-mRNA wurde durch das Einsetzen eines $\mathrm{H}-\mathrm{T}_{11} \mathrm{M}$-Primers (Wobei $\mathrm{M}=\mathrm{A}, \mathrm{C}$ oder $\mathrm{G}$ sein konnte) nur ein Teil der mRNA in cDNA umgeschrieben. Die PCR mit einem 1/10 Vol des RT-Ansatzes wurde bei einer nicht stringenten Hybridisierungstemperatur $\left(42^{\circ} \mathrm{C}\right)$ durchgeführt. In dem PCR-Ansatz wurden die $\mathrm{H}-\mathrm{T}_{11} \mathrm{M}$-Primer in doppelter Konzentration gegenüber den 13mer-Primern eingesetzt um sicherzustellen, dass der größte Teil der amplifizierten Produkte an deren 3'-Ende eine $\mathrm{H}-\mathrm{T}_{11} \mathrm{M}-\mathrm{Sequenz}$ besaß. Die verschiedenen PCR-Ansätze wurden in einem denaturierenden 6 \% PAA-Gel ihrer Größe nach aufgetrennt. Das PAA-Gel wurde am Ende des Laufes mittels 
Silberfärbung gefärbt und an der Luft getrocknet. Über einen Vergleich der Bandenmuster in den verschiedenen Bahnen ließen sich Unterschiede erkennen, die bei der cDNA-Amplifikation im Verlaufe der PCR entstanden sind (Abb. 4).

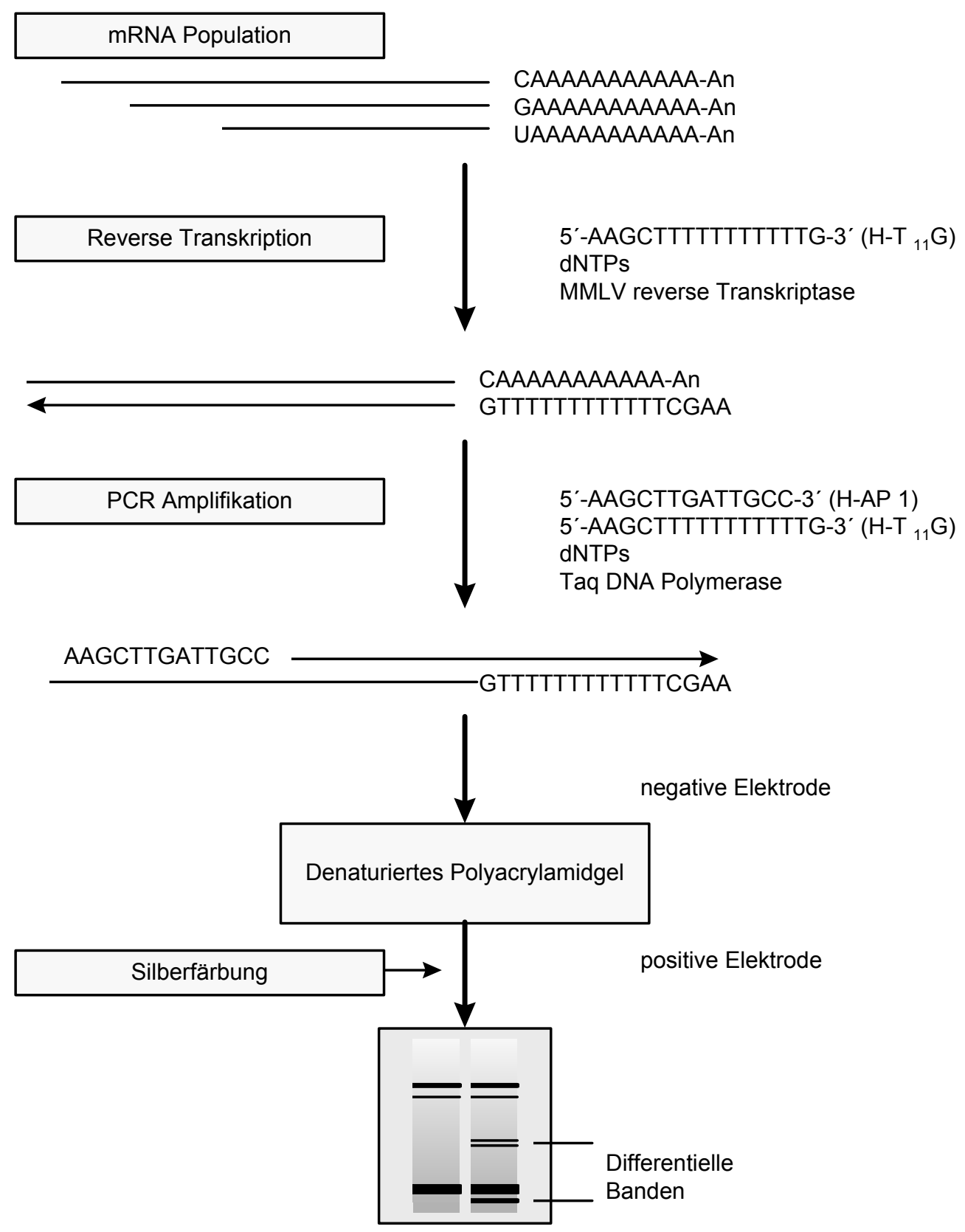

Abbildung 4:

Schematische Darstellung der Durchführung des mRNA-Differential Displays. 


\subsubsection{Downstream Primer und upstream Primer}

Die in dieser Arbeit verwendeten downstream Primer (anchored oligo dT Primer, H$\mathrm{T}_{11} \mathrm{M}$ ) mit HindlII Seite und upstream Primer (arbitrary 13mer-Primern, H-AP $1-8$ ) ebenso mit HindIII Seite wurden von der Firma WAK-Chemie GmbH (RNAimage ${ }^{\mathrm{TM}}$ Kit 1, Bad Soden) bezogen. Folgende Primer wurden verwendet (Tab 2):

\begin{tabular}{|c|c|c|c|}
\hline H-T11M & downstream Primer $(2 \mu \mathrm{M})$ & $\mathrm{H}-\mathrm{AP}_{1-8}$ & Upstream Primer $(\mu \mathrm{M})$ \\
\hline $\mathrm{H}-\mathrm{T}_{11} \mathrm{~A}$ & 5'- AAGCTTTTTTTTTTTTA- 3' & H-AP1 & 5' -AAGCTTGATTGCC- 3' \\
\hline $\mathrm{H} .-\mathrm{T}_{11} \mathrm{C}$ & 5'- AAGCTTTTTTTTTTTTC- 3' & H-AP2 & $5^{\prime}$-AAGCTTCGACTGT- 3' \\
\hline \multirow[t]{6}{*}{$\mathrm{H}-\mathrm{T}_{11} \mathrm{G}$} & 5'- AAGCTTTTTTTTTTTTG- 3' & H-AP3 & $5^{\prime}$-AAGCTTTGGTCAG- 3' \\
\hline & & H-AP4 & $5^{\prime}$-AAGCTTCTCAACG- 3' \\
\hline & & H-AP5 & $5^{\prime}$-AAGCTTAGTAGGC- 3' \\
\hline & & H-AP6 & $5^{\prime}$-AAGCTTGCACCAT- 3' \\
\hline & & H-AP7 & $5^{\prime}$-AAGCTTAACGAGG- $3^{\prime}$ \\
\hline & & H-AP8 & $5^{\prime}$-AAGCTTTTACCGC- 3' \\
\hline
\end{tabular}

Tabelle 2:

Oligo-dT-Primer und Random-13mer-Primer für die DD-PCR.

\subsubsection{Reverse Transkription von mRNA für differentielles RNA-Display}

Zur RT von mRNA wurden im mRNA-Differential Display $\mathrm{H}-\mathrm{T}_{11} \mathrm{M}$-Primer $(\mathrm{M}=\mathrm{A}, \mathrm{C}$ oder $G$ ) eingesetzt. Aus der gesamten RNA-Population wurde nur ein Teil der mRNA revers transkribiert. Der Reaktionsansatz bestand aus $2 \mu \mathrm{l}(0,1 \mu \mathrm{g} / \mu \mathrm{l})$ frisch verdünnter gesamt RNA, $2 \mu \mathrm{l} \mathrm{H}-\mathrm{T}_{11} \mathrm{M}[2 \mu \mathrm{M}](\mathrm{M}=\mathrm{A}, \mathrm{C}$ oder $\mathrm{G})$ und 9,4 $\mu \mathrm{l}$ DEPC- $\mathrm{H}_{2} \mathrm{O}$. Dieser Ansatz wurde zur Denaturierung von RNA-Sekundärstrukturen inkubiert (5 $\min , 65^{\circ} \mathrm{C}$ ) und anschließend auf Eis gegeben. Auf Eis erfolgte die Zugabe von $4 \mu \mathrm{l}$ 5x RT-Puffer, 1,6 $\mu \mathrm{l}$ dNTP $(250 \mu \mathrm{M})$ und $1 \mu \mathrm{l}$ MMLV-RTase, RNase H Minus. Die RTReaktion wurde im Thermocycler $\left(1\right.$ Stunde $37^{\circ} \mathrm{C} ; 5$ min $75^{\circ} \mathrm{C}$ ) durchgeführt. Die fertigen RT-Produkte wurden sofort zur PCR eingesetzt oder bei $-20^{\circ} \mathrm{C}$ gelagert.

\subsubsection{PCR im differentiellen RNA-Display}

Von der oben aufgeführten RT wurden 1/10 Vol in den PCR-Ansatz eingesetzt, die Reaktion fand in Reaktionsgefäßen $(500 \mu \mathrm{l})$ mit Volumenbegrenzung statt. Der Reaktionsansatz bestand aus $2 \mu \mathrm{l}$ der jeweiligen cDNA, $4 \mu \mathrm{l}$ 10x PCR-Puffer, 3,2 $\mu \mathrm{l}$ dNTPs $(25 \mu \mathrm{M}), 6 \mu \mathrm{l} \mathrm{H}-\mathrm{T}_{11} \mathrm{M}$ Primer $(2 \mu \mathrm{M}), 3 \mu \mathrm{H}$-AP 13mer-Primer $(2 \mu \mathrm{M}), 0,5 \mu \mathrm{l}$ 
Taq-Polymerase (5 U/ $\mu$; Perkin-Elmer) und $21,3 \mu \mathrm{LEPC}-\mathrm{H}_{2} \mathrm{O}$. Der Ansatz wurde abzentrifugiert und einer PCR unter folgenden Bedingungen unterworfen (Tab. 3):

\begin{tabular}{|c|c|c|c|l|}
\hline Schritt & Temperatur & Dauer & Zyklus-Zahl & Reaktionsart \\
\hline & $\left.\left({ }^{\circ} \mathrm{C}\right)\right]$ & $(\min . \mathrm{s})$. & $(\mathrm{n})$ & \\
\hline 1 & 95 & 2.00 & 1 & Denaturierung der DNA \\
\hline 2 & 94 & 0.30 & $1-45$ & Denaturierung der DNA \\
\hline 3 & 42 & 1.00 & $1-45$ & $\begin{array}{l}\text { Hybridisierung der } \\
\text { Amplifizierungsprimer }\end{array}$ \\
\hline 4 & 72 & 0,30 & $1-45$ & Elongation der DNA \\
\hline
\end{tabular}

Tabelle 3:

Zyklusprofil für die DD-RT-PCR.

Die PCR wurde mit einem Elongationsschritt $\left(8 \mathrm{~min}, 72^{\circ} \mathrm{C}\right)$ zur Fertigstellung nicht vollständig synthetisierter DNA-Fragmente abgeschlossen. Die PCR-Produkte wurden direkt auf ein denaturierendes PAA-Gel aufgetragen oder bei $-20^{\circ} \mathrm{C}$ gelagert.

\subsubsection{Polyacrylamidgel-Elektrophorese (PAGE) von Nukleinsäuren}

In Polyacrylamidgelen werden DNA Fragmente mit Unterschieden von einem Basenpaar bei einer Gesamtlänge von mehreren hundert Basenpaaren noch aufgelöst. Die Nachweisempfindlichkeit der verwendeten Polyacryamidgele ist höher als bei Agarosegelen (bis $<50$ pg Nukleinsäure pro Bande). Die Konzentration der eingesetzten Polyacrylamidgele betrug $6 \%$. Polyacrylamidgele mit Kunststoffrücken wurden gemäß der Anleitung des "Clean Gel DNA Analysis Kit" rehydriert und auf einen Film von Petroleumbenzin in die Elektrophoresekammer gelegt. Elektrodenstreifen aus Filterpapier wurden mit Elektrodenpuffer befeuchtet und auf die Gelränder gelegt. Die Geltaschen wurden sorgfältig von Pufferresten befreit.

Die Proben wurden im Verhältnis 4:1 mit Probenauftragspuffer gemischt. Zur Größenbestimmung der PCR-Produkte wurde eine 100 bp-Leiter mitgeführt. Auf ein Gel mit 48 Taschen konnten $8 \mu$ Probenvolumen in die Elektrophorese eingesetzt werden. Die elektrophoretische Auftrennung erfolgte bei $200 \mathrm{~V}$ für $10 \mathrm{~min}$ und $600 \mathrm{~V}$ für weitere $50 \mathrm{~min}$ bei $4^{\circ} \mathrm{C}$. 


\subsubsection{Darstellung von Nukleinsäuren in Polyacrylamidgelen mittels Silberfärbung}

Die Silberfärbung der PCR-Produkte nach Durchführung des mRNA-Differential Displays wurde gewählt, da diese Methode eine sensitive Darstellung der DNA ohne den Einsatz von Radionukleiden ermöglicht. Die entwickelten, fixierten und getrockneten Gele konnten daher leicht archiviert werden und waren so weiteren Untersuchungen zugänglich. Zur Silberfärbung des PAA-Gels wurde der "DNA Silver Staining Kit" (Pharmacia Biotech) benutzt. Das Polyacrylamidgel wurde 30 min in $1 \mathrm{x}$ Fixier-Lösung fixiert, $3 \mathrm{x} 2 \mathrm{~min}$ in $\mathrm{H}_{2} \mathrm{O}_{\mathrm{dd}}$ gewaschen und 30 min mit $1 \mathrm{x}$ Silbernitratlösung behandelt. Nach kurzem Waschen wurde $1 \mathrm{x}$ gekühlte Entwicklerlösung hinzugegeben. Nach Entwicklung der Banden (ca. 5 min) wurde die Reaktion durch Zugabe von 1x Stopp-Lösung (30 min) gestoppt. Schließlich wurde das Gel mit 8,7 \% Glycerin-Lösung konserviert und luftgetrocknet. Die cellophangeschützten Gele konnten bei Raumtemperatur gelagert werden.

\subsubsection{Reamplifikation von PCR-Produkten}

Jede einzelne im Polyacrylamidgel sichtbare cDNA-Bande entspricht statistisch einer mRNA nach reverser Transkription in cDNA und Amplifikation. In der PolyacrylamidGelelektrophorese wurden jeweils PCR-Produkte aus Dünndarmgewebe vor HTKPerfusion und 3 Stunden nach Reperfusion direkt nebeneinander aufgetragen. Durch visuellen Vergleich konnten Unterschiede in der Genexpression erfasst werden. Die differentiellen Banden wurden mit einem sterilen Skalpell aus dem getrockneten PAA-Gel herausgeschnitten und in ein Reagenzgefäß gegeben. Es wurden $100 \mu \mathrm{l}$ $\mathrm{H}_{2} \mathrm{O}$ hinzugefügt und die DNA durch Erhitzen $\left(10 \mathrm{~min}, 100^{\circ} \mathrm{C}\right)$ und kurzes Abzentrifugieren eluiert. Das Eluat wurde mit $450 \mu \mathrm{l} \mathrm{EtOH}(100 \%), 1 / 10 \mathrm{Vol}$ Natriumacetat $(3 \mathrm{M})$ und $5 \mu$ l Glykogen $(10 \mathrm{mg} / \mathrm{ml})$ bei $-20^{\circ} \mathrm{C}$ ü.N. gefällt. Das PCRProdukt wurde bei $13000 \mathrm{rpm}$ abzentrifugiert (10 min, $\left.4^{\circ} \mathrm{C}\right)$. Das Pellet wurde in $85 \%$ EtOH gewaschen und anschließend in $10 \mu \mathrm{H}_{2} \mathrm{O}$ resuspendiert. Die Reamplifikation des eluierten PCR-Produkts erfolgte unter den gleichen Bedingungen wie unter 3.2.13.3 beschrieben, jedoch lag die Endkonzentration der dNTPs zehnfach höher. Die Kontrolle der Reamplifikation fand in einem 1-2 \% Agarosegel statt. 


\subsubsection{Native-Agarose-Gelelektrophorese}

Die Gelelektrophorese dient der Auftrennung von DNA-Fragmentgemischen entsprechend ihrer Größe. Die von Meyers et al. beschriebene Methodik wurde zur Native-Agarose-Gelelektrophorese eingesetzt (Meyers et al. 1976).

Je nach Größe der zu trennenden DNA-Fragmente wurde die Agarose-Konzentration zwischen 1 und $2 \%$ variiert. Zur Auftrennung von DNA-Fragmenten wurden Horizontal-Gele verwendet. Dazu wurde eine 1-2 \% Agarose-Lösung mit TBE-Puffer gekocht und nach Abkühlen auf ca. $50{ }^{\circ} \mathrm{C}$ in die vorbereiteten Kammern gegossen. Neben den mit Orange G-Lösung versehenen Proben wurden zusätzlich käufliche Längenstandards (100bp DNA Ladder Plus und DNA Ladder Mix, MBI Fermentas) aufgetragen. Die Elektrophorese in der Flachbett-Gelkammer erfolgte bei einer Stromstärke von 120 mA. Nach Beendigung der Elektrophorese wurden die Gele für $10 \mathrm{~min}$ in einem Ethidiumbromid-Bad $\left(2 \mathrm{mg} / \mathrm{l} \mathrm{H}_{2} \mathrm{O}\right)$ angefärbt. Die DNA-Banden waren unter einer UV-Lampe (Wellenlänge $254 \mathrm{~nm}$ ) sichtbar. Um die DNA in präparativen Gelen nicht zu schädigen, wurde hierbei UV-Licht der Wellenlänge 366 $\mathrm{nm}$ verwendet. Die Gele wurden zur Dokumentation photographiert.

\subsubsection{Isolierung von DNA-Fragmenten aus präparativen Gelen}

Anmerkung: Protokoll nach Herstellerangaben (Qiagen, Hilden).

Zur Isolierung von DNA-Fragmenten aus Agarosegelen wurde die gewünschte Bande aus dem Gel herausgeschnitten, gewogen, mit dreifachen QG-PufferVolumen versetzt, inkubiert $\left(10 \mathrm{~min}, 55^{\circ} \mathrm{C}\right)$ und zwischendurch alle 2-3 min geschüttelt. Nach der Inkubation wurde 1x Gel-Volumen Isopropanol zugegeben und gemischt. Anschließend wurde die QIAquick Säule geladen, in ein Mikrozentrifugiertube eingeführt und für 1 min bei 13000 rpm zentrifugiert. Die erste Fraktion wurde verworfen. Zum Waschen wurden $750 \mu$ PE-Puffer hinzugegeben, 1 min zentrifugiert und die Fraktion erneut verworfen. Um alle Rückstände zu entfernen, wurde ein weiterer Zentrifugationsschritt durchgeführt. Nun wurde ein neues Mikrozentrifugiertube genommen und die DNA mit $20 \mu \mathrm{l}$ Tris/ $\mathrm{HCl}$ eluiert. 


\subsubsection{Molekulare Klonierungstechniken}

Die Methoden molekularer Klonierung befassen sich mit der Konstruktion und Vervielfältigung neuer Plasmide. Bei ihrer Konstruktion geht man von 2 DNAFragmenten aus, die ligiert werden: Vektor und Insert. Während das Insert ein DNAStück ist, das man genauer untersuchen will oder von dem ausgehend man weitere Konstruktionen plant, handelt es sich bei dem Vektor um ein vollständiges Plasmid, das als Vehikel benutzt wird. Nach der Konstruktion eines neuen Plasmids werden mit inm Zellen "transformiert", in denen es dann repliziert wird.

\subsubsection{Klonierung der PCR-Produkte mit dem TA-Verfahren}

PCR-Produkte wurden unter Verwendung des original TA Cloning ${ }^{\circledR}$-Kit (invitrogen) nach Angaben des Herstellers kloniert. Die TA-Klonierung beruht auf der Eigenschaft, der für die PCR verwendeten Taq-Polymerase, jeweils an den 3'-Ende des PCR-Produkts ein überzähliges Adenosin anzuhängen. In Kombination mit einem entsprechend linearisierten Vektor ( $p \mathrm{CR}^{\circledR} \mathrm{II}$-TOPO-Vektor; Invitrogen) mit "überstehenden" Thymidin-Enden ist dadurch eine effektive Ligation möglich.

Die experimentell erhöhte Bereitschaft von E.coli, ringförmig geschlossene PlasmidDNA in die Zelle aufzunehmen, ist die Voraussetzung für eine Transformation dieser Mikroorganismen in hoher Ausbeute. Dieser Zustand der erhöhten Kompetenz wurde für diese Arbeit durch die Rubidiumchlorid-Methode von HANAHAN erreicht (Hanahan 1985).

Die TOP10F'-Bakterien (One Shot ${ }^{\mathrm{TM}}$; Invitrogen) wurden auf 0,1-0,5 $\mu \mathrm{g}$ der zu transformierenden DNA gegeben und auf Eis inkubiert (30 min). Nach einem HitzeSchock $\left(2 \mathrm{~min}, 42^{\circ} \mathrm{C}\right)$ wurde der Ansatz für $1 \mathrm{~min}$ auf Eis gestellt. Die Zellen wurden pelletiert und in $250 \mu$ SOS-Medium resuspendiert. Die Zellen wurden für 1 Stunde bei $37^{\circ} \mathrm{C}$ inkubiert und auf LB-Platten $(5 \mathrm{~g} / \mathrm{l}$ Bacto-Hefeextrakt, $10 \mathrm{~g} / \mathrm{l} \mathrm{NaCl}, 10 \mathrm{~g} / \mathrm{l}$ Bactotrypton, $15 \mathrm{~g} / \mathrm{l}$ Bacto-Agar, $\mathrm{pH}$ 7,0) mit $50 \mathrm{mg} / \mathrm{l}$ Ampicilin ü.N. kultiviert und einzelne Klone mit negativer X-Gal-Farbreaktion zur weiteren Analyse ausgewählt. Die selektierten Klone wurden in LB-Amp.-Medium (5 g/l Bacto-Hefeextrakt, 0,5 g/l $\mathrm{NaCl}, 20 \mathrm{~g} / \mathrm{l}$ Bactotrypton, 2,5 mM KCl, $10 \mathrm{mM} \mathrm{MgCl}_{2}, 20 \mathrm{mM}$ Glucose und $50 \mathrm{mg} / \mathrm{l}$ Ampicilin, $\mathrm{pH} 7,0$ ) kultiviert. 


\subsubsection{Verdauung von DNA mit Restriktionsendonukleasen}

Die Aktivität von Restriktionsendonukleasen ist von der lonenstärke des ReaktionsPuffers abhängig. Da alle für diese Arbeit benötigten Enzyme von der Firma MBI Fermentas (St. Leon-Rot, Deutschland) stammten und prinzipiell mit den optimalen Puffern geliefert wurden, stellten sich in dieser Hinsicht keine Probleme. Für die meisten Enzyme wurden die Restriktions-Puffer 1-4 (Orange, Rot, Blau und Grün) verwendet, während für Sall, BamHI und EcoRI Spezial-Puffer eingesetzt wurden. In der Regel betrug die Inkubationstemperatur $37^{\circ} \mathrm{C}$, lediglich Agel wurde bei $25{ }^{\circ} \mathrm{C}$ inkubiert. Zur analytischen Verdauung wurden 0,2-1,0 $\mu \mathrm{g}$ DNA mit $1 \mu \mathrm{l}$ des jeweils 10-fach konzentrierten Reaktions-Puffers versetzt, mit $\mathrm{H}_{2} \mathrm{O}$ auf $10 \mu \mathrm{l}$ aufgefüllt und nach Zugabe von 2-20 U des Enzyms 1 bis 2 Stunden inkubiert, bevor die Reaktion durch Zugabe von 3 ml Orange G- bzw. $2 \mu \mathrm{l}$ BX-Farbmarker-Lösung gestoppt wurde. Zur elektrophoretischen Auftrennung wurden die Ansätze auf ein analytisches Agarose-Gel aufgetragen und elektrophoretisch aufgetrennt. Bei präparativen Verdauungen wurde die 2- bis 5-fache DNA-Menge der analytischen Ansätze verwendet und entsprechend mehr Reaktions-Puffer und Restriktionsenzym zugegeben. Grundsätzlich sollte sowohl das Volumen des 10-fach konzentrierten Puffers als auch der Enzyme nicht mehr als $10 \%$ des Gesamtvolumens ausmachen, da sonst die lonenstärke bzw. das Glycerin aus käuflichen Enzympräparaten die Enzymaktivität hemmt. Vor dem Abstoppen einer präparativen Verdauung wurde die Vollständigkeit der Verdauung durch Auftrennung eines Aliquots auf einem analytischen Gel kontrolliert. Bei Verwendung von selbst isolierten Restriktionsendonukleasen wurden nach Maniatis et al. hergestellte Puffer verwendet (Maniatis et al. 1989).

\subsubsection{Auffüllen von $3^{\prime}$-zurückliegenden Enden}

Einige Plasmid-Konstruktionen in dieser Arbeit wurden mit DNA-Molekülen vorgenommen, die mit Restriktionsendonukleasen unterschiedlicher Erkennungssequenz gespalten wurden und daher unter normalen Bedingungen aufgrund fehlender Homologie in der Basensequenz der Einzelstrangenden keine Paarung und Verknüpfung durch die T4-DNA-Ligase zuließen. Bei der Ligation von DNA-Fragmenten mit verschiedenen 5'-versetzten Enden wurde der 3'zurückliegende Strang mit Hilfe von DNA-Polymerase I und den vier 2'Desoxynukleosid-5'-Triphosphaten aufgefüllt, so dass ein doppelsträngiges, glattes 
Ende gebildet wurde. Das Klenow-Fragment der DNA-Polymerase I aus E.coli weist im Gegensatz zum gesamten Enzym nur die 5',3'-Polymerase- und die 3',5'Exonuklease-Aktivität auf (Maniatis et al. 1989). Hierzu wurde die vollständig verdaute DNA mit $1 \mu$ l einer Lösung der 4 dNTP's (je $250 \mu \mathrm{M}$ ) versetzt. Die Reaktion wurde durch Zugabe von $9 \cup$ Klenow-Fragment gestartet. Nach Inkubation (30 min, $37^{\circ} \mathrm{C}$ ) erfolgte die Inaktivierung des Enzyms durch Erhitzen (5 min, $70{ }^{\circ} \mathrm{C}$ ).

\subsubsection{Dephosphorylierung linearisierter DNA mit alkalischer Phosphatase}

Bei Klonierungen, die das Verknüpfen von Restriktionsendonukleasen gleicher Spaltungssequenz geschnittener Vektor-DNA mit Passagier-DNA verlangen, wird in 70-90 \% der Fälle die Rezirkularisierung reiner Vektor-DNA bevorzugt (Netzker 1985), was beim Auffinden rekombinanter Plasmide einer erheblichen Arbeitserschwerung gleichkommt. Die Dephosphorylierung des linearen VektorMoleküls am 5'-Ende nach Ullrich et al. vermeidet dieses Problem weitestgehend und erhöht dadurch die Ausbeute der Ligation des Vektors mit der Passagier-DNA (Ullrich et al, 1977). Nach Ligation des behandelten Vektors mit der Passagier-DNA und erfolgter Transformation in E.coli werden die beiden noch verbleibenden Einzelstrangbrüche durch zelleigene Kinasen und Ligasen repariert. Die Dephosphorylierung erfolgte nach Maniatis et al. mit alkalischer Phosphatase aus Kälberdarm (CIP) (Maniatis et al. 1989). Hierzu wurde die vollständig verdaute Vektor-DNA mit 0,5-1 U CIP versetzt und inkubiert (30 min, $37^{\circ} \mathrm{C}$ ). Nach erneuter Zugabe von 0,5-1 U CIP erfolgte ein weiterer Inkubationsschritt (15 min, $56{ }^{\circ} \mathrm{C}$ ). Die Reaktion wurde durch 10 min Inkubation bei $70{ }^{\circ} \mathrm{C}$ gestoppt.

\subsubsection{Ligation}

Nach der von Maniatis et al. beschriebenen Methode wurden die Vektor- und Passagier-DNA, die aus präparativen Gelen isoliert wurden, in einem Verhältnis von 1:10 zur Verknüpfung von DNA-Fragmenten zusammenpipettiert (Maniatis et al, 1989). Ein Verhältnis von 3:1 wurde gewählt, wenn zuerst die Vektor-DNA dephosphoryliert wurde. Bei der Sticky-Ligation betrug das Gesamtvolumen des Ligationsansatzes 10-20 $\mu \mathrm{l}$, wobei 1/10 des Volumens an 10-fach konzentriertem Ligations-Puffer plus ATP hinzugegeben wurde. Die Verknüpfungsreaktion wurde durch Zugabe von $5 \cup$ T4-DNA-Ligase gestartet. Die Inkubation erfolgte für 3 
Stunden bei $4^{\circ} \mathrm{C}$. Bei der Blunt-Ligation wurde dem Ligationsansatzes $1 / 5$ des Volumens an 5-fach konzentriertem Ligations-Puffer ohne ATP und $1 \mu$ ITP $(0,1$ $\mathrm{mM}$ ) hinzugegeben und inkubiert (ü.N, $4^{\circ} \mathrm{C}$ ).

\subsubsection{DNA-Isolierungstechniken}

\subsubsection{Analyse von Plasmidklonen}

Die Analyse von Klonen erfolgte nach der von Ruther beschriebenen Plasmidpräparation (Ruther 1982) und anschließender Restriktionsanalyse. Die Plasmidklone wurden mit Restriktionsenzymen gespalten und die DNA-Fragmente gelelektrophoretisch aufgetrennt. Hierdurch konnte ermittelt werden, ob die analysierten Plasmidklone das gewünschte DNA-Fragment besitzen.

\subsubsection{Präparation von Plasmid-DNA aus E. coli}

\subsection{Mini-Präparation}

Die Isolierung von $E$. coli Transformanden rekombinanter Plasmid-DNA erfolgte nach der Methode von Current Protocols in Molecular Biology (CPMB 1994). Die Anzucht erfolgte in mit $3 \mathrm{ml}$ LBA-Medium gefüllten Greiner-Röhrchen im Rundschüttler bei 180 UpM (ü.N, $37^{\circ} \mathrm{C}$ ). Die Zellen (1,5 ml) wurden zentrifugiert (10 min, $4000 \mathrm{rpm}$ ) und der Überstand vorsichtig mit einer Pipette abgenommen. Das Pellet wurde in 300 $\mu \mathrm{l} \mathrm{STET-Lösung} \mathrm{resuspendiert,} \mathrm{bevor} 20 \mu \mathrm{l}$ Lysozym $(20 \mathrm{mg} / \mathrm{ml})$ hinzugefügt wurden. Die Ansätze wurden invertiert, inkubiert ( 5 min, Raumtemperatur und $2 \mathrm{~min}, 100{ }^{\circ} \mathrm{C}$ ) und zentrifugiert (15 min, $13000 \mathrm{rpm}$, Raumtemperatur). Der Überstand (200 $\mu \mathrm{l})$ wurde in ein Eppendorf-Reaktionsgefäß überführt und mit $500 \mu \mathrm{L} 2,5 \mathrm{M} \mathrm{NH}_{4} \mathrm{Ac}$ und $75 \%$ Isopropanol versetzt. Die Ansätze wurden invertiert, inkubiert $(20 \mathrm{~min}$, Raumtemperatur), zentrifugiert (15 min, $13000 \mathrm{rpm}$, Raumtemperatur), der Überstand abgeschüttet und das Pellet in $500 \mu \mathrm{l} 80 \%$ Ethanol $\left(-20^{\circ} \mathrm{C}\right)$ gewaschen. Nach erneuter Zentrifugation (5 min, 13000 rpm, Raumtemperatur) wurde der Überstand vorsichtig abgenommen, das Pellet luftgetrocknet und anschließend in 20 $\mu$ I TE-Puffer gelöst. 


\subsection{Midi-Präparation}

A) Die Isolierung von DNA erfolgte mit dem "Jetstar Plasmid Kit" (Genomed). Aus einer E. coli-Kultur (über Nacht) wurden $10 \mathrm{ml}$ der Zellen für $10 \mathrm{~min}$ abzentrifugiert. Das Pellet wurde in 0,4 ml E1-Puffer aufgenommen. Die Zellen wurden durch 0,4 ml E2-Puffer aufgeschlossen. Nach $5 \mathrm{~min}$ wurden 0,4 $\mathrm{ml}$ E3-Puffer zugegeben, gemischt, 5x invertiert und zentrifugiert (10 min, 13000 rpm, Raumtemperatur). Der Überstand wurde auf eine mit E4-Puffer äquilibrierte Anionenaustauschersäule aufgetragen. Zur Entfernung von RNA und Proteinen wurde zweimal mit 2,5 ml E5Puffer gewaschen. Die Plasmid-DNA wurde mit 0,9 ml E6-Puffer isoliert. Die DNA wurde mit Isopropanol ausgefällt und zentrifugiert (30 min, $15000 \mathrm{rpm}$, bei $4{ }^{\circ} \mathrm{C}$ ). Das Pellet wurde mit 70 \% Ethanol gewaschen, rezentrifugiert und im Exsikkator (2 min) getrocknet. Die so erhaltene DNA wurde in $30 \mu \mathrm{l}$ 1x TE-Puffer aufgenommen. Das nach der Fällung mit E3 erhaltene Präzipitat besteht nach Birnboim et al. zum Großteil aus chromosomaler DNA, hochmolekularer RNA und bei den hohen Salzkonzentrationen ausfallendem Protein-SDS-Komplex (Birnboim u. Doly 1979). Das wesentliche Prinzip der Alkali-SDS-Methode besteht darin, dass die chromosomale DNA selektiv denaturiert wird und die Plasmid-DNA in Lösung bleibt. Dies geschieht in einem sehr engen $\mathrm{pH}$-Bereich, der sich beim Einhalten der Vorschrift von selbst ergibt. Anschließend wurde die Lösung durch Zugabe saurer Acetat-Lösung neutralisiert, wobei die chromosomale DNA ein unlösliches Netzwerk bildete. Damit die chromosomale DNA tatsächlich präzipierte, durfte auf keinen Fall geschüttelt werden.

B) Bei einer anderen Methode zur Midi-Präparation wurde der "Qiagen Plasmid Kit" (Qiagen) verwendet. Aus einer E. coli-Kultur (ü.N.) wurden $10 \mathrm{ml}$ der Zellen abzentrifugiert (10 min, $\left.5000 \mathrm{rpm}, 4^{\circ} \mathrm{C}\right)$. Das Pellet wurde in 0,3 $\mathrm{ml} \mathrm{P1-Puffer}$ resuspendiert, 0,3 $\mathrm{ml}$ P1-Puffer zugegeben, vorsichtig geschüttelt und inkubiert (5 min, Raumtemperatur). Die Probe wurden mit 0,3 ml P3-Puffer versetzt, vorsichtig geschwenkt, inkubiert $\left(10 \mathrm{~min}, 0^{\circ} \mathrm{C}\right)$ und zentrifugiert (15 min, $\left.10000 \mathrm{rpm}\right)$. Der Überstand wurde sofort auf eine mit $1 \mathrm{ml}$ QB1-Puffer äquilibrierte Anionenaustauschersäule gegeben. Nach Waschen mit 4x $1 \mathrm{ml}$ QC-Puffer wurde die DNA mit 0,8 ml QF-Puffer eluiert. Die Fällung der DNA erfolgte mit $0,5 \mathrm{ml}$ Isopropanol. Anschließend wurde die Probe zentrifugiert (30 min, $10000 \mathrm{rpm}, 4^{\circ} \mathrm{C}$ ). Das Pellet wurde mit 70 \% Ethanol gewaschen, im Exsikkator (2 min) getrocknet und in $20 \mu \mathrm{l}$ TE-Puffer aufgenommen. 


\subsubsection{Konzentrations- und Reinheitsbestimmung isolierter DNA}

Die Konzentration und Qualität der DNA wurde mittels eines Spektralphotometers bestimmt. Die $\mathrm{OD}_{260 \mathrm{~nm}}$ und $\mathrm{OD}_{280 \mathrm{~nm}}$ einer DNA-Suspension wurde gegen ein Lösungsmittel bestimmt, wobei $\mathrm{OD}_{260 \mathrm{~nm}}$ der DNA-Konzentration $\left(1 \mathrm{OD}_{260 \mathrm{~nm}}=50 \mu \mathrm{g}\right.$ ds-DNA/ml) und der $\mathrm{OD}_{260 \mathrm{~nm}} / \mathrm{OD}_{280 \mathrm{~nm}}$-Quotient der Reinheit entspricht. Der $\mathrm{OD}_{260 \mathrm{~nm}} / \mathrm{OD}_{280 \mathrm{~nm}}$-Quotient sollte über einem Wert von 1,8 liegen. Mit diesem Verfahren war es möglich, definierte DNA-Lösungen herzustellen.

\subsubsection{Sequenzierung von DNA}

Als DNA-Sequenzierungsmethode wurde die zyklische- oder PCR-Sequenzierung mit universellen fluoreszenzmarkierten Sequenzierprimern M13(-20) forward Primer und die Gegenstrangprimer M13 reverse Primer eingesetzt. Die Synthese der Oligonukleotide und Fluoreszenzfarbstoff-Markierung erfolgte durch MWG-Biotech (Ebersberg). Alle Reaktionen wurden mit dem "Thermo Sequenase Fluorescent Labelled Primer Cycle Sequencing Kit" (Amersham Pharmacia, Freiburg) durchgeführt. Als Templates dienten sowohl "QIAprep Miniprep Kit" (Qiagen, Hilden) aufgereinigte Plasmid-DNA als auch Silika aufgereinigte PCR-Produkte. Ein Reaktionsansatz $(8 \mu \mathrm{l})$ enthielt $2 \mu \mathrm{l} A, \mathrm{~T}, \mathrm{G}$ und $\mathrm{C}$ Reagenz, 4 pmol fluoreszenzmarkierten Primer, 0,2-1 $\mu \mathrm{g}$ Template-DNA und 1 bis 1,5\% DMSO. Nachdem die Ansätze mit einem Tropfen Mineralöl überschichtet wurden, erfolgte die Sequenzierreaktion mit dem Trioblock (Biometra) nach folgendem Reaktionsprofil (Tab. 4):

\begin{tabular}{|l|l|l|l|}
\hline 1 Zyklus & $\begin{array}{l}\text { Initiale } \\
\text { Denaturierung }\end{array}$ & $95^{\circ} \mathrm{C}$ & $5 \mathrm{~min}$ \\
\hline 30 Zyklus & Denaturierung & $95^{\circ} \mathrm{C}$ & $1 \mathrm{~min}$ \\
\hline 30 Zyklus & $\begin{array}{l}\text { Primer } \\
\text { Hybridisierung }\end{array}$ & $55^{\circ} \mathrm{C}$ & $30 \mathrm{~s}$ \\
\hline 30 Zyklus & Primer Elongation & $72^{\circ} \mathrm{C}$ & $1 \mathrm{~min}$ \\
\hline
\end{tabular}

Tabelle 4

Zyklusprofil für die Cycle-Sequencing-PCR.

Entgegen den Angaben des Herstellers wurden die Sequenzieransätze ohne weitere Aufreinigung unmittelbar nach dem Ablauf der Reaktion mit $1 \mu$ PAA-Probenpuffer 
versetzt und ein Aliquot (1 oder 1,2 $\mu$ ) auf ein $6 \%$ oder $4 \%$ Polyacrylamidgel aufgetragen. Die Analyse der Sequenzierprodukte erfolgte mit dem automatischen LI-COR 4000 DNA-Sequenzierer (MWG-Biotech, Ebersberg).

\subsubsection{Datenbank Recherche}

Die Analyse der Sequenzdaten erfolgte anhand der Datenbanken des National Center for Biotechnology Information (www.ncbi.nlm.nih.gov/). Die Programme BLASTN (Pearson u. Lipman 1988) und BLASTX wurden für Homologie Vergleiche mit Sequenzen in den Datenbanken des European Molecular Biology Laboratory (EMBL), NIH genetic sequence database (GenBank) und DNA DataBank of Japan (DDBJ) verwendet, welche alle "expressed sequence tags" (EST)- und "sequence tag side" (STS)-Sequenzen enthalten. 


\section{ERGEBNISSE}

\subsection{Hämodynamische Veränderungen und mukosale Schädigung}

Die mittlere Dauer der Reperfusion lag nach einer kalten Ischämiezeit (KIZ) von 2 Stunden bei $546 \pm 55$ Minuten und nach 20 Stunden KIZ bei $426 \pm 69$ Minuten. Nach 2 Stunden KIZ lag die mittlere Volumenstromstärke bei $216 \pm 26 \mathrm{ml} / \mathrm{min}$ und der arterielle Druck bei $62.8 \pm 21.5 \mathrm{mmHg}$ nach Beginn der Reperfusion. Der arterielle Druck stieg nach 5 Stunden Reperfusion bei stabiler Volumenstromstärke an. Der mittlere arterielle Druck lag bei $87 \pm 12 \mathrm{mmHg}$ nach 5 Stunden Reperfusion und bei $160 \pm 28 \mathrm{mmHg}$ nach 9 Stunden Reperfusion. Die mittlere Volumenstromstärke während der Reperfusion betrug $313 \pm 32 \mathrm{ml} / \mathrm{min}$ und der arterielle Druck $104 \pm 35$ $\mathrm{mmHg}$. Die reperfundierten Dünndärme, die einer KIZ von 20 Stunden ausgesetzt waren, hatten höhere arterielle Drücke bei niedrigerer Volumenstromstärke. Die mittlere Volumenstromstärke lag bei $257 \pm 29 \mathrm{ml} / \mathrm{min}$ und der arteriellen Druck bei $110 \pm 29 \mathrm{mmHg}$.

Die Dauer der kalten Konservierung war entscheidend für den Schwergrad und den zeitlichen Verlauf der mukosalen Schädigung. Die mukosalen Schädigung klassifiziert nach Chiu (Chiu et al 1970) und lag vor Reperfusion der 2 Stunden KIZ (20 Stunden $\mathrm{KIZ}$ ) bei $0,2 \pm 0,4(0,4 \pm 0,5)$, nach 1 Stunde Reperfusion bei $0,8 \pm 1,2$ $(2,2 \pm 0,8)$, nach 5 Stunden Reperfusion bei $2,0 \pm 1,3(3,4 \pm 0,8)$ und nach 8 Stunden Reperfusion bei $3,8 \pm 0,8(4,0 \pm 1,3)$.

\subsection{Proinflammatorische Mediatoren}

\subsubsection{Interleukin 6 (IL-6)}

Die Sequenz des isolierten porcinen IL-6 RNA Fragments besitzt eine 99 \%ige Homologie zu porciner IL-6 mRNA (GenBank: p26893). Der Nachweis der IL-6 mRNA-Expression erfolgte nach gelelektrophoretischer Auftrennung der isolierten Gesamt-RNA in denaturierenden Agarose-Gelen (Abb. 5 u. Abb. 7) durch NorthernBlot-Analyse. Die hierfür verwendeten Digoxygenin-markierten IL-6- und $\beta$-actinDNA-Sonden wurden mit einem kommerziell erhältlichen Kit (PCR DIG Probe Synthesis Kit) hergestellt und bei $65^{\circ} \mathrm{C}$ mit der Membran hybridisiert (Abb. $6 \mathrm{u}$. 
Abb.8). Bei Reperfusion nach 2 Stunden KIZ war ein Anstieg der IL-6 mRNAExpression nach 2 Stunden zu beobachten (Abb. 6).

$28 \mathrm{~s}$

$18 \mathrm{~s}$

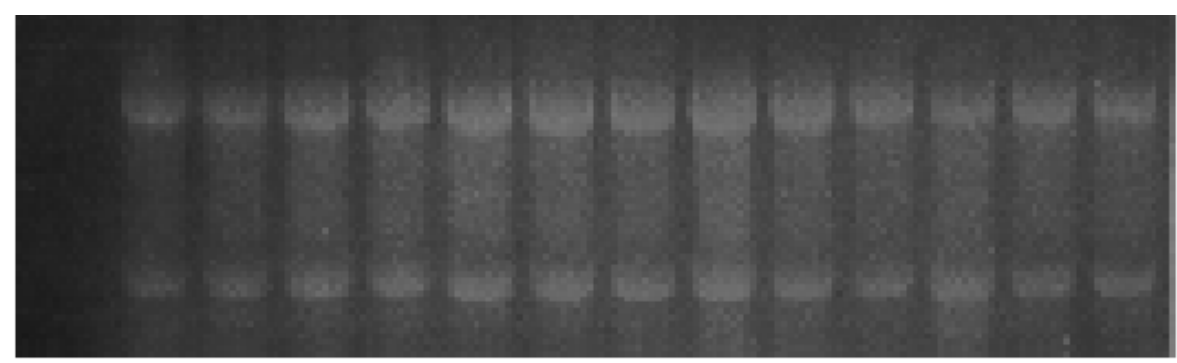

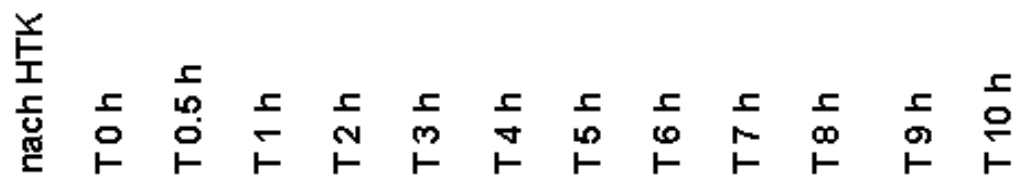

Abbildung 5:

Agarose-Formaldehyd-Gel der Gesamt RNA des Schweinedünndarms während IschämieReperfusion bei einer KIZ von 2 Stunden.
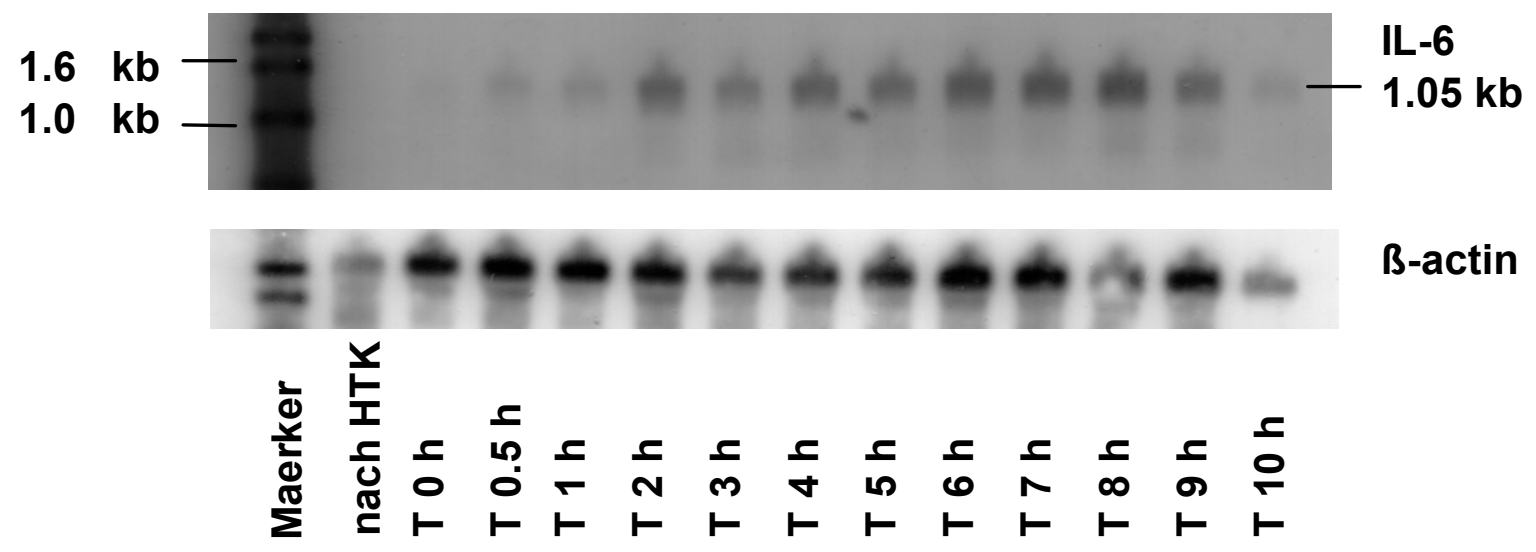

Abbildung 6:

Nachweis der IL-6 mRNA-Expression mittels Northern-Blot im Schweinedünndarm während IschämieReperfusion bei einer KIZ von 2 Stunden.

Eine Expression der IL-6 mRNA zeigte sich im Northern-Blot nach einer KIZ von 20 Stunden, jedoch nicht nach einer KIZ von 2 Stunden (Abb. 8). Die Expression der IL6 mRNA in Dünndärmen mit einer $\mathrm{KIZ}$ von 20 Stunden nahm unmittelbar nach Reperfusion ab. Im Northern-Blot wurde gezeigt, dass die IL-6 mRNA-Expression 5 Stunden nach Reperfusion in der Gruppe mit einer KIZ von 20 Stunden wieder anstieg (Abb. 8). 
$28 \mathrm{~s}$

$18 \mathrm{~s}$

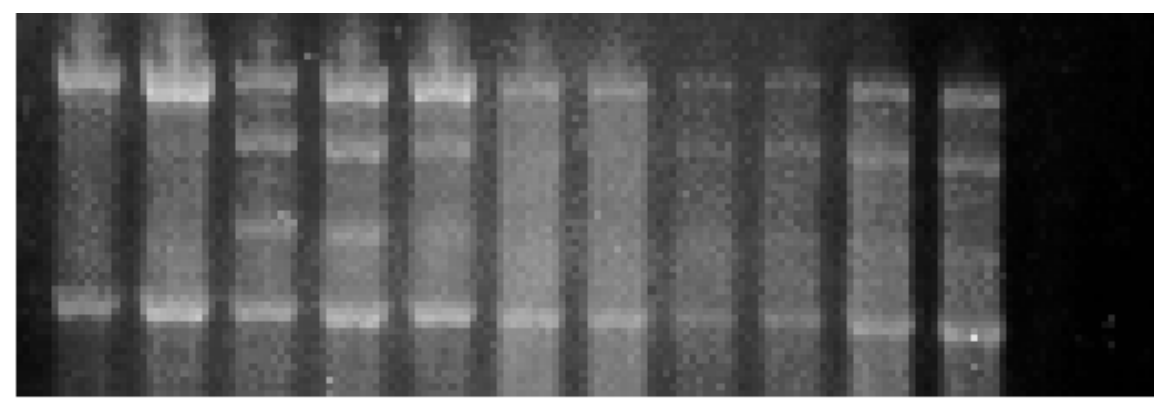

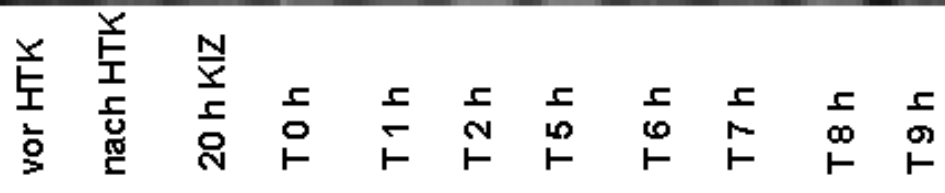

Abbildung 7:

Agarose-Formaldehyd-Gel der Gesamt RNA des Schweinedünndarms während IschämieReperfusion bei einer KIZ von 20 Stunden.

IL-6

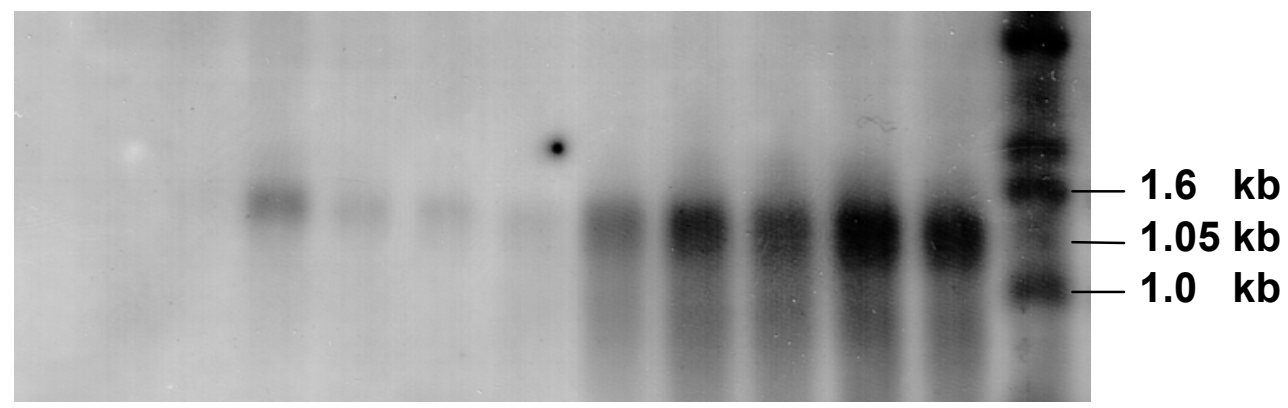

ß-actin

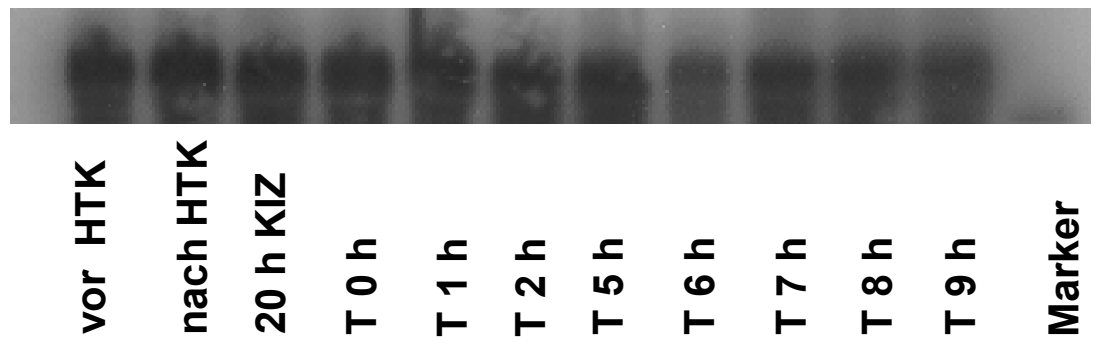

Abbildung 8:

Nachweis der IL-6 mRNA-Expression mittels Northern-Blot im Schweinedünndarm während IschämieReperfusion bei einer KIZ von 20 Stunden.

Zum Nachweis mit quantitativer RT-PCR wurde die isolierte RNA mit Oligo-dt als Primer revers transkribiert und die gleiche Menge cDNA mit sequenzspezifischen IL6-Primern amplifiziert. Die Quantifizierung erfolgte mit dem Light Cycler ${ }^{R}$. Die ermittelten Werte wurden jeweils auf das „house-keeping gene“ EF-2 als Standard bezogen. Die quantitative RT-PCR zeigte ebenfalls eine erhöhte IL-6 mRNAExpression nach einer $\mathrm{KIZ}$ von 20 Stunden (Abb. 9), was den mit Northern-Blot gemachten Befund bestätigte. Die IL-6 mRNA-Expression stieg nach Reperfusion sowohl nach einer KIZ von 2 als auch von 20 Stunden an. Eine Abnahme der IL-6 mRNA-Expression wurde ebenfalls im Anschluss an eine KIZ von 20 Stunden beobachtet (Abb.9). 


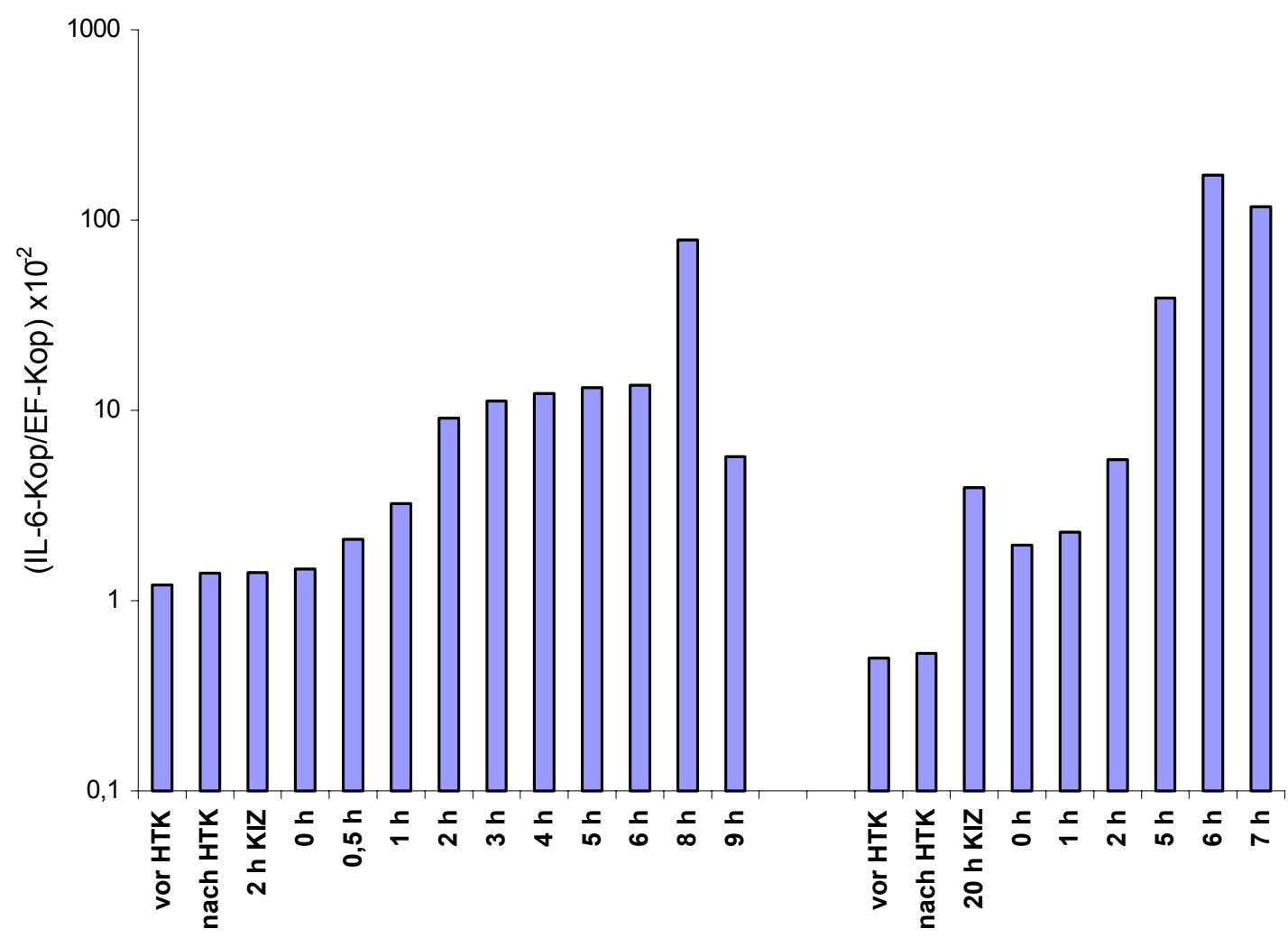

Abbildung 9:

Nachweis der IL-6 mRNA-Expression mittels quantitativer RT-PCR im Schweinedünndarm während Ischämie-Reperfusion bei einer KIZ von 2 und von 20 Stunden.

Die Expression von IL-6 mRNA konnte mittels In-situ-Hybridisierung mit Digoxygenin-markierten Antisense-RNA-Sonden in Monozyten, Endothel- und glatten Muskelzellen nachgewiesen werden (Abb.10).
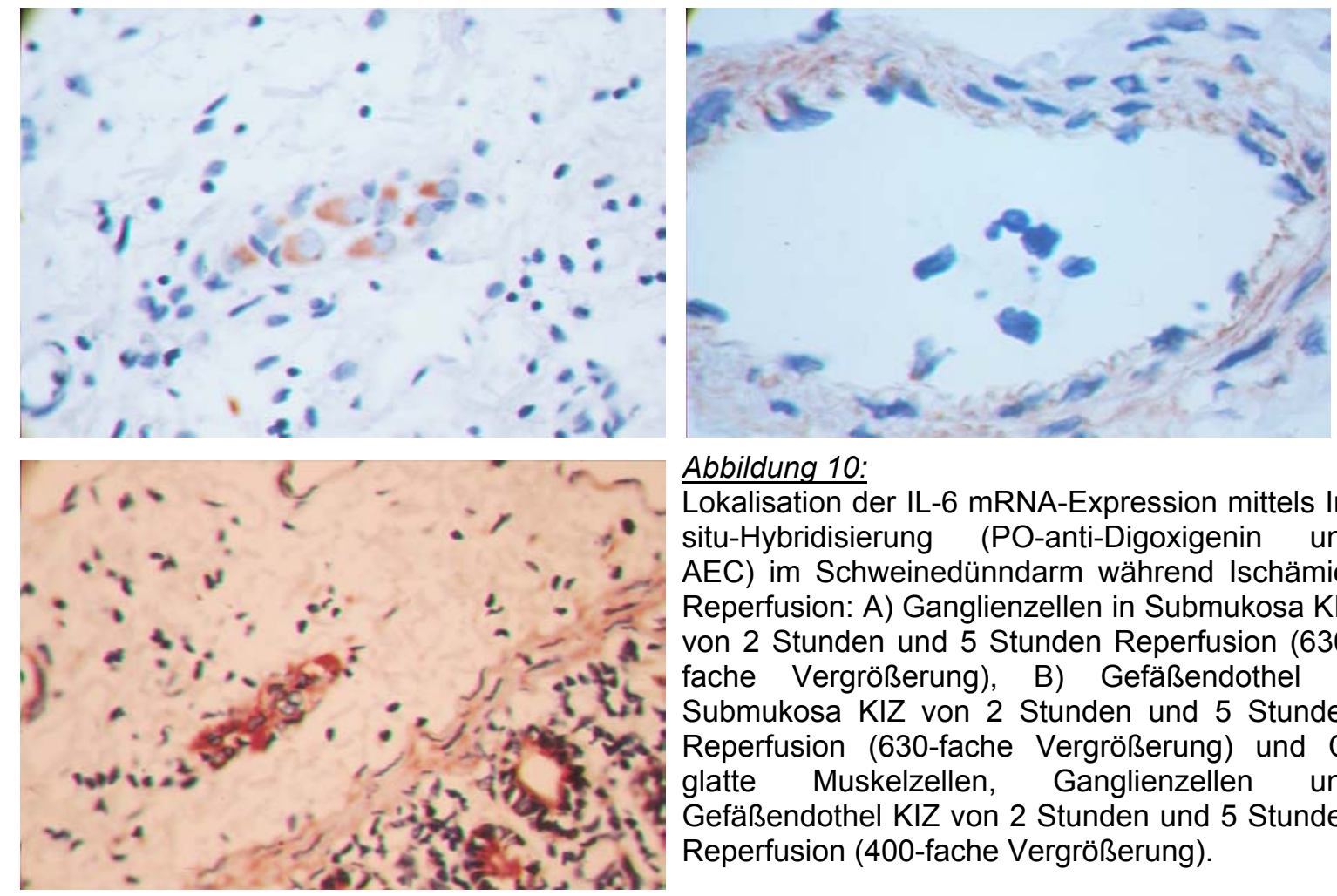

\section{Abbildung 10:}

Lokalisation der IL-6 mRNA-Expression mittels Insitu-Hybridisierung (PO-anti-Digoxigenin und $A E C)$ im Schweinedünndarm während IschämieReperfusion: A) Ganglienzellen in Submukosa KIZ von 2 Stunden und 5 Stunden Reperfusion (630fache Vergrößerung), B) Gefäßendothel in Submukosa KIZ von 2 Stunden und 5 Stunden Reperfusion (630-fache Vergrößerung) und C) glatte Muskelzellen, Ganglienzellen und Gefäßendothel KIZ von 2 Stunden und 5 Stunden Reperfusion (400-fache Vergrößerung). 


\subsubsection{Interleukin 2 (IL-2)}

Ein 387 bp isoliertes und sequenziertes RT-PCR-Fragment besitzt eine 100 \%ige Homologie zu porciner IL-2 mRNA (GenBank: X56750). Eine Expression der IL-2 mRNA zeigte sich im Northern-Blot nach Perfusion mit HTK nach einer KIZ von 2 Stunden. Anschließend stieg die Expression der IL-2 mRNA während der kalten Ischämie an, wobei die Expression 2 Stunden nach Reperfusion wieder abnahm. Ein Anstieg der IL-2 mRNA-Expression zeigte sich wieder nach 7 Stunden bei Reperfusion (Abb. 11). Mittels In-situ-Hybridisierung konnte IL-2 mRNA in Endothelzellen und Leukozyten lokalisiert werden. Des weiteren wurde IL-2 mRNA in der engen Nachbarschaft von Ganglienzellen nachgewiesen (Abb12).

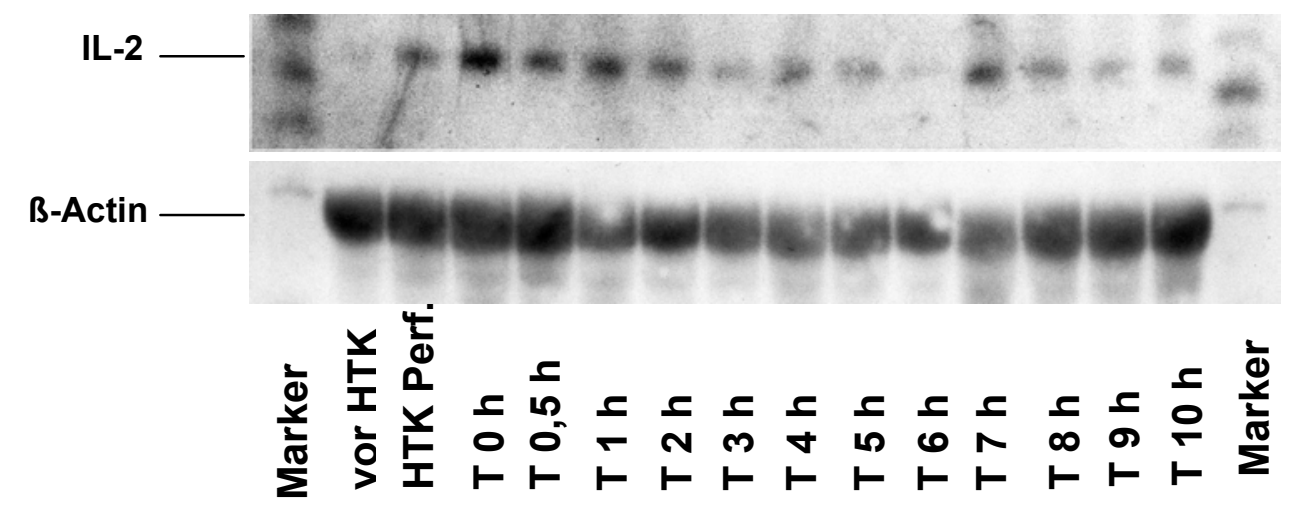

Abbildung 11:Nachweis der IL-2 mRNA-Expression mittels Northern-Blot im Schweinedünndarm während Ischämie-Reperfusion bei einer KIZ von 2 Stunden
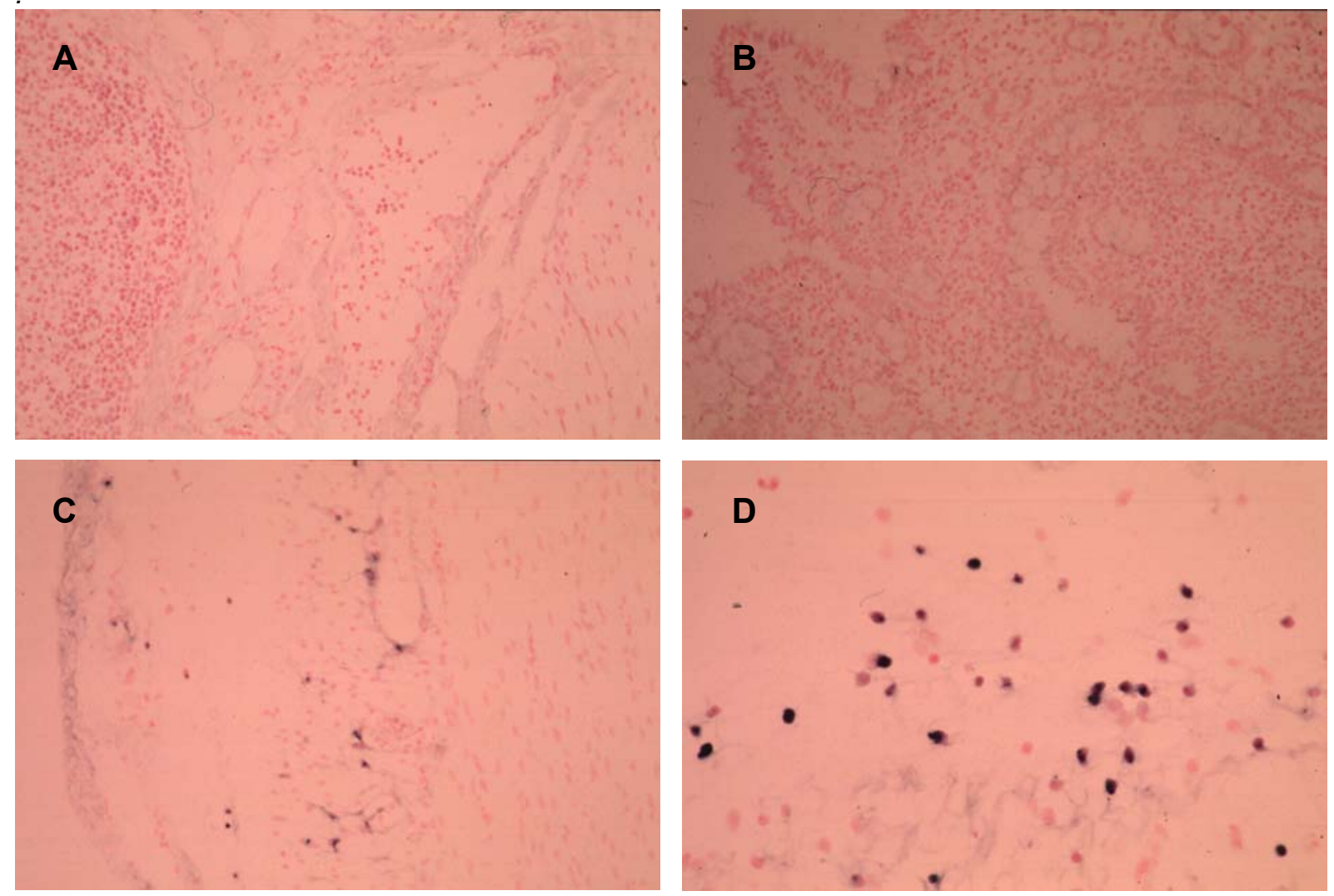

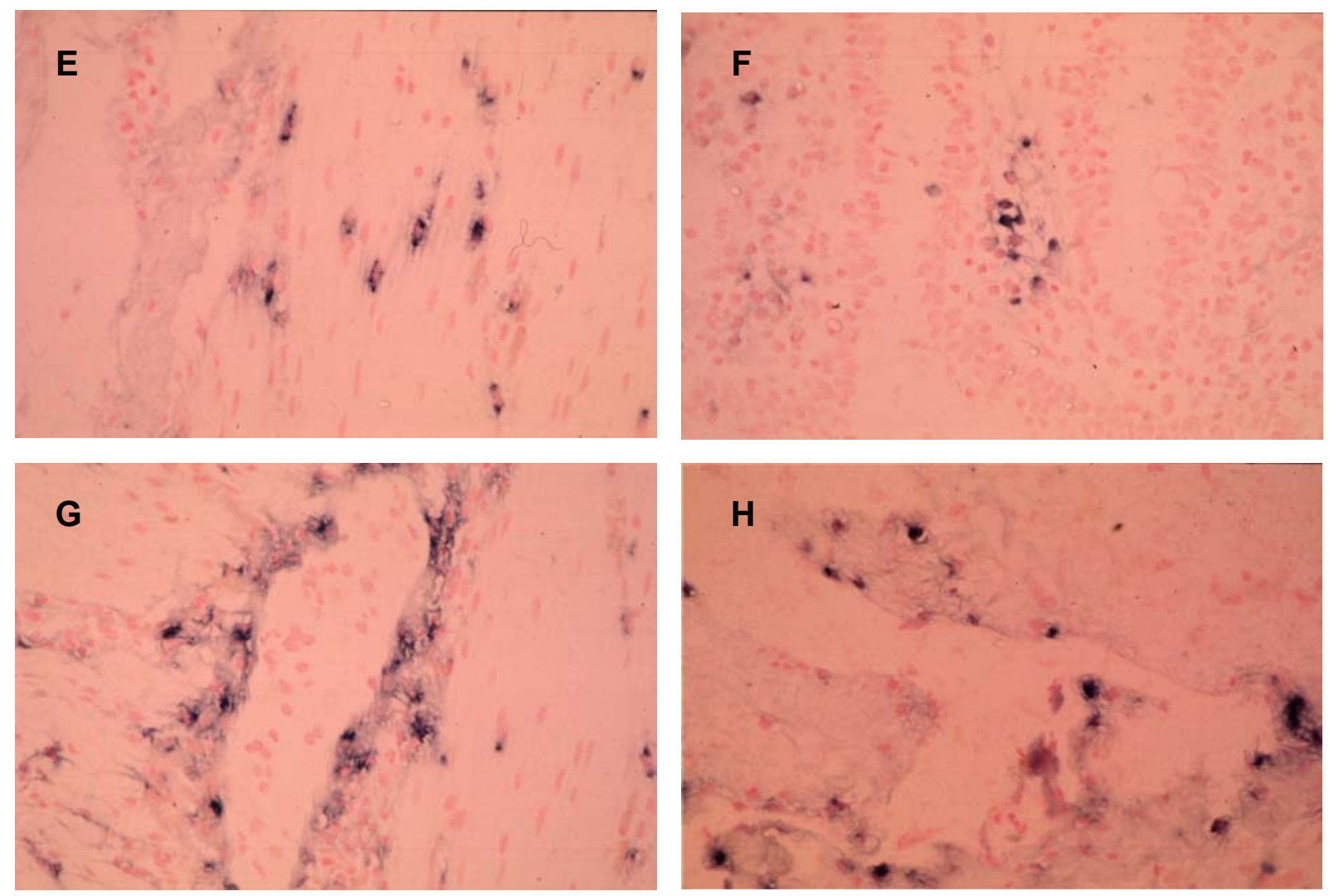

\section{Abbildung 12:}

Lokalisation der IL-2 mRNA-Expression mittels In-situ-Hybridisierung (APAAP-Färbung) im Schweinedünndarm: A und B) Übersicht Mukosa und Submukosa vor HTK-Perfusion (200-fache Vergrößerung), C) Gefäßendothel KIZ von 2 Stunden und 1 Stunde Reperfusion (400-fache Vergrößerung), D) Lymphozyten in Submukosa KIZ von 2 Stunden und 7 Stunden Reperfusion (400fache Vergrößerung), E) ) Ganglienzellen in Submukosa KIZ von 2 Stunden und 7 Stunden Reperfusion (400-fache Vergrößerung), F) Lymphozyten in Mukosa KIZ von 2 Stunden und 7 Stunden Reperfusion (400-fache Vergrößerung), G) Gefäßendothel im Bereich der Muscularis propria KIZ von 2 Stunden und 7 Stunden Reperfusion (400-fache Vergrößerung) und H) Gefäßendothel in Submukosa KIZ 2 von Stunden und 7 Stunden Reperfusion (400-fache Vergrößerung).

\subsubsection{Hitze-Schock-Protein 70 (HSP70)}

Eine geringgradige Expression von HSP70 mRNA zeigte sich im Dünndarm mittels semi-quantitativer RT-PCR und quantitativer RT-PCR (Light Cycler ${ }^{\circledR}$ ) bereits während der Spenderoperation. Eine deutlich erhöhte Expression der HSP70 mRNA wurde nach einer KIZ von 20 Stunden beobachtet, während sich nach einer KIZ von 2 Stunden nur ein geringfügiger Anstieg zeigte (Abb. 13, 14, 15). Die Expression der HSP70 mRNA in Dünndärmen mit einer KIZ von 20 Stunden nahm unmittelbar nach Reperfusion ab (Abb.15). Eine quantitative RT-PCR zeigte, dass die HSP70 mRNAExpression $\geq 1$ Stunde nach Reperfusion in der Gruppe mit einer KIZ von 20 Stunden und $\geq 3$ Stunden nach Reperfusion in der Gruppe mit einer KIZ von 2 Stunden anstieg (Abb.15). 


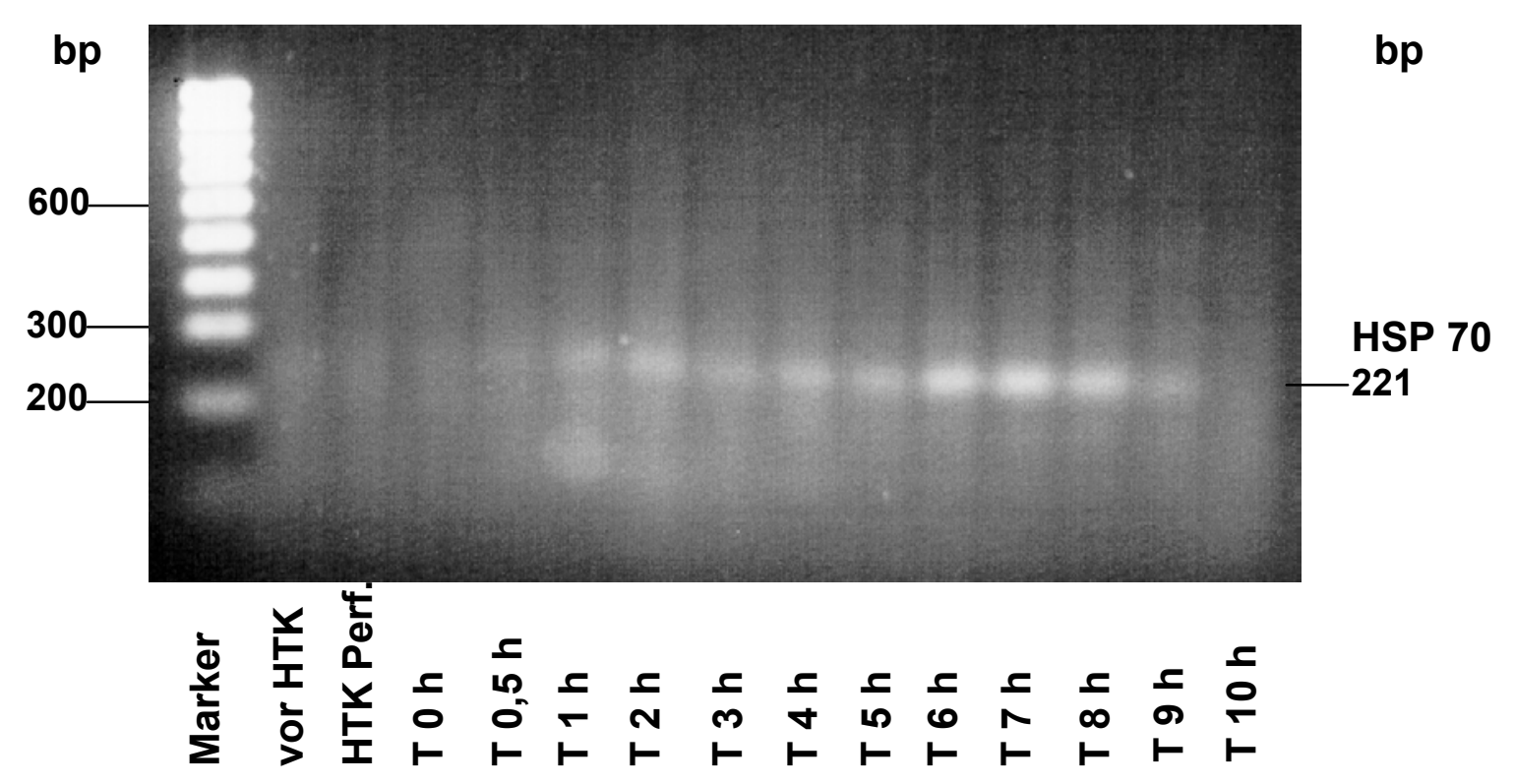

Abbildung 13:

Nachweis der HSP70 mRNA-Expression mittels PCR auf einem Agarosegel im Schweinedünndarm während Ischämie-Reperfusion bei einer KIZ von 2 Stunden.

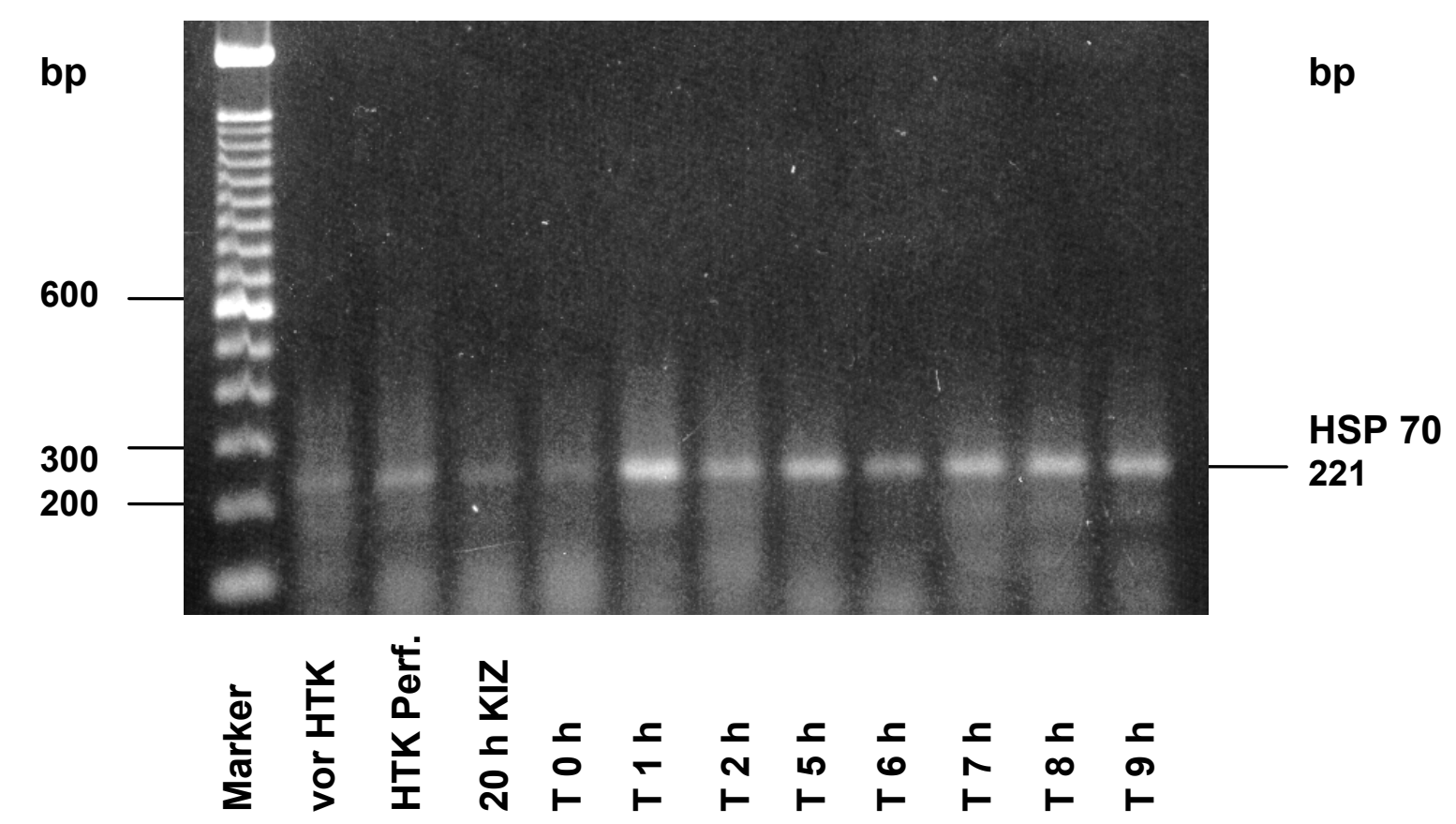

Abbildung 14

Nachweis der HSP70 mRNA-Expression mittels PCR auf einem Agarosegel im Schweinedünndarm während Ischämie-Reperfusion bei einer KIZ von 20 Stunden. 


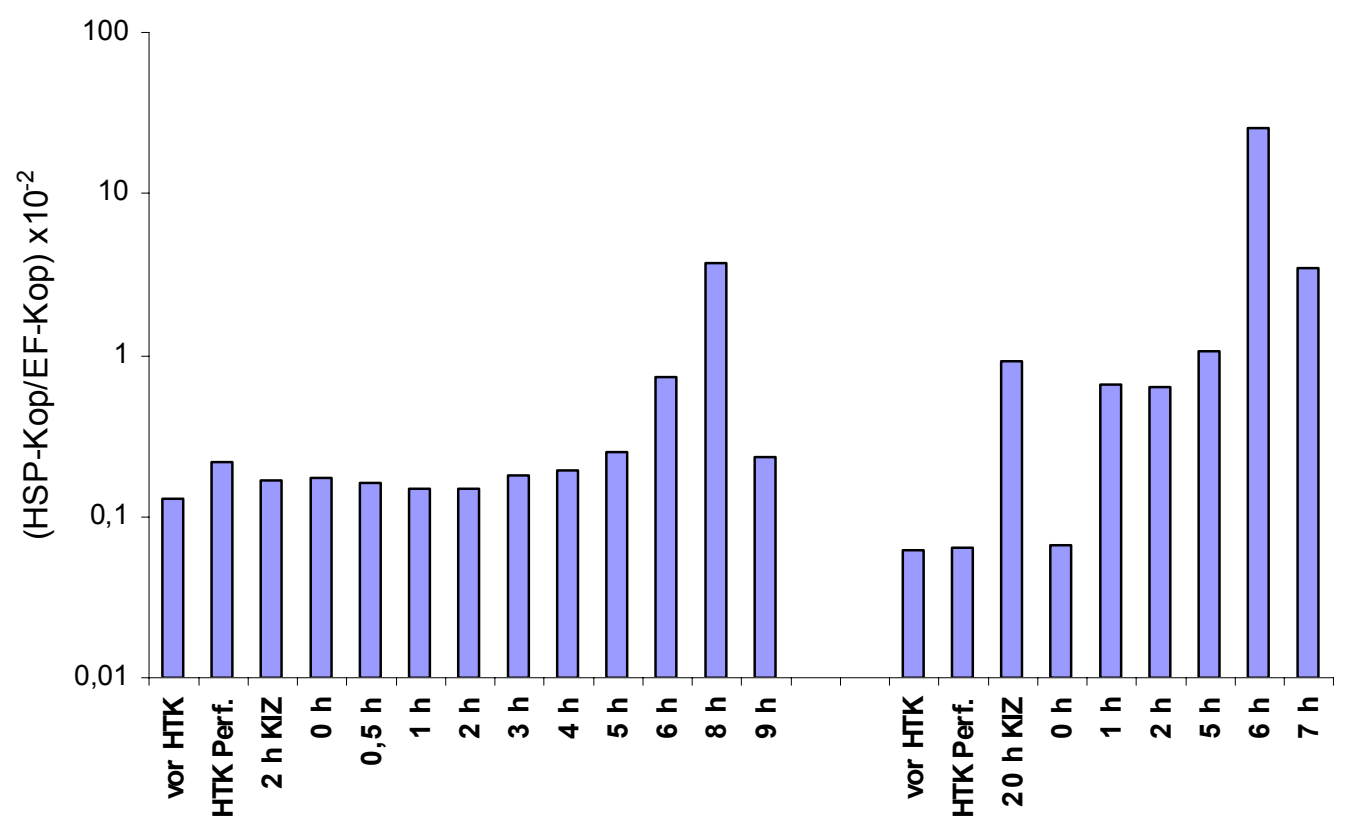

Abbildung 15:

Nachweis der HSP70 mRNA-Expression mittels quantitativer RT-PCR im Schweinedünndarm während Ischämie-Reperfusion bei einer KIZ von 2 und von 20 Stunden.

HSP70 mRNA wurde mittels In-situ-Hybridisierung mit Digoxygenin-markierten Antisense RNA-Sonden in Endothelzellen und glatten Muskelzellen nachgewiesen(Abb.16).
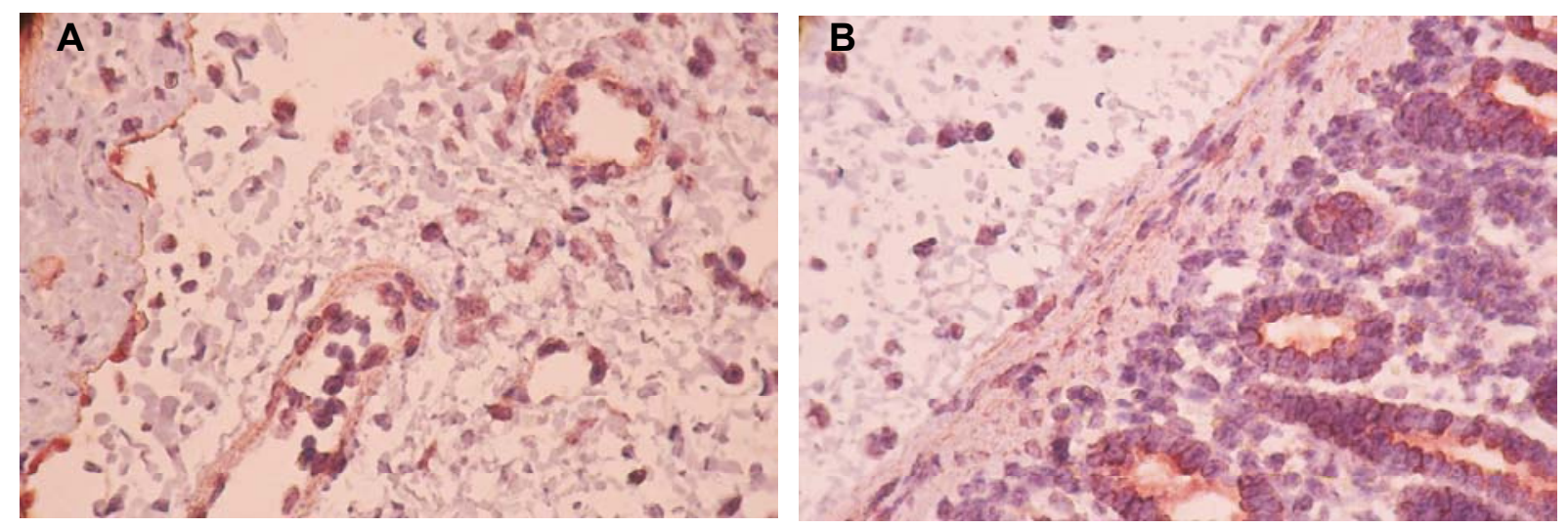

Abbildung 16:

Lokalisation der HSP70 mRNA-Expression mittels In-situ-Hybridisierung im Schweinedünndarm nach einer KIZ von 2 Stunden und einer Reperfusionsdauer von 1 Stunde. Als Färbung wurde PO-antidigoxigenin und AEC verwendet. Abbildung $A$ zeigt den Nachweis von HSP70 mRNA in Endothelzellen und Abbildung $B$ in glatten Muskelzellen. 


\subsubsection{Interferon-gamma (IFN $\gamma$ )}

Eine $365 \mathrm{bp}$ isolierte und sequenzierte semi-quantitative RT-PCR Bande zeigte eine 100 \%ige Homologie zu Sus scrofa Interferon-gamma. Die Expression von IFN $\gamma$ konnte im Gegensatz zu IL-6 mittels Northern-Blot in Dünndärmen bereits nach einer KIZ von 2 Stunden vor Reperfusion nachgewiesen werden. Unter der Reperfusion stieg die IFN $\gamma$ mRNA-Expression bis zu 1 Stunde an und nahm dann bis zur 7 . Stunde ab (Abb. 17).

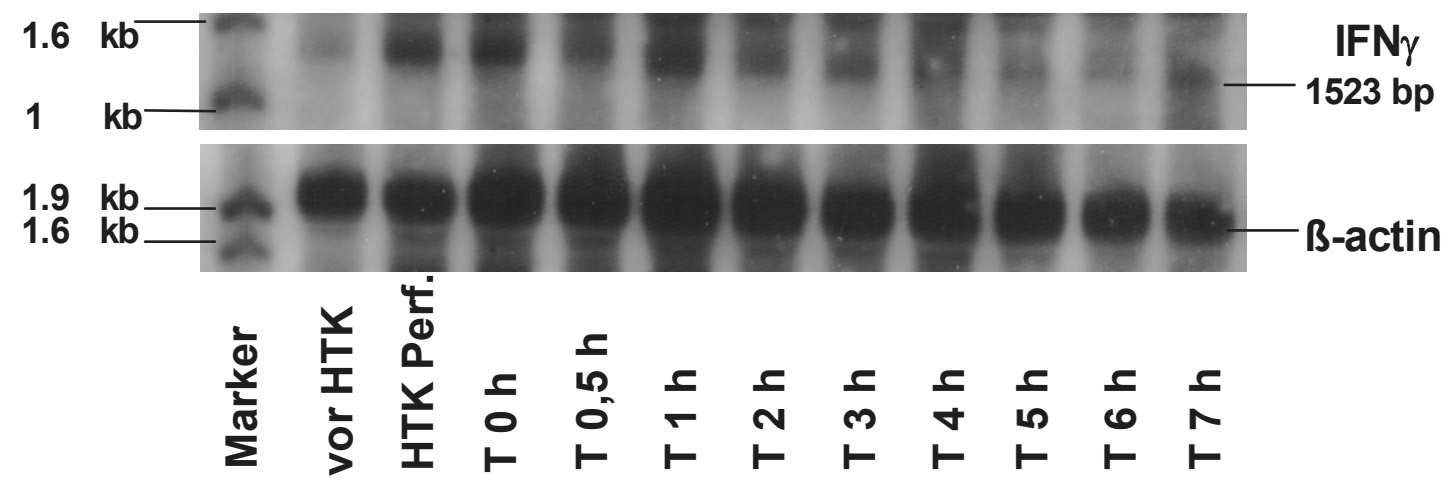

Abbildung 17:

Nachweis der IFN $\gamma$ mRNA-Expression mittels Northern-Blot im Schweinedünndarm während Ischämie-Reperfusion bei einer KIZ von 2 Stunden.

Die Expression von IFN $\gamma$ mRNA konnte mittels In-situ-Hybridisierung in Lymphozyten nachgewiesen werden (Abb. 18).

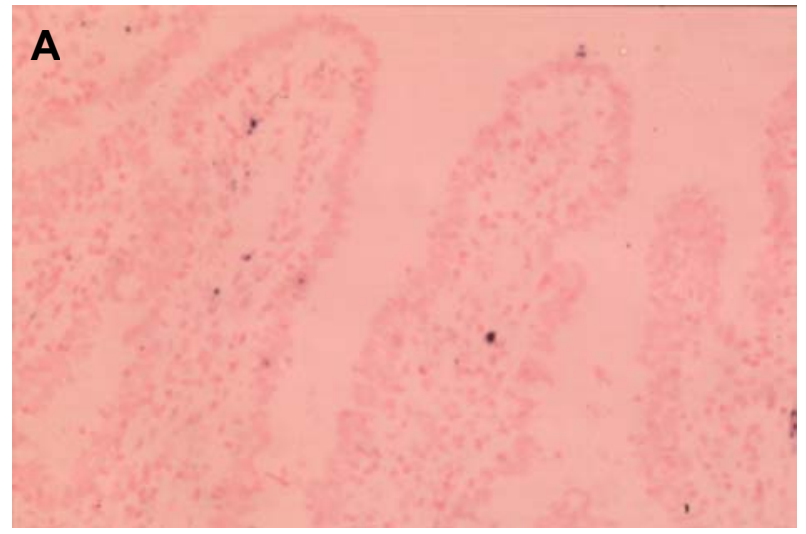

B
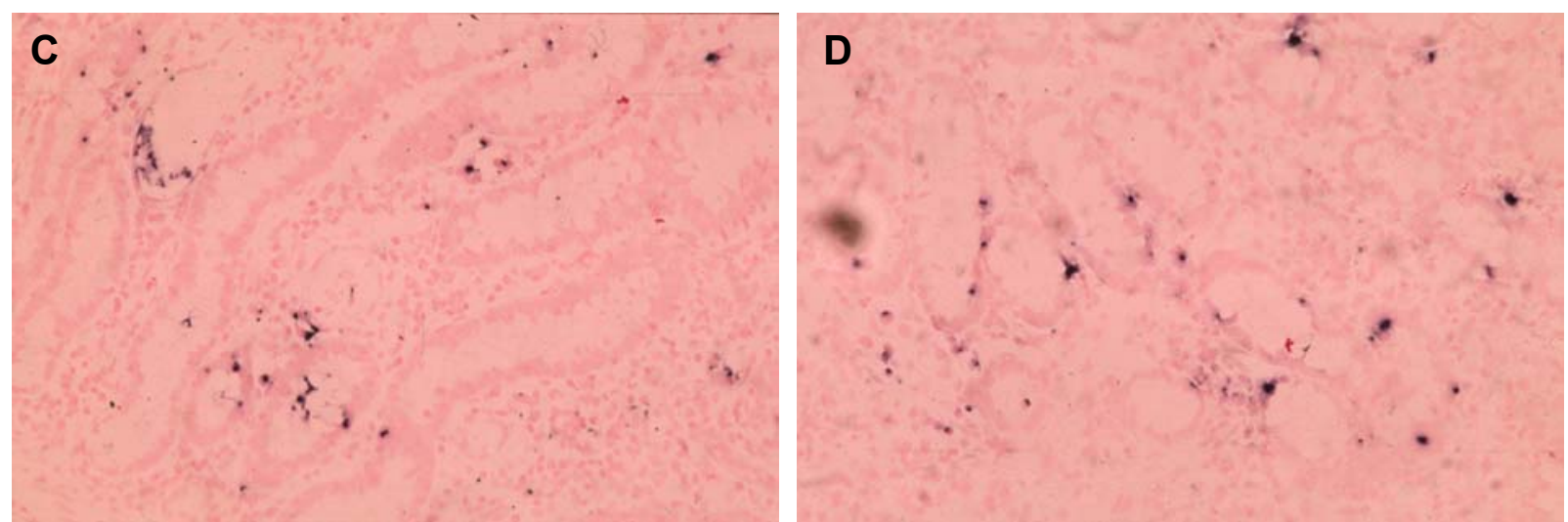

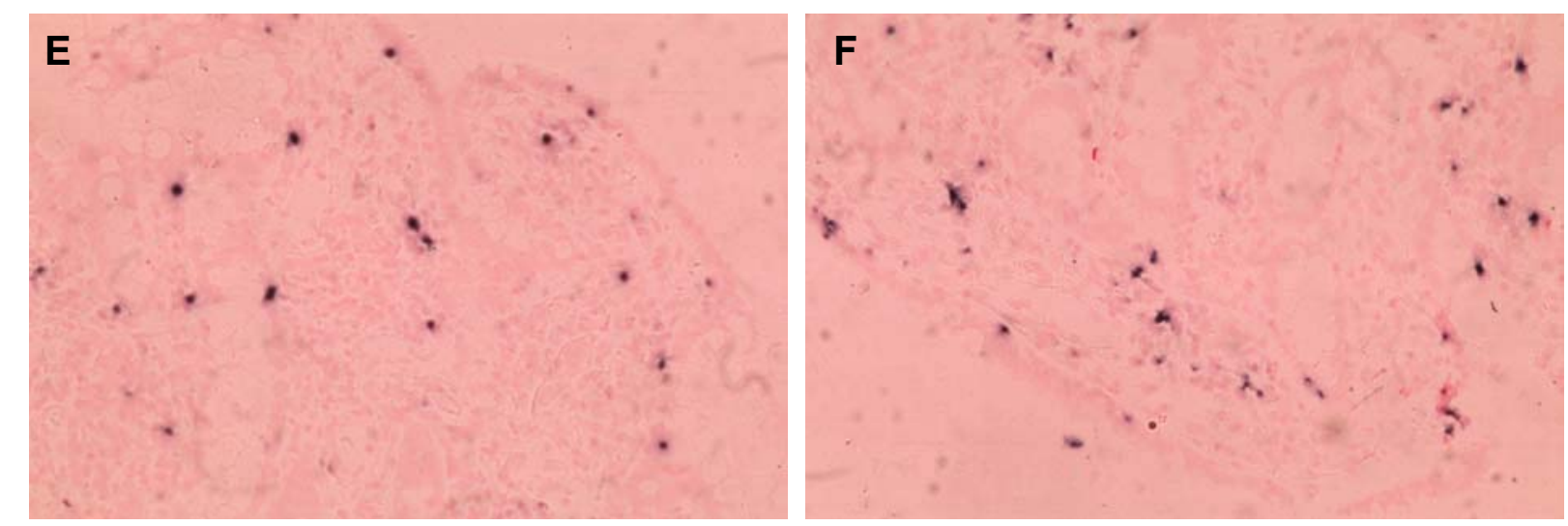

Abbildung 18:

Lokalisation der IFN $\gamma$ mRNA-Expression mittels In-situ-Hybridisierung im Schweinedünndarm: A) vor HTK-Perfusion, B) KIZ von 2 Stunden und 2 Stunden Reperfusion, C u. D) KIZ von 2 Stunden und 6 Stunden Reperfusion.

\subsubsection{E-Selektin}

Zur Untersuchung der E-Selektin mRNA-Genexpression wurde die cDNA aus Dünndärmen mit einer $\mathrm{KIZ}$ von 2 und 20 Stunden mit genspezifischen Primern amplifiziert, sequenziert und auf ein 1,5 \%iges Agarose Gel aufgetragen. Als Kontrolle wurde GAPDH eingesetzt (Abb. 19).

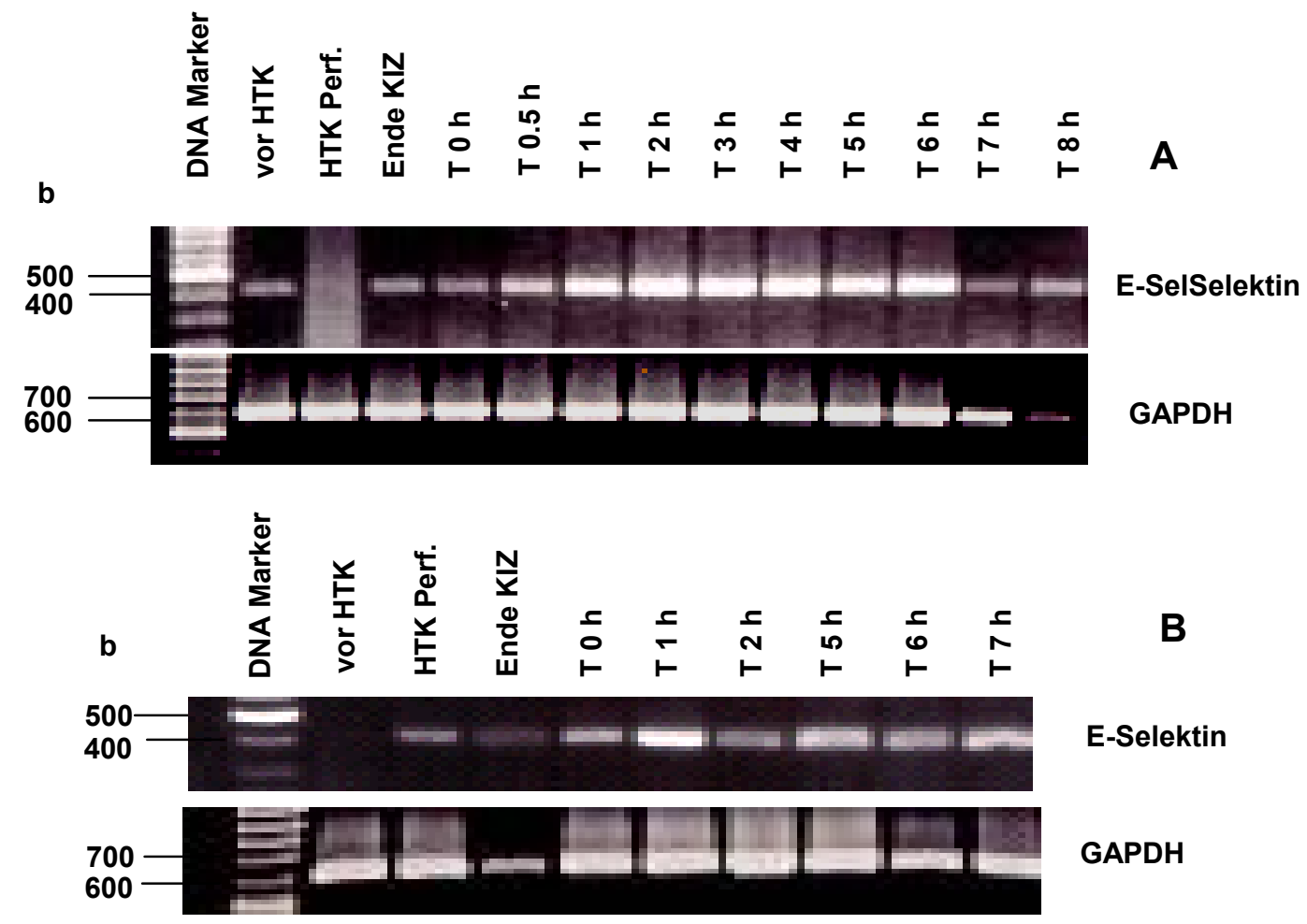

Abbildung 19:

Nachweis der E-Selektin mRNA-Expression mittels RT-PCR auf einem Agarosegel im Schweinedünndarm während Ischämie-Reperfusion bei einer KIZ von A)2 Stunden und B)20 Stunden Als Kontrolle wurde GAPDH eingesetzt. 
Eine E-Selektin mRNA-Expression zeigte sich bei quantitativer RT-PCR nach einer $\mathrm{KIZ}$ von 20 Stunden deutlich ausgeprägter als nach einer KIZ von 2 Stunden. Die Expression der E-Selektin mRNA in Dünndärmen nahm nach Reperfusion zu, wobei jedoch wie bei IL-6 und HSP70 eine Abnahme der mRNA-Expression mit einer KIZ von 20 Stunden unmittelbar nach Reperfusion beobachtet wurde (Abb. 20).

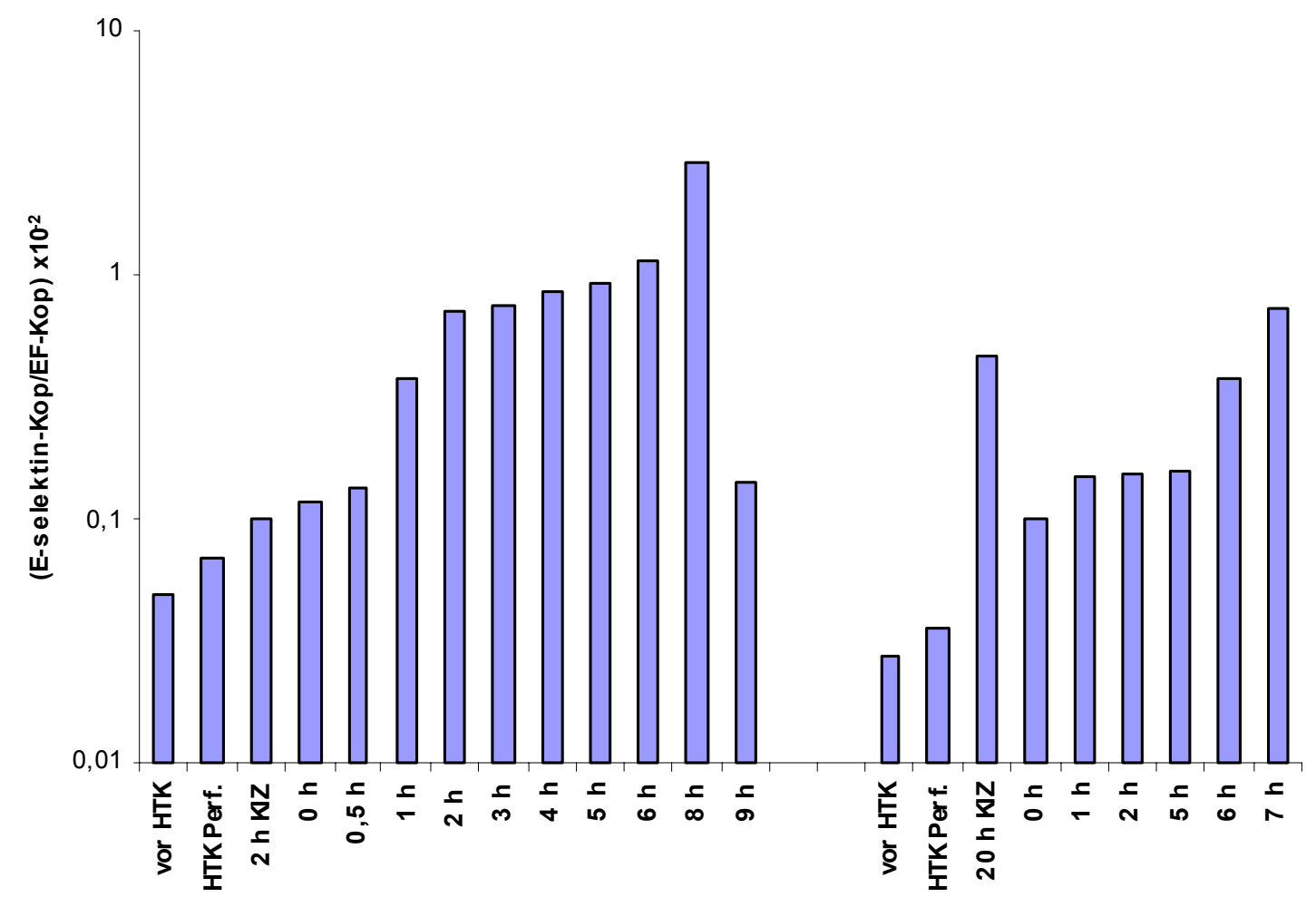

Abbildung 20:

Nachweis der E-Selektin (CD62E) mRNA-Expression mittels quantitativer RT-PCR im Schweinedünndarm während Ischämie-Reperfusion bei einer KIZ von 2 und von 20 Stunden.

Die E-Selektin mRNA-Expression konnte mittels In-situ-Hybridisierung an der luminalen Oberfläche der muskulären, submukösen und mukösen Endothelzellen nachgewiesen werden. Die mRNA-Expression war während der extrakorporalen Reperfusion verstärkt. Wie mit der In-situ-Hybridisierung gezeigt wurde, wurde die ESelektin mRNA-Expression am frühesten im submukösen und mukösen Endothel und am spätestens im muskulären Endothel nachgewiesen. Nach 2 Stunden Reperfusion zeigten sich eine erhöhte E-Selektin mRNA-Expression in den Endothelzellen kleiner submuköser Arterien, die sich im weiteren Verlauf der Reperfusion verstärkten (Abb. 21). 

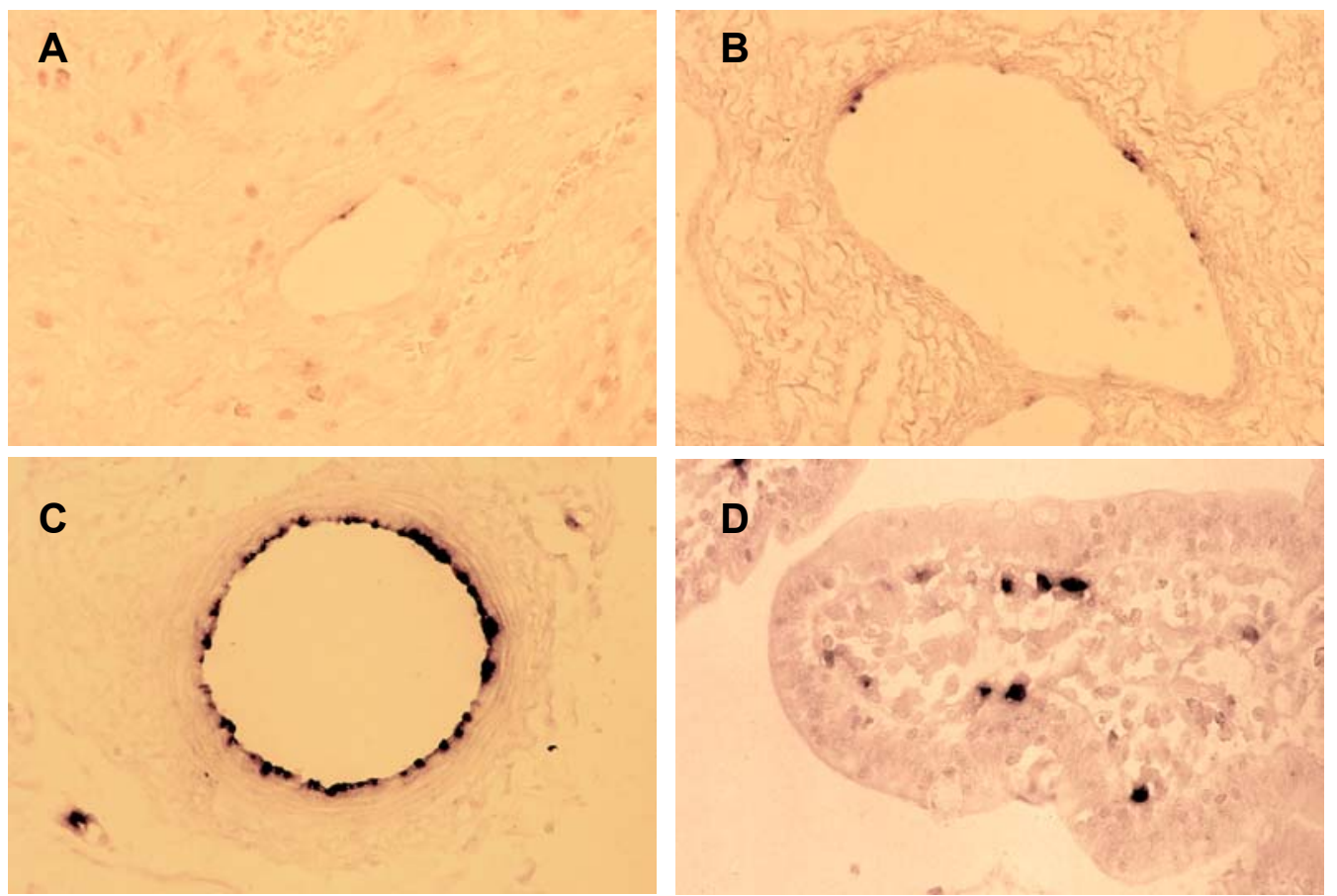

\section{Abbildung 21:}

In-situ-Hybridisierung der E-Selektin mRNA-Expression im Schweinedünndarm während IschämieReperfusion. A) vor HTK-Perfusion, B) KIZ von 2 Stunden und 2 Stunden Reperfusion, C) Endothel nach 2 Stunden KIZ und 7 Stunden Reperfusion, D) Dünndarmzotte nach 2 Stunden KIZ und 7 Stunden Reperfusion. 


\section{3. mRNA-Differential Display}

Die von Liang und Pardee (1992) publizierte Methode zur Darstellung des Status der zellulären Genexpression wurde in dieser Arbeit verwendet, um die Gene zu identifizieren, welche durch Ischämie-Reperfusion differentiell reguliert werden. Durch die Verwendung unterschiedlicher „downstream“ und „upstream“ PrimerKombinationen wurden sehr viele unterschiedliche Bandenmuster erzeugt.

Die Gesamt-RNA wurde aus vor HTK-Perfusion und 3 Stunden nach Reperfusion entnommenen Biopsaten gewonnen. Zuerst wurde die RNA mittels einer reversen Transkription (RT) in getrennten Ansätzen mit drei verschiedenen $\mathrm{H}_{-11} \mathrm{~T}_{11} \mathrm{M}$ Primern $(\mathrm{M}=\mathrm{A}, \mathrm{C}$ oder $\mathrm{G})$ in cDNA umgeschrieben. Die cDNAs wurden anschließend mit den entsprechenden RT-Primern und je einem von 8 verschiedenen 13mer-Primern durch PCR amplifiziert. Die PCR-Produkte wurden auf ein PAA-Gel aufgetragen und durch Silberfärbung sichtbar gemacht. In Abbildung 22 ist ein Foto eines PAA-Gels dargestellt, in dem die Amplifikate unterschiedlicher Primerkombinationen aufgetragen wurden. Eine Vielzahl hoch- und herunterregulierter Banden konnte mittels mRNA-Differential Display nachgewiesen werden (Abb. 22).

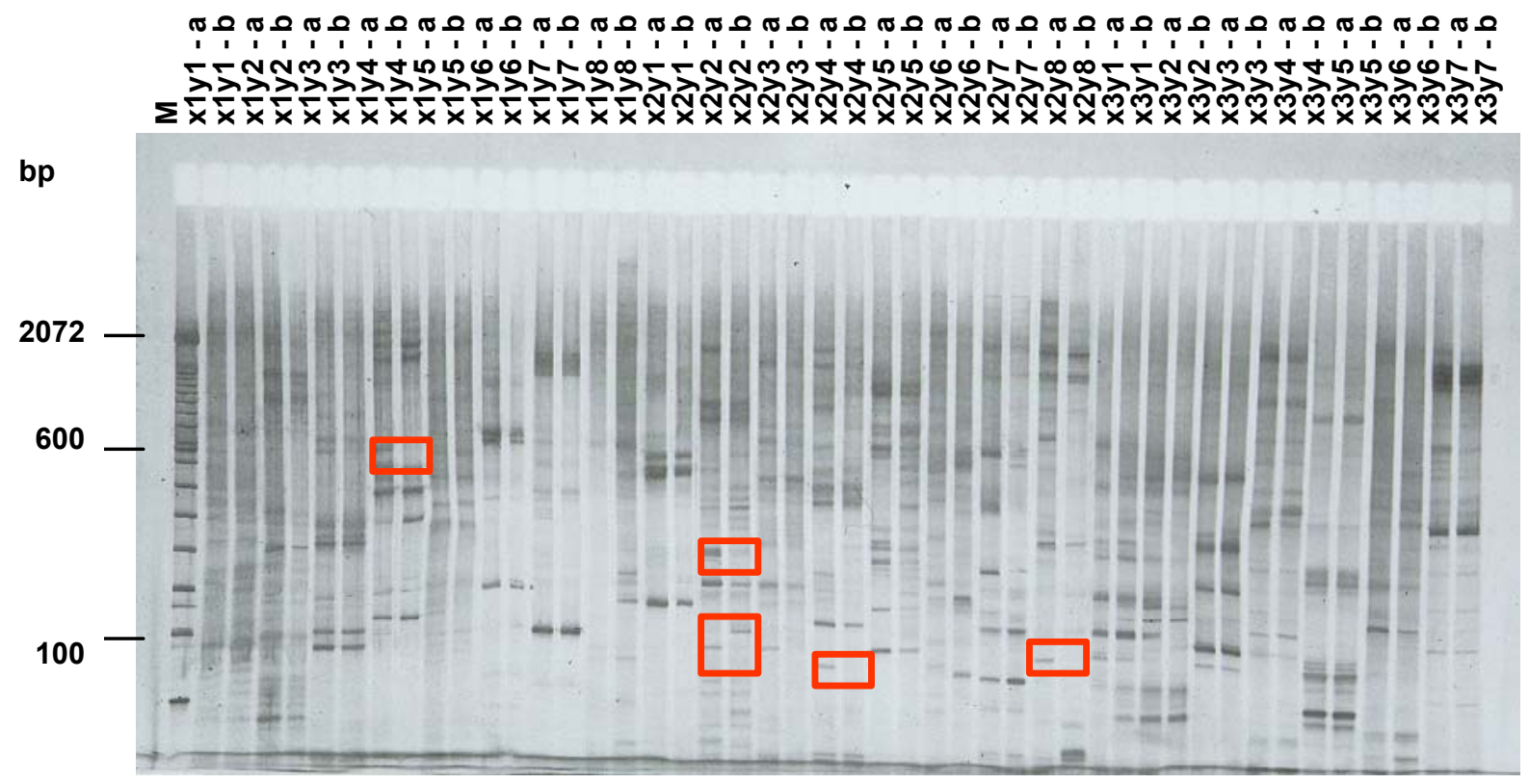

Abbildung 22:

Nachweis differentiell regulierter Banden mittels mRNA-Differential Display, die exemplarisch als rote Kästen gekennzeichnet sind. Die mit „a“ bezeichneten Kolumnen zeigen die Gewebeprobe vor HTKPerfusion und die mit „b“ bezeichneten Kolumnen die Gewebeproben nach einer Reperfusionsdauer von 3 Stunden. Für das mRNA-Differential Display wurden 3 mit „x“ bezeichnete „forward primer" und 8 mit „y" bezeichnete „arbitrary primer" verwendet. 
Von Bedeutung für die Auswahl differentiell amplifizierter cDNA-Fragmente zur weiteren Analyse waren einerseits die Reproduzierbarkeit der differentiellen Amplifikation in einem erneuten RNA-Display und die Bandenintensität der amplifizierten cDNAs. Die Reproduzierbarkeit der Amplifikation einer cDNA bei gleichbleibender Bandenintensität sollte sicherstellen, dass nur solche cDNAFragmente weiter untersucht wurden, die mit großer Wahrscheinlichkeit auch differentiell exprimiert wurden. Die aus dem 6 \%igen Polyacrylamidgel ausgeschnittenen Banden wurden in $\mathrm{H}_{2} \mathrm{O}$ gelöst, aufgereinigt und unter Verwendung der korrespondierenden Primerkombination reamplifiziert. Die isolierten PCRProdukte zeigten, dass die reamplifizierten DNA-Fragmente in ihrer Größe mit der zu erwarteten Größe übereinstimmten (Abb.23; Fragment SNAP23 und SLA-DQ). Für weitere Analysen wurden nur solche cDNA-Fragmente weiter untersucht, die in ihrer Größe nach der Reamplifikation dem Größenbereich entsprachen, in dem sie im PAA-Gel detektiert wurden.

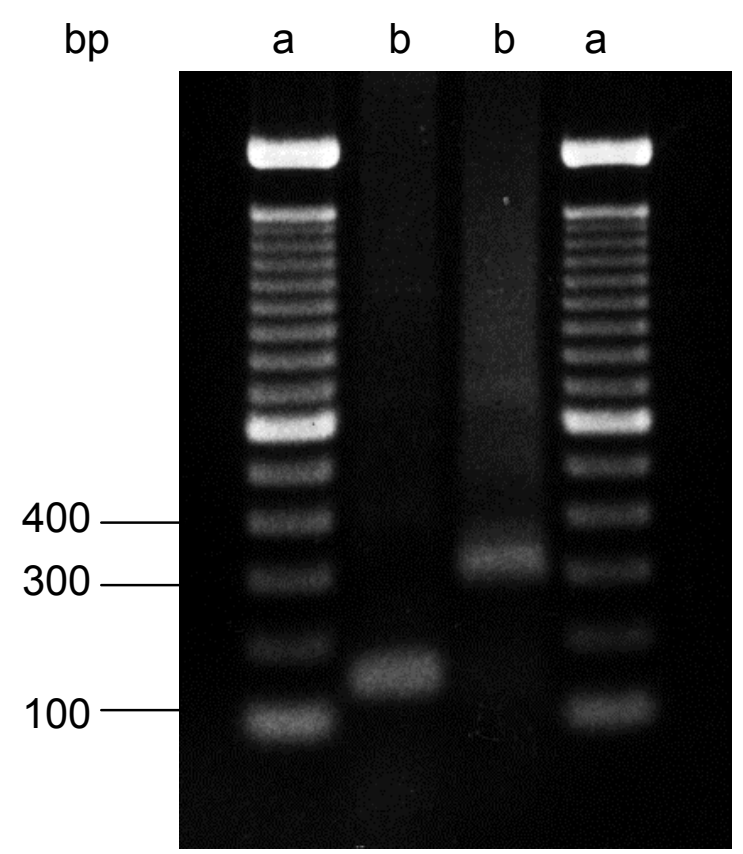

Abbildung 23:

Nachweis reamplifizierter differentieller Banden mittels Agarose-Gel a) DNA Marker, b) Reamplifikation 2 differentieller Banden.

Anschließend wurden die reamplifizierten Fragmente aus dem Agarosegel eluiert, in einen $\mathrm{pCR}{ }^{\circledR} \mathrm{II}$-TOPO-Vektor kloniert und zur Identifizierung der entsprechenden cDNAs 5 Klone sequenziert. 
Die Sequenzen der einzelnen Banden wurden auf Homologien in der BLAST-2 GenBank Datenbank abgeglichen. Die Sequenzanalyse der differentiellen Banden zeigte höchste Homologien zu „Nascent-Polypetide-Associated Complex Alpha Polypeptide“ (alpha-NAC), „ß-Amyloid b-Protein Precursor“ (AD1), Cingulin, „Development and Differentiation Enhancing Factor 1“ (DDEF1), „FAT Tumor Suppressor Gene“ (FAT), FLJ22116, „Guanylat-Cyclase 1B3“ (GUCY1B3), „Ig gamma heavy-chain“, Interleukin 7 (IL-7), Map Kinase Phosphatase-M B2 (MKP-7), mc7 Protein, „Mitochondrial DNA D-Loop Region“, „Mitochondrial NADH Dehydrogenase Subunit 4“ (NADH4), „Mitochondrial NADH Dehydrogenase Subunit 6“ (NADH6), „MHC Class II SLA-DQ Haplotype d and c“ (SLA-DQ), „Muscle lambda zap 2“ (TIS11d), Myosin 5B (MYO 5B), „Retionic Acid Receptor alpha“ (RARA), „Ribosomal Protein L3“ (RPL3), „Serine/Threonine kinase 12“ (STK12), „SMH-1“, „Synaptosomal-Associated Protein 23 kD“ (SNAP23), „Thyreoid Receptor Interacting Protein“ (TRIP7), „Transcription Factor 7 mRNA“ (TCF7) und „Ubiquitin-Like Containing PHD and RING Finger Domains 1" (UHRF1). Einige dieser Gene besaßen lediglich eine Homologie in der "expressed sequence tags" (EST)Datenbank. Die Homologien der Sequenzen der differentiellen Banden mit den korrespondierenden Genen, welche die GenBank Suche ergeben hat, lagen zwischen 83 und $100 \%$ (Tab. 5). Die Mehrzahl der differentiell exprimierten Gene wurde durch Nachweis mittels nicht radioaktiven Northern-Blots oder Slot-Blots verifiziert. Einige der analysierten mRNA-Sequenzen wurden weitergehend untersucht und mit Digoxygenin-markierten Antisense-RNA-Sonden mittels In-situHybridisierung lokalisiert. 
Die korrespondierenden Gene, Spezies, GenBank-Nummer, prozentuale Homologie, Synonyme, Basenpaarlänge und differentielle Regulation sind in Tabelle 5 dargestellt.

\section{A)}

\begin{tabular}{|c|c|c|c|c|c|}
\hline Gen & Species & GenBank-Nr. & Homologie (\%) & Synonyme & bp \\
\hline FLJ22116 & Homo sapiens & NM_024624 & 93 & clon HEP18520 & 150 \\
\hline GUCY1B3 (guanylate cyclase 1 B3) & Bovine & Y00770 & 88 & $\begin{array}{l}\text { GC-S-beta-1, } \\
\text { GUC1B3, GC-SB3 }\end{array}$ & 222 \\
\hline Map kinase phosphatase-M B2 & Mus musculus & AF345954 & & MKP-7 & 245 \\
\hline mitochondrial DNA D-loop region & Sus scrofa & D16483 & 89 & control region & 252 \\
\hline $\begin{array}{l}\text { mitochondrial NADH dehydrogenase } \\
\text { subunit } 4\end{array}$ & Sus scrofa & AJ002189 & 100 & NADH4 & 158 \\
\hline $\begin{array}{l}\text { mitochondrial NADH dehydrogenase } \\
\text { subunit } 6\end{array}$ & Sus scrofa & AF304203 & 100 & NADH6 & 182 \\
\hline Mc7protein & Mus musculus & AJ278191 & 94 & mc7 & 93 \\
\hline SMH-1 & Homo sapiens & AL050310 & 84 & $\begin{array}{l}\text { from clone RP5- } \\
\text { 842K24 GeneBank }\end{array}$ & 124 \\
\hline $\begin{array}{l}\text { SNAP23 (synaptosomal-associated } \\
\text { protein, } 23 \mathrm{kD} \text { ) }\end{array}$ & Homo sapiens & AJ011915 & 88 & SNAP23 & 133 \\
\hline $\begin{array}{l}\text { Transcription factor } 7 \text { (T-cell specific, } \\
\text { HMG-b (TCF7) mRNA }\end{array}$ & Homo sapiens & XM_047719 & 92 & TCF1 & 272 \\
\hline $\begin{array}{l}\text { Ubiquitin-like, containing PHD and RING } \\
\text { finger domains, } 1\end{array}$ & Homo sapiens & XM_035627 & 90 & $\begin{array}{l}\text { UHRF1, Np95; } \\
\text { ICBP90; FLJ21925 }\end{array}$ & 219 \\
\hline
\end{tabular}

B)

\begin{tabular}{|c|c|c|c|c|c|}
\hline Gen & Species & GenBank-Nr. & Homologie (\%) & Synonyme & bp \\
\hline ß-amyloid b-protein precursor & Sus scrofa & $\mathrm{AB} 032550$ & 100 & $\begin{array}{l}\text { AD1, amyloid beta } \\
\text { (A4) precursor protein }\end{array}$ & 148 \\
\hline cingulin & Homo sapiens & AF263462 & 88 & KIAA1319 protein & 689 \\
\hline $\begin{array}{l}\text { DDEF1( development and differentiation } \\
\text { enhancing factor } 1 \text { ) }\end{array}$ & Homo sapiens & NM_018482 & 97 & $\begin{array}{l}\text { PAP, AGNC: } 15640, \\
\text { ZG14P, KIAA1249, } \\
\text { ASAP1 }\end{array}$ & 57 \\
\hline FAT tumor suppressor gene & Sus scrofa & AF255344 & 100 & CDHF7 & 587 \\
\hline $\begin{array}{l}\text { Ig gamma heavy-chain, membrane- } \\
\text { bound-type and secrete-type }\end{array}$ & Homo sapiens & D78345 & 97 & $\lg G 3$ & 673 \\
\hline Interleukin 7 & Sus scrofa & AD049327 & 96 & IL-7 & 63 \\
\hline $\begin{array}{l}\text { muscle lambda zap } 2 \text { (SMLZ-2) similar to } \\
\text { U07802 TIS11d }\end{array}$ & Sus scrofa & AA063667 & 98 & BRF2, ERF-2, TIS11d & 99 \\
\hline Myosin 5B & Homo sapiens & AB032945 & 83 & KIAA1119 & 201 \\
\hline NADH-ubiquinone oxidoreductase chain 4 & Sus scrofa & AF304203 & 97 & NADH4 & 158 \\
\hline retinoic acid receptor, alpha & Homo sapiens & U41743 & 93 & RARA & 420 \\
\hline ribosomal protein L3 & Sus scrofa & AF203699 & 100 & RPL3 & 133 \\
\hline SLA-DQ haplotype d & Sus scrofa & M29939 & 98 & SLA-DQ & 300 \\
\hline SLA-DQ haplotype c & Sus scrofa & M29938 & 98 & SLA-DQ & 300 \\
\hline Nascent-polypeptide-associated complex & Homo sapiens & AJ278883 & 85 & Alpha-NAC & 311 \\
\hline STK12 (serine/threonine kinase 12) & Sus scrofa & AF244364 & 100 & $\begin{array}{l}\text { ARK2, AIM-1, IPL1, } \\
\text { Aik2 }\end{array}$ & 472 \\
\hline SON (SON DNA-binding protein); SON3 & Homo sapiens & AY072691 & 93 & $\begin{array}{l}\text { DBP-5, KIAA1019, } \\
\text { NREBP }\end{array}$ & 525 \\
\hline Thyreoid receptor interacting protein 7 & Homo sapiens & L40357 & 90 & TRIP7 & 247 \\
\hline
\end{tabular}

Tabelle 5:

A) Übersicht über die korrespondierenden Gene, die Spezies, die GenBank-Nummer, die prozentuale Homologie, die Synonyme, die Basenpaarlänge und die Regulation zu den detektierten differentiell herunterregulierten mRNA-Sequenzen. B) Übersicht über die korrespondierenden Gene, die Spezies, die GenBank-Nummer, die prozentuale Homologie, die Synonyme, die Basenpaarlänge und die Regulation zu den detektierten differentiell hochregulierten mRNA-Sequenzen. 
Die mRNA-Expression von FLJ22116, GUCY1B3, MKP-7, mitochondrial DNA D-loop region, NADH4, NADH6, mc 7 Protein, SMH-1, SNAP23 (Abb. 24), TCF7 und UHRF1 wurden nach einer Reperfusionsdauer von 3 Stunden differentiell herunterreguliert.

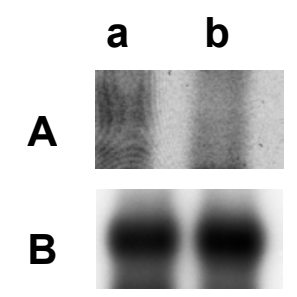

Abbildung 24:

Differentielle Herunterregulation von SNAP23 mRNA (oben) und Kontrolle B-Actin mRNA (unten) und a) vor HTK-Perfusion und b) 3 Stunden nach Reperfusion.

SNAP23 wurde mittels In-situ-Hybridisierung in der Membran der submukosalen Muskelzellen nachgewiesen (Abb. 25).

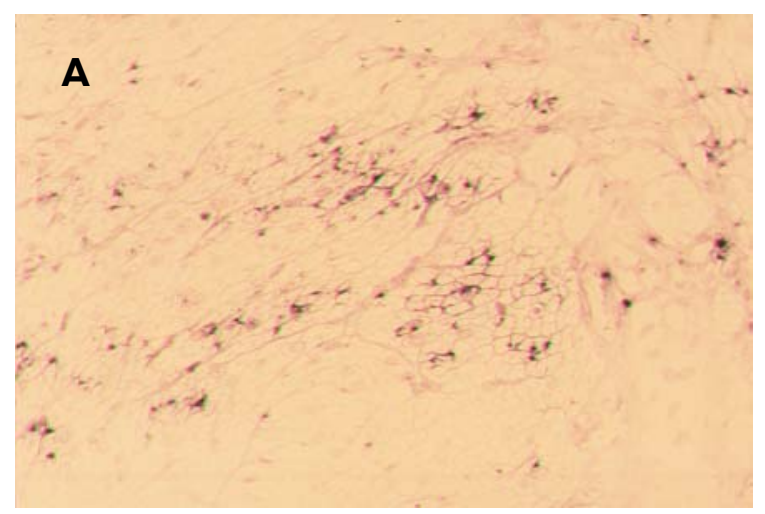

B

Abbildung 25:

In-situ-Hybridisierung von SNAP23 mRNA vor HTK-Perfusion (A) und 3 Stunden nach Reperfusion (B).

Eine der differentiell herunterregulierten Banden wies eine 84 \%ige Homologie zu einer bekannten DNA-Sequenz auf, die einen Teil eines neuartigen ZinkFingerproteins aufweist und unter der GenBank „Accession Number“ AL050310 registriert ist. Die korrespondierende, von uns identifizierte mRNA-Sequenz, nannten wir SMH1 (Abb. 26). Die Expression von SMH-1-mRNA wurde durch Slot-Blot Technik verifiziert. Die SMH-1 mRNA war zum Ende der KIZ hochreguliert, jedoch nicht vor Perfusion mit HTK-Lösung. Die Expression der SMH-1 mRNA war nach einer KIZ von 20 Stunden höher als nach einer $\mathrm{KIZ}$ von 2 Stunden. Interessanterweise konnte die SMH-1 mRNA-Expression noch 3 Stunden nach Reperfusion nachgewiesen werden, jedoch nicht mehr nach einer Reperfusionsdauer von 7 Stunden (Abb. 27). 


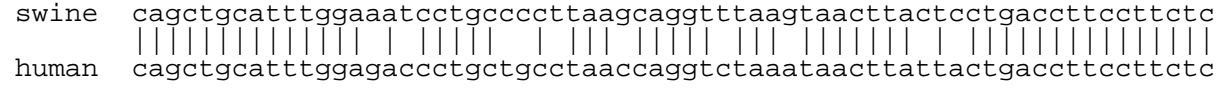

Abbildung 26:

mRNA Sequenz von SMH-1.

SMH-1

$\begin{array}{llll}\text { vor } & \text { Ende } & 3 \mathrm{~h} & \mathbf{7 h} \\ \text { HTK } & \text { KIZ } & & \end{array}$

ß-Actin (Kontrolle)

vor Ende $3 \mathrm{~h} \quad 7 \mathrm{~h}$

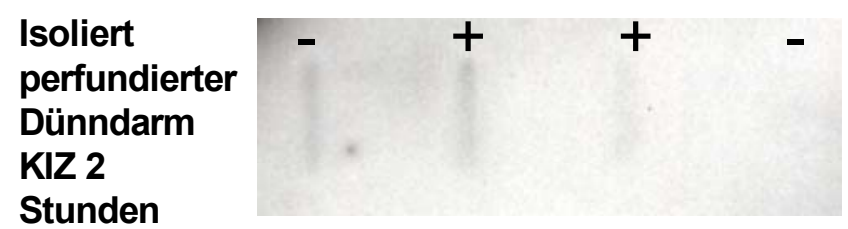

Isoliert

perfundierter

Dünndarm

KIZ 20

Stunden
HTK KIZ
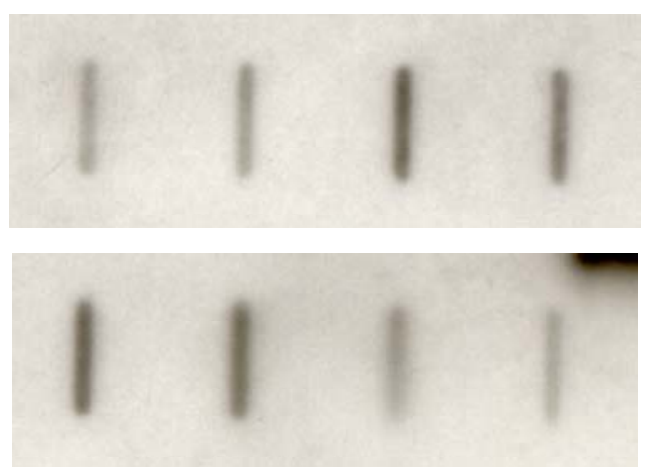

\section{Abbildung 27:}

Nachweis der Expression von SMH-1 mRNA im Schweinedünndarm vor HTK-Perfusion, am Ende der KIZ sowie nach einer Reperfusionsdauer von 3 und 7 Stunden. Die Slot-Blot Analyse des Dünndarmgewebes mit einer KIZ von 2 Stunden ist im oberen Blot dargestellt und nach einer KIZ von 20 Stunden im unteren Blot.

Die SMH-1 mRNA-Expression konnte mittels In-situ-Hybridisierung in submukosalen glatten Muskelzellen nachgewiesen werden (Abb. 28).
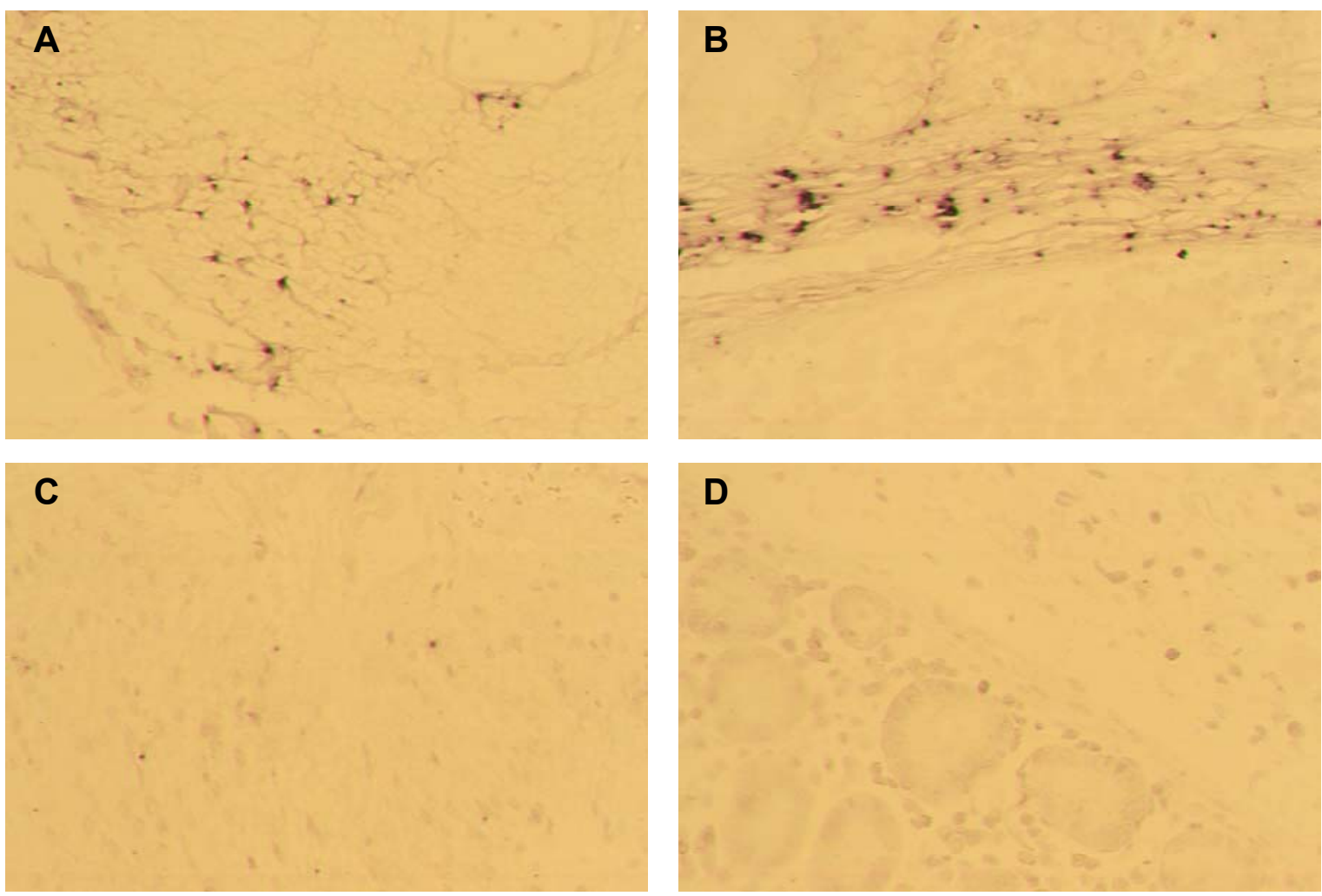

Abbildung 28: Lokalisation der SMH-1 mRNA-Expression im Schweinedünndarm mittels In-situHybridisierung: A) vor HTK-Perfusion, B) vor HTK-Perfusion, C) 2 Stunden KIZ und 3 Stunden Reperfusion und D) 2 Stunden KIZ und 7 Stunden Reperfusion. 
Im Gegensatz hierzu wurden die mRNA-Sequenzen von AD1, cingulin, DDEF1, FAT, Ig gamma heavy-chain, NADH4, SMLZ-2, RARA, RPL3, SLA-DQ, IL-7, alpha-NAC, MXO5B, STK12 und TRIP7 nach 3 Stunden Reperfusion differentiell hochreguliert.

Die differentiell hochregulierte Bande, die als SLA-DQ identifiziert wurde, zeigte eine 98 \%ige Homologie zu SLA-DQ mRNA Haplotyp c und d (Abb. 29). Eine Expression der SLA-DQ mRNA konnte bereits vor und nach Perfusion mit HTK-Lösung im Northern-Blot nachgewiesen werden. Unmittelbar nach Reperfusion stieg die SLADQ mRNA-Expression an und blieb erhöht bis zum Ende der Reperfusionsphase (Abb. 30).

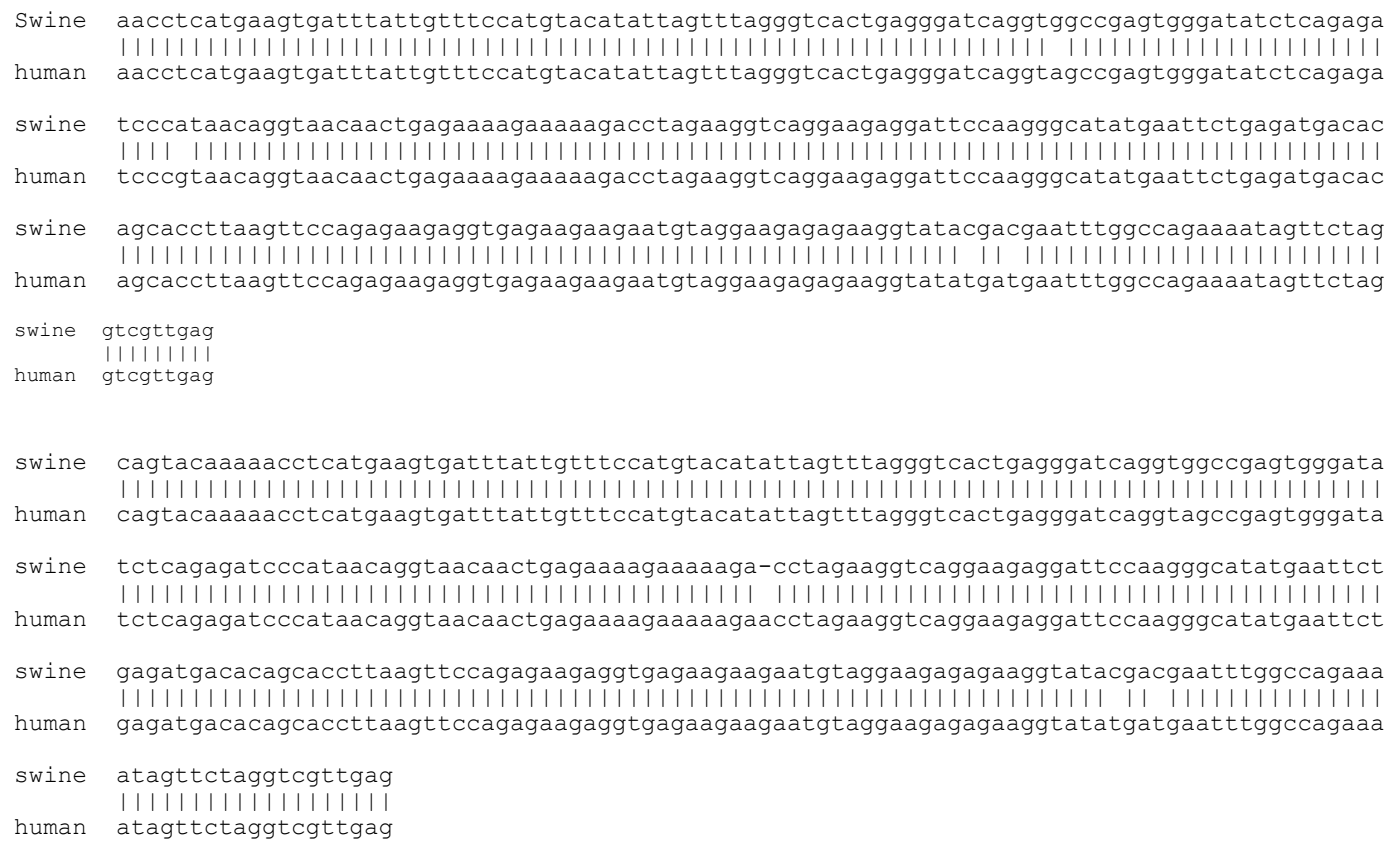

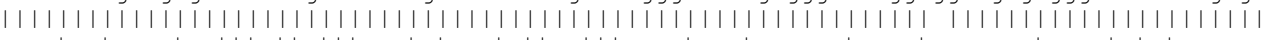

Abbildung 29:

mRNA-Sequenz von SLA-DQ Haplotyp c (oben) und d (unten).

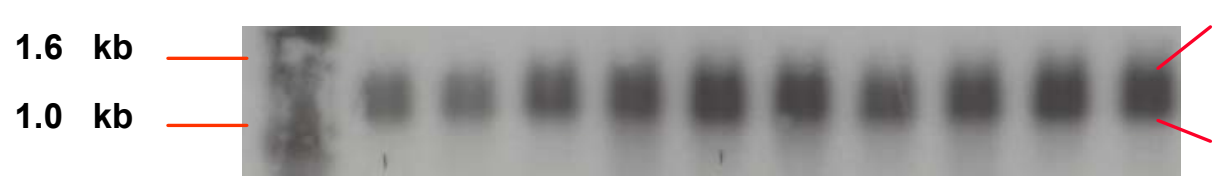

SLA-DQ d 1174 bp

\section{$1.0 \mathrm{~kb}$}

SLA-DQ c 1105 bp

$1.9 \mathrm{~kb}$

$1.6 \mathrm{~kb}$

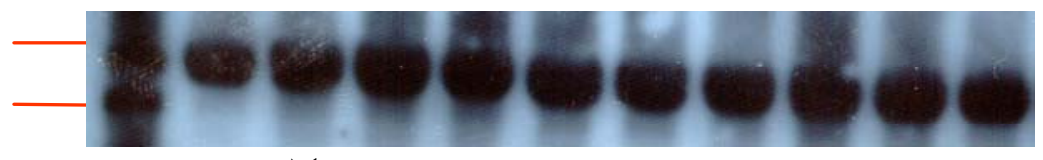

B-Actin

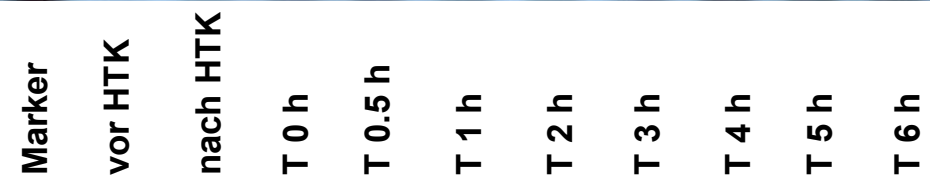

Abbildung 30:

Northern-Blot der SLA-DQ mRNA im Dünndarmgewebe bei einer KIZ von 2 Stunden. 
Mittels In-situ-Hybridisierung konnte im Dünndarmgewebe nach einer KIZ von 2 Stunden und einer Reperfusionsdauer von 6 Stunden SLA-DQ mRNA im mukosalen Epithel und in submukosalen Endothelzellen nachgewiesen werden (Abb. 31).
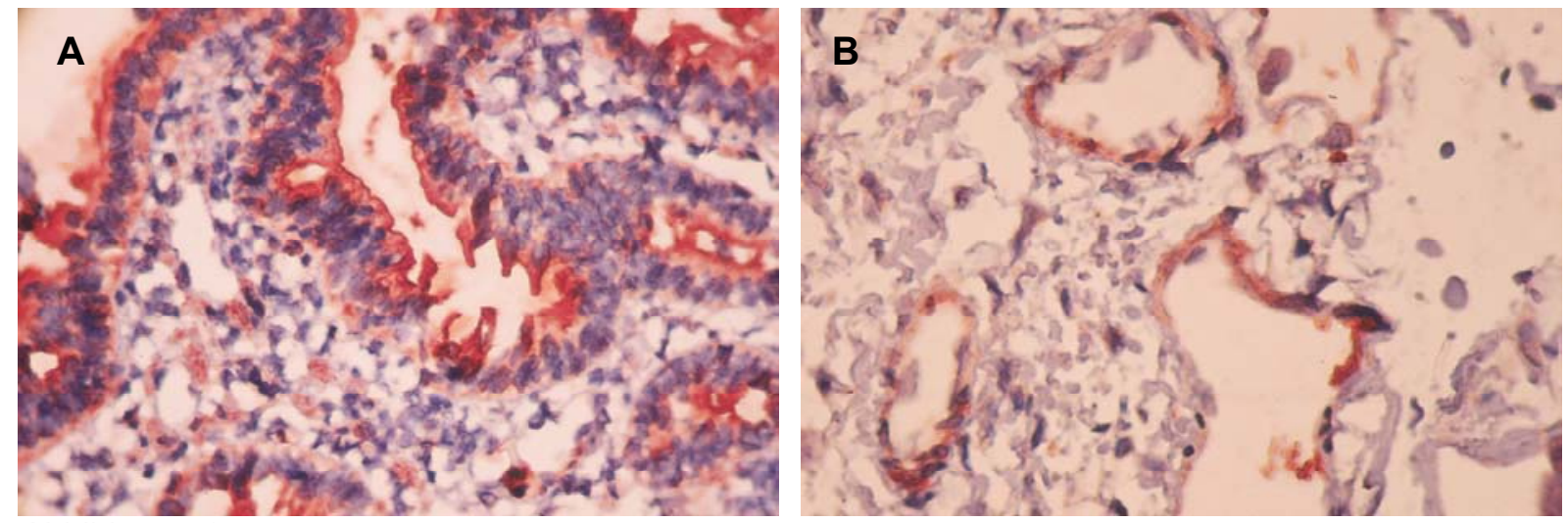

\section{Abbildung 31:}

Nachweis der MHC II (SLA-DQ Haplotyp d und c) mRNA-Expression im Schweinedünndarm mittels In-situ-Hybridisierung nach einer KIZ von 2 Stunden und einer Reperfusionsdauer von 6 Stunden.

IL-7 wurde über ein differentielles mRNA-Display 3 Stunden nach Reperfusion identifiziert. Die differentielle Expression von IL-7 konnte über Northern-BlotAnalysen mit Gesamt-RNA bestätigt werden (Abb. 32).

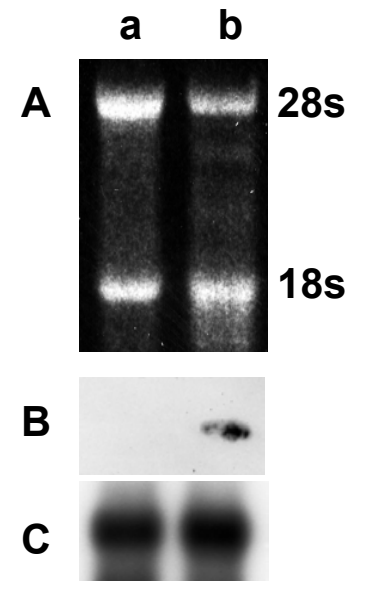

Abbildung 32:

RNA-Gel (A), differentielle Hochregulation von IL-7 mRNA (B), Kontrolle B-Actin mRNA (C), vor HTK (a) und 3 Stunden nach Reperfusion (b)).

Zur Bestätigung der im mRNA-Differential Display ermittelten differentiellen Expression von Myosin 5B (Abb. 33) und alpha-NAC (Abb. 34) wurde ein NorthernBlot mit Gesamt-RNA durchgeführt.

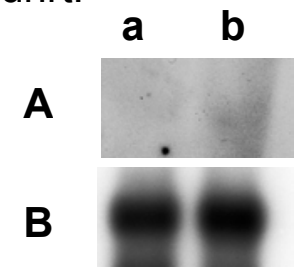


A

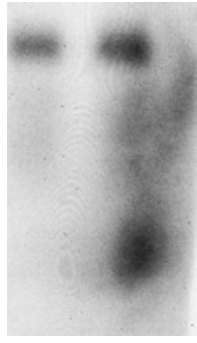

B

Abbildung 34:Differentielle Hochregulation von alpha-Nac mRNA (A) und Kontrolle ß-Actin mRNA (B).

Vier neu entdeckte partielle CDS mRNA-Sequenzen von differentiell hochregulierten Genen wurden in der GenBank registriert. Zu den 4 neu entdeckten Genen gehören Sus scrofa FAT tumor suppressor gene (GenBank AF255344; 100 \%ige Homologie; synonym: CDHF7; 587 bp), Sus scrofa ribosomal protein L3 (GenBank AF203699; 100 \%ige Homologie; synonym: RPL3; 133 bp), Sus scrofa Serin/Threonin kinase 12 (GenBank AF244364; 100 \%ige Homologie; Synonym: ARK2, AIM-1, IPL1, Aik2; 472 bp) und Sus scrofa SON DNA-Binding Protein (GenBank AY072691; 93 \%ige Homologie; Synonym: DBP-5, KIAA1019, NREBP; 525 bp).

Die Serin/Threonin kinase 12 wurde mittels In-situ-Hybridisierung mit Digoxygenin markierten Antisense RNA Sonden in mukosalem Epithel und in submukosalen Endothelzellen sowie in Lymphozyten der Submukosa lokalisiert (Abb. 35).
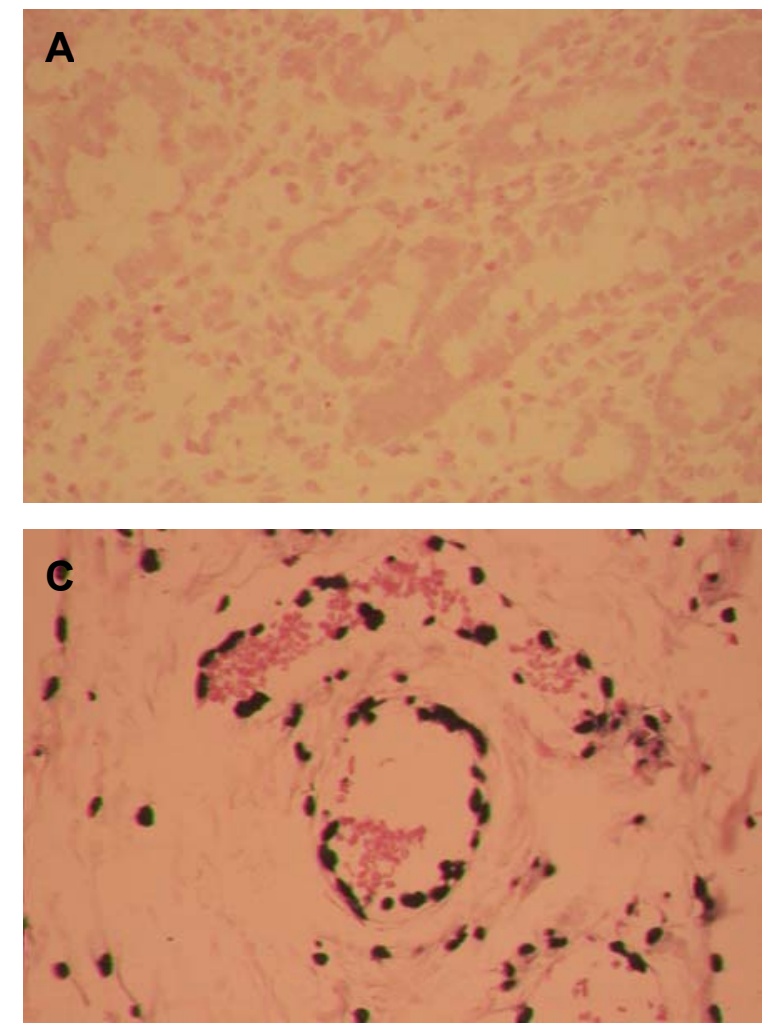

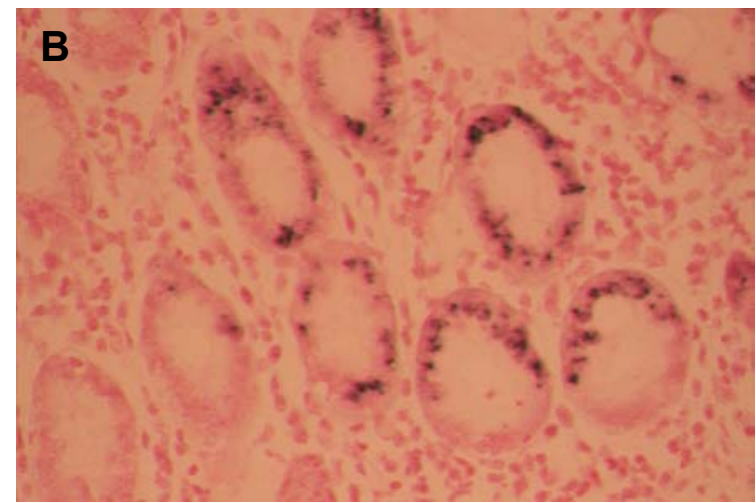

Abbildung 35:

In-situ-Hybridisierung von STK12 (Serin/Threonin kinase 12) vor HTKPerfusion (A) und 3 Stunden nach Reperfusion (B, C). 
Die Methode der RACE-PCR wurde eingesetzt, um das 3'-Ende einer EST Sequenzhomologie zu identifizieren. Das amplifizierte und aus dem Agarose Gel isolierte Fragment mit einer Länge von 525 bp besaß in der GenBank Analyse eine 93 \%ige Homologie zu Homo sapiens Son DNA bindendem Protein. Diese identifizierte Sequenz wurde in der GenBank unter der „Accession Number“ AY072691 registriert (Abb. 36), auf dem Northern-Blot analysiert (Abb. 37) und mittels In-situHybridisierung lokalisiert (Abb. 38).

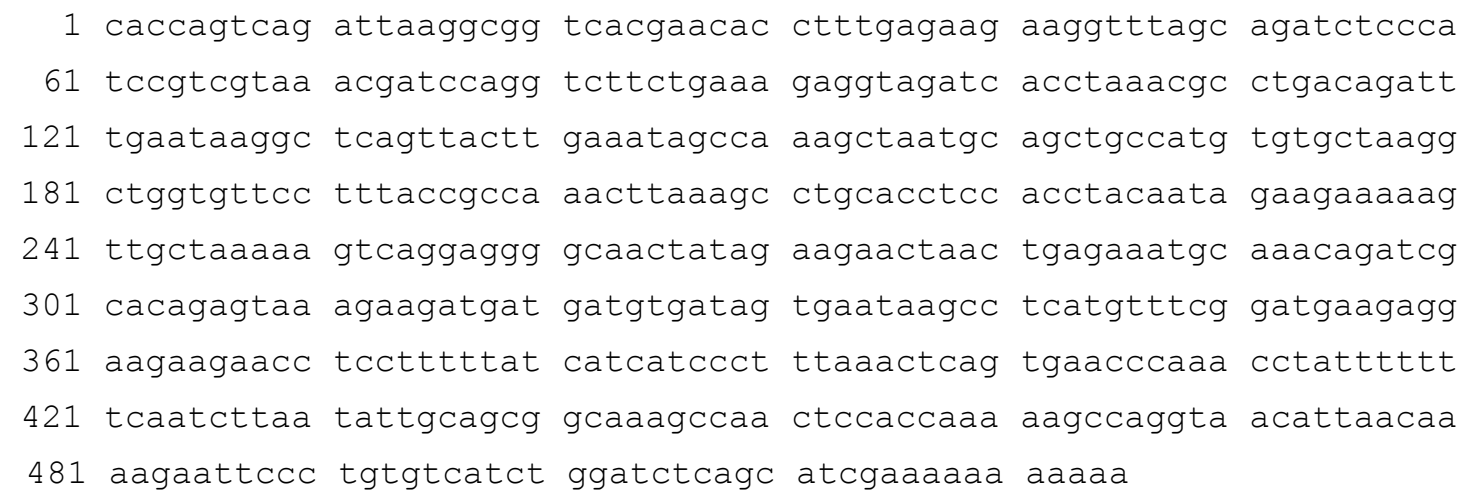

Abbildung 36:

mRNA-Sequenz von Sus scrofa Son DNA bindendem Protein (GenBank AY072691).

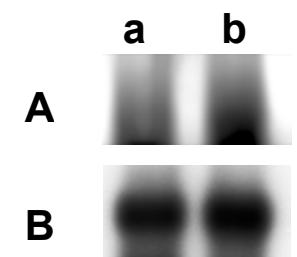

Abbildung 37: Differentielle Hochregulation von SON3 mRNA (oben) und Kontrolle B-Actin mRNA (unten)
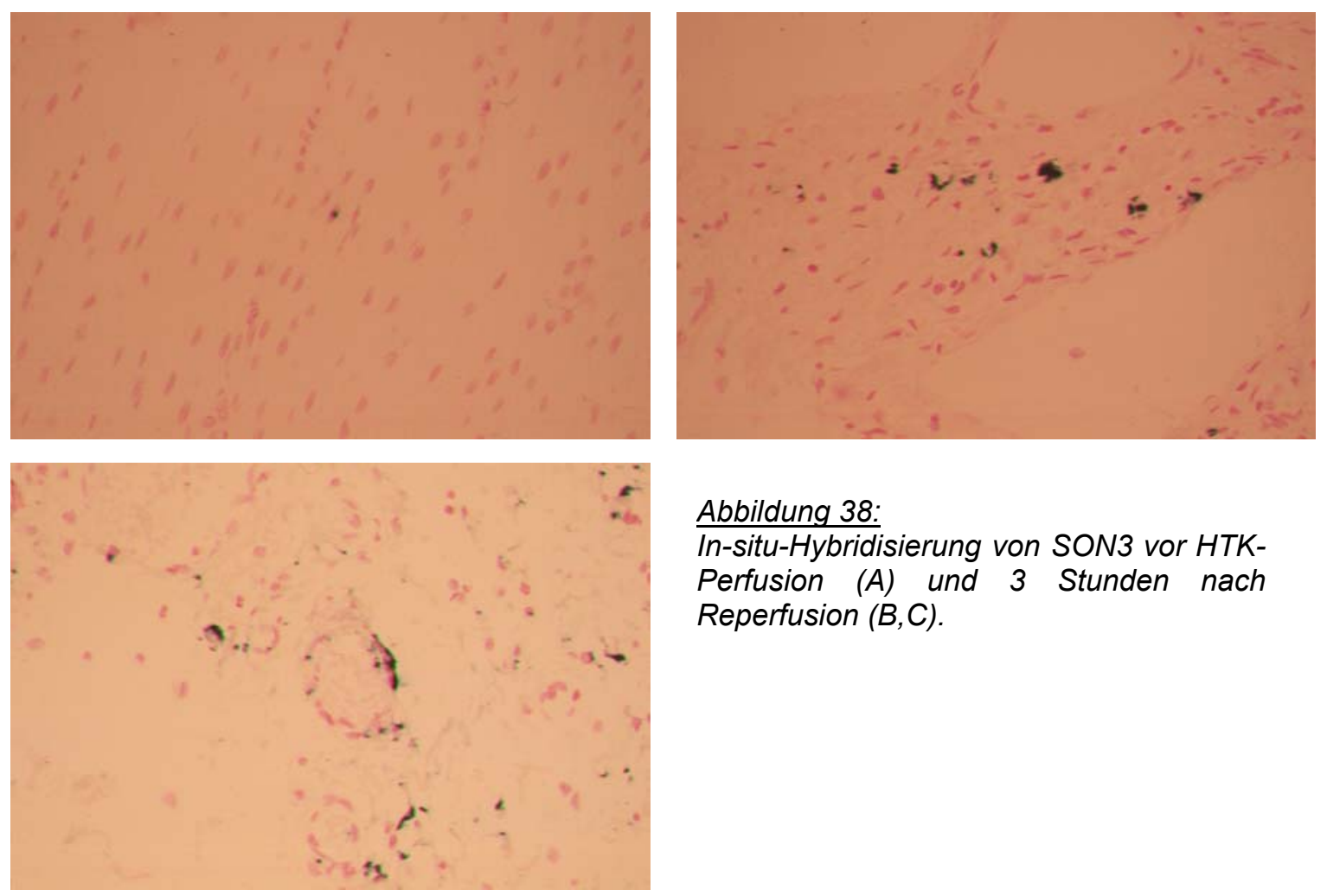

Abbildung 38:

In-situ-Hybridisierung von SON3 vor HTKPerfusion (A) und 3 Stunden nach Reperfusion $(B, C)$. 


\section{DISKUSSION}

Der Dünndarm steht über die Mukosa in direktem Kontakt zur Außenwelt, die pathogene Mikroorganismen, Toxine und Pankreasenzyme enthält. Die gastrointestinale Barriere bildet ein natürliches Schutzschild gegenüber der Außenwelt und schützt das Individuum vor potentiell schädigenden Einflüssen. Der intestinale Ischämie-Reperfusionsschaden führt zur mukosalen Schädigung und somit zur Zerstörung der gastrointestinalen Barriere (Cicalese et al. 2001).

Der Ischämie-Reperfusionsschaden induziert komplexe Schädigungs- und Reparaturmechanismen. Ein tiefergehendes Verständnis der komplexen Pathophysiologie des intestinalen Ischämie-Reperfusionsschadens erscheint daher erforderlich, um effektive Interventionsstrategien zur Limitierung des IschämieReperfusionsschadens zu entwickeln. Die isolierte Immunantwort des Dünndarms ist in den meisten Tierexperimenten schwer zu interpretieren, da sie durch eine systemische Immunantwort überlagert wird. Deshalb erscheint es sinnvoll, den intestinalen Ischämie-Reperfusionsschaden in einem isolierten extrakorporalen Dünndarmperfusionssystem zu untersuchen.

In unserem Modell resultierte der Ischämie-Reperfusionsschaden in einer mukosalen Schädigung, die von den Spitzen der Villi ihren Ursprung nahm und basiswärts voranschritt. Die mukosale Schädigung trat erst nach Reperfusion der Dünndärme auf, wobei eine Verlängerung der kalten Ischämiezeit von 2 auf 20 Stunden in einer frühzeitigeren und initial schwereren mukosalen Schädigung resultierte. Das Ende der Reperfusionsphase war durch eine Denudation der Villi, Ödeme und Hämorrhagien gekennzeichnet. Der Verlauf der mukosalen Schädigung nach Reperfusion entsprach den Beobachtungen von Chiu et al., die den Reperfusionsschaden im Rattenmodell histologisch charakterisiert haben (Chiu et al. 1970). In unserem Modell war der Reperfusionsschaden mit einem Anstieg des arteriellen Druckes bei gleichbleibender Volumenstromstärke verbunden. Diese Beobachtung kann durch eine Umverteilung des Blutflusses durch spontan eröffnete "shunts" erklärt werden und spiegelt das Eintreten einer mit zunehmender Dauer der Reperfusionsphase progredienten Mikrozirkulationsstörung wider.

Als Mediatoren der intestinalen Ischämie-Reperfusionsschädigung haben wir zunächst Parameter nachgewiesen und lokalisiert, deren Rolle als proinflammatorische Mediatoren in der Pathophysiologie des Ischämie- 
Reperfusionsschadens bekannt waren. Als Parameter wurden zunächst Interleukin-6 (IL-6), Interleukin-2 (IL-2), das Hitze-Schock-Protein 70 (HSP70), Interferon gamma (IFN $\gamma$ ) und E-Selektin untersucht.

\subsection{Proinflammatorische Mediatoren}

Die Nukleotidsequenzen des IL-6-Gens und des für den "granulocyte-colony stimulating factor" (G-CSF) kodierenden Gens zeigen Ähnlichkeiten, was auf eine evolutionäre Verwandtschaft hinweist. Das IL-6 Gen besteht aus fünf Exons und vier Introns und enthält zahlreiche regulatorische Elemente ("enhancer elements"), die u.a. auf Glukokortikoide reagieren. Die wichtigsten IL-6-Produzenten sind stimulierte Monozyten/Makrophagen, Fibroblasten, Monozyten/Makrophagen, Epithel- und Endothelzellen, glatte Muskelzellen, T- und B-Lymphozyten sowie multiple Tumorzellinien, die IL-6 als autokrinen Wachstumsfaktor benötigen. Die IL-6Synthese wird durch bakterielle Lipopolysaccharide, Viren, verschiedene Zytokine wie IL-1, TNF $\alpha$, IFN $\gamma$ und GM-CSF induziert und gesteigert. Während Monozyten/Makrophagen vorzugsweise durch bakterielle Lipopolysaccharide stimuliert werden, reagieren Endothelzellen besser auf die endogenen Zytokine IL-1 und TNF $\alpha$, deren Wirkung durch die beiden "second messenger"-Systeme Proteinkinase $\mathrm{C}$ und Adenylatcyclase vermittelt wird und zu einer gesteigerten IL-6Transkription führt. Als Zytokin bewirkt IL-6 die terminale Differenzierung von durch IL-4 und IL-5 aktivierten B-Zellen zu immunglobulinsezernierenden Plasmazellen, Aktivierung und Proliferation von T-Zellen und zusammen mit IL-2 die Aktivierung von zytotoxischen T-Zellen. Zusätzlich führt es über eine Aktivierung von Megakaryozyten zur Thrombozytose (Hyams et al. 1993) und wirkt neben IL-1, TNF $\alpha$ und Interferon als starkes endogenes Pyrogen. Muraoka et al. zeigten, dass die Aktivierung des IL-6 Gens ein durch Hypoxie vermittelter Prozess ist. Sie zeigten in einem in vitro-Versuch, dass Hypoxie aber nicht Reoxygenierung die Aktivierung von

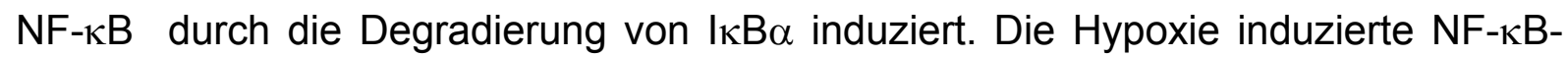
Aktivierung resultiert in der $\mathrm{kB}$ ähnlichen transkribierenden Aktivierung des IL-6-Gens (Muraoka et al. 1997). In Übereinstimmung mit Muraoka et al. fanden wir, dass die IL-6 mRNA-Expression nach 20 Stunden, aber nicht nach 2 Stunden kalter Lagerung vorhanden war. Muraoka et al. spekulieren, dass die massive Produktion von reaktiven Sauerstoffzwischenstufen ("reactive oxygen intermediates", ROIs) unter hypoxischen Bedingungen unwahrscheinlich ist. Aber es könnte möglich sein, dass 
eine sehr geringe Menge ROls bei niedrigem Sauerstoff produziert wird und somit die NF-kB-Aktivierung vermittelt (Muraoka et al. 1997). Rauen und Groot beschrieben, dass tatsächlich die ROls eine entscheidende Rolle an hypothermischen Schäden in diversen Säugetierzellen spielen. Bei Leber- und Nierenzellen z. B. scheinen sie den entscheidenden Beitrag zum Entstehen des hypothermischen Schadens zu leisten, und dabei noch wichtiger $\mathrm{zu}$ sein als das Gleichgewicht der zellulären Ionenhomeostase (Rauen u. Groot 2002). Interessant ist aber, dass die Expression von IL-6 mRNA, die nach 20 Stunden KIZ produziert wurde, nach intestinaler Reperfusion mit Schweine-Vollblut vorübergehend zurückging. Diese Feststellung impliziert, dass Prozesse, die die IL-6 mRNA-Expression inhibieren, während der frühen Phase der Reperfusion initiiert werden. Es ist bekannt, dass Glucocorticoide, IL-4, IL-10, IL-13, NO und Prostaglandin E2 die IL-6 Expression vermindern (Biff et al. 1996). Kukielka et al. beschrieben einen Anstieg der IL-6 Konzentrationen in der Reperfusionsphase nach Ischämie im Myokard des Kaninchens, wobei maximale IL6 Konzentrationen nach 3 Stunden Reperfusion auftraten (Kukielka et al. 1994). Unsere Ergebnisse der hochregulierten IL-6 mRNA-Expression während der Reperfusion stimmen bezüglich des zeitlichen Verlaufs mit den Resultaten von Kukielka et al. überein. Wir konnten die Expression von IL-6 mRNA mittels In-situHybridisierung in Endothelzellen, Monozyten und sogar in glatten Muskelzellen und Ganglienzellen nachweisen. Kürzlich wurde die Modulation der IL-1 $\beta$ induzierten IL6-Produktion in intestinalen glatten Muskelzellen der Ratte demonstriert. Van Assche et al. schlossen daraus, dass diese Interaktion zu einer veränderten Muskelfunktion während intestinaler Inflammation beitragen könnte (van Assche et al.1999). Die Rolle der IL-6 mRNA-Expression in Endothelzellen, in glatten Muskelzellen und in Ganglienzellen ist noch nicht vollständig geklärt, weist aber auf eine mögliche Rolle dieser Zellen als Quelle der IL-6-Synthese während des intestinalen IschämieReperfusionsschädens hin.

Zur Synthese von IL-2 brauchen die T-Zellen unter physiologischen Bedingungen einen von außen kommenden Stimulus. Dies kann entweder ein Antigen oder ein Mitogen sein. Unterstützung erfährt die Synthese durch IL-1. IL-2 fördert weiterhin autokrin die eigene Synthese, aber dazu muss der IL-2 Rezeptor exprimiert werden. IL-2 besitzt eine zentrale Rolle bei intestinalen Entzündungsreaktionen. Der IL-2 und der IL-2 Rezeptor werden während Entzündungsprozessen hoch reguliert, und die 
Hemmung IL-2 produzierender Zellen hat einen günstigen Einfluss auf die intestinale Entzündungsreaktion (Fiocchi 1996). Die Expression von IL-2 in unserem Modell zeigte einen zweiphasigen Verlauf: Unmittelbar nach Beginn ( 0 Stunden Reperfusion) und 7 Stunden nach Reperfusion waren Sie am ausgeprägtesten. In einem Ischämie-Reperfusionsmodell der Hundelunge konnte eine erhöhte IL-2Freisetzung in der Bronchiallavage 4 Stunden nach Reperfusion nachgewiesen werden (Serrick et al. 1994). In dieser Arbeit wurde IL-2 mRNA erstmalig im Dünndarm mittels In-situ-Hybridisierung in Gefäßendothelzellen, Lymphozyten der Submukosa, Lymphozyten der Mukosa, Zellen um die Ganglien herum und Gefäßendothelzellen im Bereich der "Muscularis propria" nachgewiesen. Da IL-2 nur von T-Zellen und eventuell NK-Zellen synthetisiert werden kann und ebenso relativ begrenzt auf T-Zellen, B-Zellen, NK-Zellen und Vorgänger-LAK-Zellen (Lymphokinaktivierte "Killer-Zellen") wirkt, könnte es in das Bild eines selektiv erhöhten Aktivierungsstatus' von T-Zellen passen. Der erhöhte Aktivierungsstatus, bestehend aus einer vermehrten Expression von MHC II, IL-2 Rezeptor und dem Transferin Rezeptor (Zeitz et al. 1988), könnte durch eine konstitutionelle IL-2-Synthese hervorgerufen werden, die regional begrenzt $v$. a. die T-Zellen in einen ebenso begrenzten Aktivierungszustand versetzt. Unter den IL-2 sezernierenden Lymphozyten stellen $\mathrm{CD} 4^{+}$T-Zellen die Hauptgruppe, während $\mathrm{CD} 8^{+}$T-Zellen nur wenig zur IL-2-Synthese beitragen (Kusugami et al. 1991). Wegen seiner Wirkung auf T- und B-Zellen gilt IL-2 als zentrales Regulatormolekül der Immunantwort (Fiocchi 1992, Ibelgaufts 1992).

Die Hitze-Schock-Proteine sind durch ihre Funktion als "Chaperone" am Transport und Schutz von Proteinen als Antwort auf zellulären Stress beteiligt. Sie werden universell in Eukaryontenzellen gebildet und wurden als erstes bei thermischem Stress (Hitze, Kälte) beschrieben, woher der Name stammt (Craig u. Gross 1991, Kregel u. Moseley 1996). Die Produktion von HSP wird über zwei Gene (HSF1 und 2) reguliert, die durch Stress vermutlich über ein membrangebundenes Sensorprotein und den HSE-Komplex aktiviert werden (Hightower 1991, Locke u. Tanguay 1996 , Morimoto 1993, Morimoto 1991). Die HSP70-Expression wurde durch IschämieReperfusion (Marber et al. 1995, Radford et al. 1996) sowie durch Hypoxie induziert, wodurch postischämische Schäden vermindert wurden. Die Hitze-Schock-Proteine erhöhen die Stresstoleranz bei Ischämie. Dass HSP eine wichtige Rolle bei der 
antiischämischen Reaktion der Zelle spielt, wurde zuerst am Herzen gezeigt, wo ischämisches "Preconditioning" die Infarktgrösse verringert. Myokardiales HSP wird kurz nach Ischämie gebildet (Knowlton et al. 1991). Die HSP-Antwort korreliert mit der Myokardprotektion, die durch Hyperthermie erzeugt wird (Currie et al. 1993). Die Expression von HSP70 wurde in unserem Modell mittels semi-quantitativer RT-PCR und durch quantitative RT-PCR (Light Cycler $^{R}$ ) während der gesamten IschämieReperfusion nachgewiesen, wobei nach einer KIZ von 20 Stunden eine erhöhte Expression nachweisbar war. Als wesentliche Faktoren für die HSP-Induktion wurden bisher metabolische Faktoren, Energieverarmung und freie Radikale diskutiert. In einem extrakorporalen Schweine-Leberperfusionsmodell wurde gezeigt, dass die HSP70 Expression von der Dauer der KIZ und der hepatozellulären Energiereserve abhängig ist (Schütz et al. 1997). In unserem Modell stieg die HSP70 Expression in der Reperfusionsphase an. Reperfusion bedeutet einen besonders hohen oxidativen Stress und HSF wird aktiviert. Ein erhöhtes myokardiales HSP wurde nach herzchirugischen Eingriffen mit extrakorporaler Zirkulation und Reperfusion beobachtet (Taggart et al. 1997). In Zellkulturversuchen wurde gezeigt, dass HitzeSchock in Astrozyten über Induktion von HSP70 über eine verminderte NF-kBAktivierung zu einer reduzierten iNOS-Expression führte (Feinstein et al. 1996). Darüber hinaus resultierte die Überexpression von HSP70 in Ratten Insulinomzellen in der Hemmung zytotoxischer NO-Effekte (Bellmann et al. 1996). HSP70 mRNA konnten wir zum ersten Mal im Dünndarm mittels In-situ-Hybridisierung in Endothelzellen, glatten Muskelzellen und mukosalen Epithelzellen nachweisen. Eine erhöhte Expression von HSP70 wurde bisher in Endothelzellen (Zhu et al.1994), vaskulären glatten Muskelzellen (Zhu et al. 1995) und auf der Oberfläche von zirkulierenden Leukozyten nach akuter intensiver körperliche Belastung nachgewiesen (Fehrenbach u. Niess 1999). Eine erhöhte mRNA-Expression von HSP70 hängt eventuell mit der Bildung freier Radikale, mechanischer Belastung, zirkulierenden Zytokinen (Pederson et al. 1996) und einer immunologischen Funktion von HSP zusammen. Die HSP70-Expression wird als zellulärer Schutzmechanismus diskutiert, der in einer Reduktion des intestinalen Reperfusionsschadens resultieren kann.

Interferon gamma (IFN $\gamma$ ) wurde ursprünglich als antivirale Substanz im Zellüberstand von Phytohämagglutinin stimulierten Leukozyten entdeckt (Wheelock 1965). IFN $\gamma$, 
auch als Immun-Interferon bezeichnet, wird physiologischerweise nach Aktivierung durch Antigene, Mitogene oder Allogene hauptsächlich von aktivierten NK-Zellen, TH1 Zellen, und zytotoxischen T-Zellen produziert (Boehm et al. 1997). IL-2 induziert ebenfalls die IFN $\gamma$-Synthese. IFN $\gamma$ ist ein potenter Stimulator der MHC II AntigenExpression in humanen und porcinen Endothelzellen (Collins et al. 1984, Murray et al. 1994, Bravery et al. 1995). In Monozyten/Makrophagen induziert IFN $\gamma$ die Sekretion von TNF $\alpha$ sowie die Freisetzung von Sauerstoffradikalen und verstärkt die LPS-induzierte IL-1 $\beta$-Produktion (Arend et al. 1989). IFN $\gamma$ wirkt synergetisch mit IL-1 und IL-2 und scheint für die Expression des IL-2R auf der Zelloberfläche von T-Zellen notwendig zu sein, um auf diese Weise die zellvermittelte Zytotoxizität zu beeinflussen. Eine Hemmung des IL-2R inhibiert ebenfalls die Synthese von IFN $\gamma$. Das durch IL-4 induzierte Wachstum von B-Zellen und die durch IL-4 ausgelöste Produktion von IgG1 und IgE durch LPS-stimulierte B-Zellen wird durch IFN $\gamma$ gehemmt. In unserem Modell war eine IFN $\gamma$ mRNA-Expression vor und nach Reperfusion nachweisbar, wobei die Expression in der Reperfusionsphase zunahm. IFN $\gamma$ konnten wir mittels In-situ-Hybridisierung in der intestinalen Mukosa (Lymphozyten) nachweisen. Über eine konstitutionelle Expression von IFN $\gamma$ mRNA in der Mukosa gibt es bisher keine weiteren Arbeiten. Zwar kann IFN $\gamma$ in vitro durch eine ganze Reihe von Stimuli wie Mitogene, Allogene und gegen den MHC-Komplex gerichtete Antigene, wie auch durch gegen Lymphozytenoberflächenantigene gerichtete Antikörper induziert werden, jedoch scheint die Expression sehr eng reguliert zu sein. Über ein regulatorisches Supressorprotein, wie auch einen posttranslationalen Regulationsmechanismus wird die IFN $\gamma$-Synthese kontrolliert (Chan et al. 1991). Auf Grund des erhöhten Aktivierungsgrades intestinaler T-Zellen wäre eine IFN $\gamma$-Synthese nicht unerwartet gewesen. IFN $\gamma$ induziert die Expression des MHC II und des IL-2 Rezeptors, welche beide auf intestinalen, Antigen präsentierenden Zellen und T-Zellen verstärkt exprimiert werden. Darüber hinaus beeinträchtigt IFN $\gamma$ epitheliale "tight junction" mit der Folge erhöhter intestinaler Permeabilität, induziert intrazelluläre Adhäsionsmoleküle, welche die Transmigration neutrophiler Granulozyten fördern (Jones et al.1995) und verursacht in hohen systematischen Dosen Nekrosen intestinaler Villusspitzen (Sartor 1994).

E-Selektin, welches erstmals von Bevilacqua et al. 1989 charakterisiert wurde, wird von Endothelzellen nach Aktivierung mit Zytokinen, insbesondere IL-1 und TNF $\alpha$ 
oder mit Lipopolysacchariden exprimiert (Bevilacqua et al. 1989). Da die Aktivierung des E-Selektin auf Transkriptionsebene über eine De-Novo-Synthese erfolgt, erreicht die E-Selektin-Konzentration erst nach ca. 4 Stunden ihr Maximum und geht nach ca. 16-24 Stunden auf das Ausgangsniveau zurück (McEver 1997). Auch fanden Wyble et al. eine E-Selektin-Expression in humanen Endothelzellen nach Zusatz von TNF $\alpha$ und IL-1 frühestens nach 2 Stunden, mit maximaler Intensität erst nach 4 Stunden (Wyble et al. 1996). Die Expression von E-Selektin wurde in unserem Modell mittels semi-quantitativer RT-PCR und quantitativer RT-PCR (Light Cycler ${ }^{R}$ ) während der gesamten Ischämie-Reperfusion nachgewiesen, wobei nach einer KIZ von 20 Stunden eine erhöhte Expression wie bei IL-6 und HSP70 nachweisbar war. Interessanterweise war die E-Selektin mRNA-Expression 2 Stunden nach Reperfusion deutlich erhöht. Direkt nach Beginn der Reperfusion erhöhte sich die ESelektin mRNA-Expression in Darmgewebe nach 2 Stunden KIZ, während sie bei 20 Stunden KIZ vermindert wurde. Danach erhöhte sich die E-Selektin mRNAExpression während der Reperfusionsphase kontinuierlich. E-Selektin-mRNA wurde wie IL-2 und HSP70 zum ersten Mal mittels In-situ-Hybridisierung in Endothelzellen des Dünndarms nachgewiesen. Da diese Effekte früh nach Reperfusion auftraten und möglicherweise einen Beitrag zum Ischämie-Reperfusionsschaden leisten, bietet es sich an, E-Selektin als Marker für eine Aktivierung der Endothelzellen zu verwenden. Eine erhöhte E-Selektin mRNA-Expression zeigte sich während der Reperfusion. Die Expression des Gens für das E-Selektin wird durch den Transkriptionsfaktor NF-kB gesteuert (Schindler u. Baichwal 1994). Da dessen Aktivierung über reaktive Sauerstoffspezies erfolgt, die im Normalzustand der Zelle durch eine Balance mit Radikalfängern unterdrückt werden (Lee u. Burckart 1998), wird wahrscheinlich, dass die Wirkung oxidativer Stressfaktoren auf die Zelle zu einer verstärkten Exprimierung von E-Selektin führt. Erhöhte NF-kB-Aktivität wurde schon nach 1 Stunde Reperfusion in einem intestinalen Ischämie-Reperfusionsmodell der Ratte nachgewiesen (Yeh et al. 2000). Collins et al. zeigten, dass die Aktivierung des NF-kB-Pathways zu einer De-Novo-Synthese von E-Selektin mRNA führt (Collins et al. 1995). Die verstärkte E-Selektin mRNA-Expression während der KIZ in unserem Modell reflektiert die Transkription während des hypoxischen Zustandes. In vitro wird E-Selektin mRNA nicht nur allein durch Hypoxie exprimiert, sondern auch durch zusätzliche Stimulatoren wie TNF $\alpha$ oder LPS hochreguliert (Zund et al 1996). Wir konnten eine transmurale Richtung der E-Selektin mRNA-Expression feststellen, die 
sich von den mukösen Endothelzellen ausgehend in Richtung der muskulären Endothelzellen bewegte. Dies lässt vermuten, dass Agentien oder Toxine (z. B. LPS) die gastrointestinale Barriere vom Darmlumen aus durchdringen und in die Darmwand wandern, wobei sie Parameter z. B. TNF $\alpha, N F-\kappa B$ induzieren, die konsekutiv die Transkription von E-Selektin während der KIZ stimulieren.

\section{2. mRNA-Differential Display}

Die Komplexität der Schädigungs- und Reperaturmechanismen, die durch den Ischämie-Reperfusionsschaden initiiert werden, lässt die Aktivierung und Deaktivierung verschiedenster Transkriptionsfaktoren vermuten, die an diesen Prozessen beteiligt sind. Die Aktivierung von „early gene response“-Genen scheint einen essentiellen Schritt in der Initiierung des Reperfusionsschadens darzustellen. Die Gene, die die Entstehung des intestinalen Reperfusionsschadens starten und nachgeschaltete Schädigungs- und Reperaturprozesse initiieren, sind bislang weitestgehend unbekannt. Yeh et al. untersuchten den IschämieReperfusionsschaden in Ratten-Jejunumsegmenten, die einer Ischämiezeit von 30 Minuten ausgesetzt wurden. Der Ischämie-Reperfusionsschaden induzierte eine schnelle und prolongierte Aktivierung von NF-KB und AP-1 in den Zellkernen der intestinalen Mukosa und von Epithelzellen. Yeh et al. beschrieben eine organspezifische Immunantwort als Folge der Ischämie-Reperfusionsschädigung, welche durch eine prolongierte Aktivierung von NF-kB und AP-1 unter Beteiligung von NF-kB p50 Dimeren aber ohne Beteiligung von AP-1 c-Jun Protein charakterisiert war (Yeh et al. 2000).

Deshalb verglichen wir nicht geschädigtes und geschädigtes Dünndarmgewebe während des intestinalen Ischämie-Reperfusionsschadens im standardisierten Modell der extrakorporalen Dünndarmperfusion. Als nicht geschädigtes Gewebe wurde ein Dünndarmresektat vor Perfusion mit der Konservierungslösung eingesetzt, und als geschädigtes Gewebe verwendeten wir ein Dünndarmresektat nach einer KIZ von 2 Stunden und einer Reperfusionsdauer von 3 Stunden. Eine Zeitspanne von 3 Stunden nach Reperfusion wurde ausgewählt, da sich in Vorversuchen gezeigt hatte, dass eine Reihe inflammatorischer Mediatoren zu dieser Zeit im Perfusat nachweisbar sind und sich bereits eine mukosale Schädigung manifestiert hat. Als Nachweismethode haben wir das mRNA-Differential Display eingesetzt, welches den Vorteil besitzt, eine Vielzahl hoch- und herunterregulierter Gene zu detektieren. Dazu 
wurde die Gesamt-RNA in einer Reversen Transkription in stabilere cDNA umgeschrieben. Dieses erfolgte durch poly (dT)-Downstream Primer mit einer angehängten spezifischen alternativen Base am 3'-Ende, die zu Beginn des poly (A)Schwanzes der mRNA binden sollen. Für die folgende Amplifikation der cDNA stand neben dem poly (dT)-Downstream Primer ein zweiter "arbitrary" Upstream Primer je durchgeführte PCR zur Verfügung. Die Auftrennung der ursprünglich unterschiedlichen mRNA-Populationen in den Geweben wurde nach der Umschreibung in die cDNA-Fraktionen auf Polyacrylamidgelen vorgenommen. Die cDNA-Banden wurden durch Silberfärbung sichtbar gemacht. Die von Liang und Parde (Liang u. Parde 1992) beschriebene Verfahrensweise der Detektion der cDNABanden beim mRNA-Differential Display beinhaltet die radioaktive Detektion unter Nutzung markierter dNTPs. Die hier angewendete nicht radioaktive Silberfärbung wurde soweit modifiziert, dass eine Sensitivität beim Nachweis von doppelsträngiger DNA von ein bis $10 \mathrm{pg} / \mathrm{mm}^{2}$ erreicht werden konnte, was der Empfindlichkeit radioaktiver Methoden durchaus vergleichbar ist (Bassam et al. 1991). Ein Nachteil des mRNA-Differential Displays ist, dass es keine gezielte Auswahl differentieller Banden für die weitergehende Analyse erlaubt und zudem einen hohen zeitlichen Aufwand erfordert. Jedoch ermöglicht es die Detektion unbekannter Gene, wohingegen bei neueren Methoden wie der "Electronic Microarray" Analyse eine gezielte Untersuchung bekannter Gene im Vordergrund steht und eine grosse Menge von 50-200 $\mu \mathrm{g}$ pro Target und Array für die Hybridisierung benötigt wird.

Eine Vielzahl differentieller Banden wurden auf dem Gel des mRNA-Differential Displays identifiziert. Bei der Suche nach Homologien zu den analysierten mRNASequenzen fanden sich Gene wie SLA-DQ, dessen Rolle bei der IschämieReperfusionsschädigung seit längerer Zeit diskutiert und untersucht wird. Jedoch wurde die Mehrzahl der detektierten Gene bislang nicht im Zusammenhang mit der intestinalen Ischämie-Reperfusionsschädigung beschrieben.

Die Expression von GUCY1B3 mRNA und von MKP-7 mRNA wurde in unserem Modell nach Reperfusion differentiell herunterreguliert. Die Guanylatzyklase katalysiert die Synthese von zyklischem GMP, welches als intrazellulärer "messenger" fungiert (Giuili et al. 1992). MKP-7 ist eine dual-spezifische Phosphatase, die für Mitogen-aktivierte Proteinkinasen (MAPKs) spezifisch ist. Masuda et al. vermuteten, dass MKP-7 die Lokalisation der MAPKs im Zytoplasma determiniert (Masuda et al. 2001). MAPKs werden durch Dephosphorilierung am 
Thyreonin- oder Thyrosinrest inaktiviert oder beide im P-loop durch Proteinphosphatasen katalysiert, die Serin/Threonin-Phosphatasen, ThyrosinPhosphatasen und dual-spezifische Phosphatasen enthalten. Bislang sind 9 MKPs bekannt, und jede MKP besitzt ihre eigene Substratspezifität, Gewebsverteilung und subzelluläre Lokalisation. In Zellkulturen ist MKP-7 überwiegend im Zytoplasma lokalisiert. MKP-7 bindet und inaktiviert p38 MAPK und JNK/SAPK aber nicht ERK (Tanoue et al. 2001).

Ein weiteres herunterreguliertes Gen in unserem Modell ist TCF7 (Synonym TCF1). TCF1 ist als T-Zell spezifischer Transkriptionsfaktor beschrieben worden (van de Wetering et al. 1992). Roose et al. zeigten, dass TCF7 ein Zielgen von TCF4 in Epithelzellen ist. TCF7 -/- Mäuse entwickeln Adenome im Darm und in der Brustdrüse. TCF7 wurde mittels Northern-Blot in 5 von 6 Kolorektalzellinien nachgewiesen, die APC oder onkogenen Mutationen des beta-Catenin besaßen. Roose et al. wiesen nukleäres TCF7-Protein in normalem menschlichen Gewebe, proliferierenden intestinalen Epithelzellen und in Epithelzellen der Brustdrüse nach. TCF7 agiert vermutlich als „feedback“-Transkriptionsrepressor von beta-Catenin in TCF4 Zielgenen. Die Unterbrechung des negativen „feedback-loops“ wird deshalb in der Pathogenese von epithelialen Tumoren diskutiert (Roose et al. 1999).

Ein weiteres differentiell herunterreguliertes Gen in unserem Modell ist UHRF1 (Synonym ICBP90), welches ein neuartiges humanes CCAAT Bindungsprotein ist. ICBP90 ist in die Regulation der Topoisomerase-II-alpha-Expression involviert. Hopfner et al. vermuten, dass ICBP90 an Zellproliferationsprozessen beteiligt ist (Hopfner et al. 2000).

Ebenfalls herunterreguliert in unserem Modell ist das SNAP23-Gen. Die vermutete Funktion von SNAP23, welches als Bestandteil des Rezeptors für den allgemeinen Membranfusionsapparat fungiert, ist die Regulation der Transportvesikel-Bindung und -Fusion (Ravichandran et al. 1996). Bei der Suche nach „immediate-early“ Zytokin responsiven Genen entdeckten Morikawa et al. SNAP23 mittels mRNADifferential Display. SNAP23 wurde durch IL-2, IL-3, IL-5, IL-10, Stammzellfaktor, GCSF, GM-CSF, den Leukämie inhibitorischen Faktor und Erythropoetin induziert. Die Expression von SNAP23 war assoziiert mit dem Ras-Raf-MAPK Signalweg jedoch nicht mit dem JAK-STAT Signalweg. Die Expression von SNAP23 wurde in Herz-, Lungen-, Nieren-, Milz- und Dünndarmgewebe nachgewiesen. Des weiteren zeigte sich, dass SNAP23 während Proliferations- und Differenzierungsprozessen induziert 
wird (Morikawa et al. 1998). Demzufolge hätten wir eine hochregulierte Expression von SNAP23 in unserem Modell erwartet. Interessanterweise wird die SNAP23 mRNA-Expression nach Reperfusion jedoch differentiell herunterreguliert. Die SNAP23 mRNA-Expression wurde mittels In-situ-Hybridisierung in der Membran der submukosalen Muskelzellen nachgewiesen.

Die von uns "SMH-1" benannten Sequenz besitzt eine Homologie zu einer neuen Gensequenz (GenBank AL050310), die Teile eines kürzlich entdeckten Zinkfingerproteins enthält und derzeit noch untersucht wird. Zinkfingerproteine sind eine Untergruppe von Transkriptionsfaktoren. Die SMH-1 mRNA-Expression war nach einer KIZ von 20 Stunden höher als nach einer KIZ von 2 Stunden und nahm nach Reperfusion ab. Die hochregulierte Expression der SMH-1 mRNA während der KIZ lässt vermuten, dass es sich um ein Hypoxie-reguliertes Gen handelt. Die Funktion von $\mathrm{SMH}-1$ ist bislang unbekannt. Die SMH-1 mRNA-Expression konnte mittels In-situ-Hybridisierung in submukosalen glatten Muskelzellen nachgewiesen werden. Weitere Untersuchungen sind notwendig, um zu prüfen ob SMH-1 als Parameter zu Detektion Hypoxie vermittelter Schädigung geeignet ist.

"Amyloid beta (A4) protein precursor" (APP) mRNA wurde in unserem Modell differentiell hochreguliert. APP wird in der Pathophysiologie des Morbus Alzheimer diskutiert (McLendon et al. 2000). Oxidativer Stress soll zu Amyloid Ablagerungen führen, die bei Morbus Alzheimer auftreten. Fowler et al. vermuten, dass oxidativer Stress zum Verlust von Phosphoinositiden und somit zur Diacylglycerol-vermittelten Aktivierung der Proteinkinase C (PKC) führt. Die Aktivierung von PKC reduziert die Produktion der beta-Amyloid-Peptide vom "amyloid precursor protein" (Fowler 1997). DDEF-1 wurde ebenfalls in der Reperfusionsphase differentiell hochreguliert. DDEF1 oder ASAP1 ist ein ADP-Ribosylierungsfaktor (ARF) und GTPase-aktivierendes Protein der Centaurin $\beta$ Familie. DDEF-1 bindet ARF sowie die Tyrosinkinase Src und Phosphatidylinositol 4,5-Biphosphonat, welche beide Regulatoren des AktinZellskellettes sind. ASAP1 ist an fokalen Adhäsionen beteiligt, wenn die Zelle zur Bewegung stimuliert wird. Eine Überexpression von ASAP1 verändert die Morphologie fokaler Adhäsionen und blockiert die Zellbewegung (Furman et al. 2002). Randazzo et al. vermuten, dass ASAP1 das "Remodelling" des Zellskelettes 
reguliert und der ARF-Signalweg ein Ziel für die PDGF-Signalübertragung darstellt (Randazzo et al. 2000).

NADH-Ubichinon Oxidoreduktase, die in unserem Modell eine hochregulierte Expression zeigte, gehört zum Komplex I der mitochondrialen Atmungskette (Friedrich 2001). Die Abnahme intramitochondrialer ATP Konzentrationen führt zur mitochondrialen Dysfunktion bei ischämischen Lebern (Watanabe et al. 1983). Nishida et al. zeigten, dass Ubichinon-Cytochrom-c-Oxidoreduktase und NADHUbichinon-Oxidoreduktase empfindlich auf den Oxidationsschaden während der Reperfusionsphase von kalt konservierten Lebern und während der gekühlten Inkubation von Rattenleber-Mitochondrien reagieren. Nishida et al. folgerten, dass die Leber bei Ischämie-Exposition durch einen Anstieg der Protonenpermeabilität während Hypoxie und durch den Abfall der Enzymaktivitäten des Elektronentransportsystems während der Reoxygenierung geschädigt wird (Nishida et al. 1987). Die differentielle Hochregulation der NADH-Ubichinon-Oxidoreduktase impliziert einen Schutzmechanismus zum Erhalt der mitochondrialen Atmungskette während der Ischämie-Reperfusion.

SLA-DQ mRNA wurde nach Reperfusion differentiell hochreguliert. Die Expression von SLA-DQ mRNA konnte im mukosalen Epitehl und in submukosalen Endothelzellen mittels In-situ-Hybridisierung nachgewiesen werden. Ähnlich dem humanen Leukozytenantigen reguliert das Schweine-Leukozytenantigen die Immunantwort (Pescovitz et al. 1984). Nach Oragntransplantationen kommt es zur Interaktion zwischen Haupthistokompatilibitätsantigenen (MHC) und dem T-ZellRezeptor, welcher das erste Signal der T-Zell-Aktivierung darstellt. MHC Klasse II Antigene werden auf Antigen-präsentierenden Zellen (APC) exprimiert und stimulieren $\mathrm{CD}^{+} \mathrm{T}$-Zellen. Intestinale Epithelzellen exprimieren das Antigen über HLA der Klasse II in vitro (Kaiserlian et al. 1989, Hershberg et al. 1997). Hershberg et al. vermuten, dass die intestinalen Epithelzellen während inflammatorischer Prozesse als zusätzliche APC agieren und die mukosale CD4 ${ }^{+}$T-Zell-Immunreaktion stimulieren (Hershberg u. Mayer 2000). Eine Spezies-spezifische Stimulation der Expression des MHC Klasse II-Gens durch IFN $\gamma$ konnte für porcine und humane Endotehlzellen nachgewiesen werden (Murray et al. 1994, Bravery et al. 1995, Collins et al. 1984, Batten et al. 1996). Die Hochregulation von MHC Klasse II steuert somit die T-Zell-vermittelte Immunantwort bei inflammatorischen Prozessen. 
Zu den hochregulierten Genen in unserem Modell gehörten des weiteren Interleukin7 und TIS11. Interleukin-7 wird als ein potenter Regulator der mukosalen Lymphozyten im Dünndarm diskutiert. Die Expression von IL-7 mRNA wurde von Watanabe et al. in intestinalen Epithelzellen und insbesondere in Becherzellen immunohistochemisch und durch In-situ-Hybridisierung nachgewiesen (Watanabe et al. 1995). Die kontinuierliche Expression von TTP/TIS11 Protein in physiologischen Konzentrationen führt zum Zelluntergang durch Apoptose. Johnson et al. vermuten, dass TTP und TIS11 „immediate early“ Proteine sind, die Einfluss auf die Signalwege von Zellwachstum und Zellüberleben ausüben (Johnson et al. 2000). In einem Hypoxie-Ischämie-Modell des Rattenhirns konnte gezeigt werden, dass TIS11 ein „immediate early" Gen ist, welches nach 1, 2 und 3 Stunden nach Hypoxie hoch reguliert wird (Gubits et al. 1993). Die Hochregulation von IL-7 und TIS11 nach Reperfusion in unserem Modell impliziert eine potentielle Beteiligung von IL-7 als Mediator für mukosale Lymphozyten, und TIS11 vermittelt potentiell Apoptose- und Regenerationsprozesse im Dünndarm.

In unserem Modell fanden wir eine Sequenz, die eine hohe Homologie zu alpha-NAC mRNA aufweist. Mittels Northern-Blot konnten wir eine differentielle Heraufregulation der alpha-NAC mRNA-Expression bestätigen. Die differentielle Expression von alpha-NAC wurde von Yotov et al. sowie Moreau et al. in differenzierten Osteoblasten während deren Entwicklung beschrieben (Yotov et al. 1998, Moreau et al. 1998). Wiedmann et al. reinigten NAC auf und fanden einen heterodimeren Komplex. Die beta-NAC-Untereinheit wurde als BTF3b identifiziert (Wiedmann et al. 1994). BTF3b ist an der Regulation der Transkription bei Hefen und höheren Eukaryoten beteiligt (Parthun et al. 1992, Hu u. Ronne 1994, Zheng et al. 1990). StArnaud und Quelo untersuchten die Rolle von alpha-NAC bei der Kontrolle der Transkription. Das alpha-NAC-Protein agiert in vivo als transkriptionaler Koaktivator, indem es die Aktivität des chimären Aktivators GAL4/VP-16 potenziert (St-Arnaud u. Quelo 1998). Alpha-NAC potenziert auch die Aktivität des homodimeren c-JunAktivators, wohingegen die heterodimere c-Fos/c-Jun vermittelte Transkription nicht beeinflusst wird (Moreau et al. 1998). Alpha-NAC stabilisiert den AP-1-Komplex, der von c-Jun Homodimeren gebildet wird, durch eine 8-fache Reduktion der Dissoziationskonstante des Komplexes. Es wird vermutet, dass die hohe Affinität von alpha-NAC für c-Jun die Interaktion der c-Jun Homodimere mit dem basalen Transkriptionsapparat stabilisiert. St-Arnaud und Moreau folgerten, dass die 
Transkriptionsrate eines c-Jun-abhängigen Promotors durch den alpha-NAC Koaktivator erhöht wird, welcher die c-Jun Dimere auf ihrer Bindungsseite stabilisiert (Moreau et al. 1998, St-Arnaud u. Quelo 1998). Es bleibt spekulativ, inwieweit eine Interaktion zwischen alpha-NAC und dem organ-spezifischen Ausbleiben der Expression des AP-1 c-Jun-Proteins besteht, die von Yeh et al. bei der intestinalen Ischämie-Reperfusionsschädigung beschrieben wurde (Yeh et al. 2000).

TRIP7 wurde nach Reperfusion differentiell hochreguliert. TRIP7 interagiert mit der Liganden-Bindungsdomäne des Schilddrüsenhormonrezeptors. Die Schilddrüsenhormonrezeptoren sind Hormon-abhängige Transkriptionsfaktoren. TRIP7 benötigt für die Interaktion die Anwesenheit von Schilddrüsenhormon. Lee et al. vermuten, dass der indirekte Schilddrüsenhormon (T3)-Effekt einen neuartigen Mechanismus in der hormonellen Aktivierung der Genexpression darstellt (Lee et al. 1995).

Vier bei unserem Versuch neu entdeckte partielle CDS mRNA-Sequenzen von differentiell hochregulierten Genen wurden bei der GenBank registriert. "FAT tumor supressor gene" ist ein Cadherin-verwandter "Tumorsuppressor-HomologPrecursor". Cadherine vermitteln Kalzium-abhängige Zell-Zell-Adhäsionen in einer Vielzahl von Geweben und sind wichtige Regulatoren der Morphogenese (Takeichi 1991, Geiger und Ayalon 1992). Ein Verlust der FAT-Funktion wird bei der Invasion und Metastasierung von malignen Tumoren diskutiert (Takeichi 1993). FAT wird überwiegend in Epithelzellen und weniger in Endothel- und glatten Muskelzellen exprimiert. Dunne et al. vermuten des weiteren, dass FAT eine wichtige Rolle bei Entwicklungsprozessen und der Zellkommunikation besitzt (Dunne et al. 1995). Die Hochregulation von FAT nach Reperfusion in unserem Modell impliziert eine potentielle Beteiligung von FAT an Reparaturprozessen.

Die mRNA des ribosomalen Proteins L3 (RPL3) wurde nach Reperfuison hochreguliert. Der effiziente Zusammenschluss von Ribosomen erfordert eine ausgeglichene Synthese ribosomaler RNA und jedes ribosomalen Proteins (Pearson et al. 1982). RPL3 ist an der Formation des Peptidyltransferasezentrums beteiligt und ist für dessen katalytische Aktivität essentiell. RPL3 bindet in vitro NukleotidTriphosphate mit hoher und spezifischer Affinität. Die Affinität von RPL3 zu Nukleotid-Triphosphaten ist 500-fach höher als zu den korrespondierenden Nukleotid-Mono- und Diphosphatasen (Avliyakulov et al. 2000). Ou et al. fanden eine hohe Expression von RPL3 in Kolonkarzinom- und Lymphomzell-Linien und folgerten 
daraus, dass eine RPL3 Überexpression eine Eigenschaft von sich schnell teilenden Zellen ist (Ou et al. 1987).

Die STK12 (Synonym: ARK2) mRNA-Expression war nach Reperfusion differentiell hochreguliert. Die chromosomale Trennung während Mitose und Meiose wird durch Kinasen und Phosphatasen reguliert. ARK2 wird in der S und G2/M Phase exprimiert (Shindo et al. 1998). Eine Expression von STK12 konnte im Thymus, Dünndarm, Testes, Kolon, Milz und Gehirn nachgewiesen werden (Kimura et al. 1998). STK12 wurde mittels In-situ-Hybridisierung im mukosalen Epithel, in submukosalen Endothelzellen und in Lymphozyten der Submukosa nachgewiesen.

Das 3'-Ende einer EST-Sequenz und hochregulierte mRNA-Expression wurde nach der Methode der RACE-PCR identifiziert. Diese zeigte eine Homologie zu Homo sapiens Son-DNA-bindendem-Protein und wurde in der GenBank registriert (GenBank: AY072691). Das menschliche Son-Gen wurde ursprünglich bei Hybridisierung in der GC-reichen genomischen DNA-Sequenz (Bliskovskii et al. 1992) oder in der pyrimidinreichen Sequenz (Mattioni et al. 1992) kloniert. Die Funktion des Son ist bis heute noch nicht klar, aber die Überexpression des rekombinanten Proteins kann die Morphologie der Zellen verändern (Kai u. Mishina 1997). 


\subsection{Schlussfolgerung}

Anhand des isoliert perfundierten Schweinedünndarms haben wir gezeigt, dass es besonders während der Reperfusion mit Schweinevollblut zu einer starken Entzündungsreaktion mit Freisetzung von Zytokinen und einer Induktion der entsprechenden mRNA-Expression kommt. Diese Reaktion zeigte sich schon während der kalten Ischämiezeit, wobei sie nach 20 Stunden KIZ deutlich ausgeprägter war als nach 2 Stunden. Nach Reperfusion kam es zu einer mukosalen Schädigung, wobei eine verlängerte kalte Ischämiezeit zu einer frühzeitigeren und initial schwereren mukosalen Schädigung nach Reperfusion führte. Als Ausdruck der Ischämie-Reperfusionsschaden-vermittelten Entzündungs-reaktion beobachteten wir eine zunehmende Expression von IL-6, IL-2, HSP70, IFN $\gamma$ und E-Selektin.

Durch In-situ-Hybridisierung konnten wir die mRNA-Expression von IL-6 nicht nur in immunkompetenten Zellen sondern sogar in Endothel-, glatten Muskel- und Ganglienzellen nachweisen. Daraus scheint zu folgen, dass auch diese Zellen, neben den immunkompetenten Zellen, eine wesentliche Rolle bei der Initiierung des intestinalen Ischämie-Reperfusionsschadens spielen.

Erstmals gelang uns mittels In-situ-Hybridisierung die Lokalisation der mRNAExpression von IL-2, HSP70 und E-Selektin in Dünndarmgewebe. Dabei fand sich ESelektin mRNA-Expression in Endothelzellen. Da diese Effekte früh nach Reperfusion auftraten und möglicherweise einen Beitrag zum IschämieReperfusionsschaden leisten, bietet es sich an, E-Selektin als Marker für eine Aktivierung der Endothelzellen zu verwenden.

Des weiteren konnten wir mittels Differential Display eine Vielzahl von hoch- und herunterregulierten Genen identifizieren, darunter das Schweine-Leukozytenantigen SLA-DQ (MHC Klasse II), dessen mRNA-Expression unmittelbar nach Reperfusion hochreguliert wird. MHC Klasse II ist für die Antigenität von Transplantaten von ausschlaggebender Bedeutung. Für alpha-NAC, GUCY1B3, TCF7, TIS11, TRIP7 und das von uns genannte $\mathrm{SMH}-1$ Gen kommt eine Rolle als Transkriptionsfaktor in Frage, während SNAP23, UHRF1, DDEF1, FAT, RPL-3 und STK12 an Differenzierungs- und Proliferationsprozessen beteiligt zu sein scheinen.

Bei unseren Versuchen entdeckten wir außerdem vier, beim Schwein bisher nicht bekannte, Gene, die wir in der GenBank registrieren ließen: Das zur CadherinSuperfamilie gehörende FAT Tumor-Suppressor-Gen, welches an der Zell-ZellInteraktion beteiligt ist, STK, welches Proteine der frühen Entzündungsreaktion 
phosphoryliert, RPL3, welches an der Bildung des Peptidyltransferasezentrums beteiligt ist und für dessen katalytische Aktivität essentiell ist sowie Son-DNAbindendes Protein, dessen Funktion bis heute unklar ist. Die Überexpression des rekombinanten Proteins kann jedoch die Zellmorphologie verändern.

Schließlich identifizierten wir ein während der Reperfusion differentiell herunterreguliertes, bisher gänzlich unbekanntes Gen, welches wir SMH-1 nannten. Dieses Gen besitzt eine Homologie zu einer humanen DNA-Sequenz, die einen Teil eines kürzlich entdeckten Zink-Fingerproteins aufweist. Es scheint ein Hypoxie reguliertes Gen zu sein, dessen Funktion noch nicht näher bekannt ist.

Das mRNA-Differential Display erscheint als geeignete Methode zur Detektion von Genen, die bei der intestinalen Ischämie-Reperfusionsschädigung differentiell exprimiert werden. Wir konnten Gene nachweisen, die bislang nicht in der Pathophysiologie des Ischämie-Reperfusionsschadens diskutiert wurden und eine potentielle Rolle bei den hierdurch hervorgerufenen Schädigungs- und Reperaturprozessen spielen.

Die in unserer Arbeit detektierten differentiellen Gene können der weiteren Aufklärung der Pathophysiologie des Ischämie-Reperfusionsschadens dienen und stellen potentielle Angriffspunkte für therapeutische Interventionen dar. 


\section{ZUSAMMENFASSUNG}

In dieser Arbeit wurde das Modell des isoliert perfundierten Schweinedünndarms verwendet. Der Darm wurde einer kalten Ischämiezeit (KIZ) von 2 oder 20 Stunden in Organprotektionslösung (HTK) ausgesetzt und anschließend unter physiologischen Bedingungen mit Schweinevollblut perfundiert. Der Ischämie-Reperfusionsschaden des Dünndarms führte in unserem standardisierten extrakorporalen Dünndarmperfusionsmodell vor allem zu einer Schädigung der intestinalen Mukosa während der Reperfusionsphase. In Darmbiopsien wurde die Genexpression von bekannten proinflammatorischen Mediatoren nach 2 und 20 Stunden kalter Ischämiezeit in stündlichen Intervallen bis zu einer maximalen Reperfusionszeit von 10 Stunden sowohl quantitativ bestimmt als auch lokalisiert. Darüber hinaus wurde in Biopsien vor Perfusion und 3 Stunden nach Reperfusion mit mRNA-Differential Display untersucht, welche bisher nicht näher untersuchten Gene durch diesen Versuchsaufbau induziert bzw. herabreguliert wurden. Für einige Kandidatengene wurde ebenfalls deren Lokalisation mit DIG-markierten cRNA-Sonden durch In-situHybridisierung bestimmt.

In der bisher ungeklärten Pathogenese entzündlicher Darmerkrankungen spielen Zytokine eine Schlüsselrolle, wobei die dysregulierte Zytokinexpression eine inflammatorische Antwort auf ätiologisch unterschiedliche Ereignisse darstellt, welche die Spezifität dieser resultierenden Antwort bedingt. Die Art und Menge exprimierter und sezernierter Zytokine mag dabei vom auslösenden Prozess abhängig sein. In unserem Modell, das ebenfalls zu einer Entzündungsreaktion im Darm führt, fand die IL-6 mRNA-Expression in der Frühphase der Reperfusion statt und könnte zur Überwachung schwerer Ischämie-Reperfusionsschäden dienen. Eine verlängerte Hypoxie war mit deutlich schwereren Mukosaschäden nach Reperfusion assoziiert und scheint die IL-6 mRNA-Expression zu induzieren. Die Rolle der IL-6 mRNAExpression in Endothelzellen, Monozyten, glatten Muskelzellen und Ganglienzellen ist noch nicht vollständig geklärt.

Die Expression von IL-2 zeigte einen zweiphasigen Verlauf und waren unmittelbar nach Beginn (0 Stunden) sowie 7 Stunden nach Reperfusion am ausgeprägtesten. IL-2 wurde zum ersten Mal im Dünndarm mittels In-situ-Hybridisierung in Gefäßendothelzellen der Mukosa, in Lymphozyten der Submukosa und Mukosa 
sowie in Gefäßendothelzellen im Bereich der "Muscularis propria" nachgewiesen. Wegen seiner Wirkung auf T- und B-Zellen gilt IL-2 als zentrales Regulatormolekül der Immunantwort.

Die HSP70 mRNA-Expression im Dünndarm stieg unmittelbar nach Reperfusion deutlich an, wobei eine erhöhte Expression von HSP70 mRNA nach einer KIZ von 20 Stunden nachgewiesen wurde. Eine Abnahme der HSP70 mRNA-Expression nach Reperfusion (20 Stunden KIZ) wurde beobachtet. Die erhöhte mRNA-Expression von HSP70 hängt wahrscheinlich mit der Bildung freier Radikale, zirkulierenden Zytokinen und einer immunologischen Funktion von HSP70 zusammen. HSP70 mRNA wurde zum ersten Mal im Dünndarm mittels In-situ-Hybridisierung in Endothelzellen, in glatten Muskelzellen und in mukosalen Epithelzellen nachgewiesen.

IFN $\gamma$ ist ein inflammatorisches Zytokin, das essentielle Funktionen in der angeborenen Immunantwort besitzt. IFN $\gamma$ war vor und nach Reperfusion exprimiert, wobei die Expression in der Reperfusionsphase nach 2 Stunden KIZ zunahm. IFN $\gamma$ wurde mittels In-situ-Hybridisierung in der intestinalen Mukosa (Lymphozyten) nachgewiesen. Über eine konstitutionelle Expression von IFN $\gamma$ mRNA in der Mukosa gibt es bisher keine weiteren Arbeiten, aber auf Grund des erhöhten Aktivierungsgrades intestinaler T-Zellen wäre eine IFN $\gamma$-Synthese nicht unerwartet gewesen.

Die E-Selektin mRNA-Expression war bereits nach der Laparatomie nachweisbar und stieg danach während der KIZ an. Verlängerte $\mathrm{KIZ}$ prädisponierte zu verstärkter E-Selektin-Transkription und war mit früherer und verstärkter Mukosaschädigung infolge Reperfusion assoziiert. E-Selektin-mRNA wurde wie bei HSP70 und IL-2 zum ersten Mal mittels In-situ-Hybridisierung in Endothelzellen nachgewiesen.

Mittels mRNA-Differential Display konnten wir eine Vielzahl nach 3 Stunden hochund herunterregulierter Banden identifizieren. Die mRNA-Sequenzen von FLJ22116, GUCY1B3, MKP-7, der mitochondrialen DNA D-loop-Region, NADH4, NADH6, mc 7Protein, SNAP23, TCF7, UHRF1 und das von uns genannte SMH-1 Gen waren nach einer Reperfusionsdauer von 3 Stunden differentiell herunterreguliert. Im Gegensatz hierzu wurden die mRNA-Sequenzen von $\beta$-Amyloid, Cingulin, DDEF1, FAT, Ig Gamma "heavy-chain", IL-7, NADH4, SMLZ-2, MYO 5B, RARA, RPL3, SLA-DQ, STK12, SON3, alpha-NAC und TRIP7 nach 3 Stunden Reperfusion differentiell 
hochreguliert. Während die durch den Ischämie-Reperfusionsschaden differentiell regulierten Gene alpha-NAC, GUCY1B3, SMH-1, TCF7, TIS11 und TRIP7 als Transkriptionsfaktor in Frage kommen, scheinen SNAP23, UHRF1, DDEF1, FAT, RPL3 und STK12 an Differenzierungs- und Proliferationsprozessen beteiligt zu sein.

Das differentiell herunterregulierte $\mathrm{SMH}-1$ besitzt eine hohe Homologie zu einer DNA-Sequenz, die einen Teil eines kürzlich entdeckten Zink-Fingerproteins aufweist. SMH-1-mRNA wurde am Ende der KIZ exprimiert, jedoch nicht vor HTK-Perfusion. Die Expression der SMH-1 mRNA war nach einer KIZ von 20 Stunden höher als nach 2 Stunden und wurde während der Reperfusionsphase herunterreguliert. $\mathrm{SMH}$ 1-mRNA konnte in submukosalen glatten Muskelzellen nachgewiesen werden. SMH1 scheint ein Hypoxie reguliertes Gen zu sein, dessen Funktion noch nicht näher bekannt ist.

Die Hochregulation der NADH-Ubiquinon-Oxidoreduktase impliziert eine protektive Rolle gegen den Ischämie-Reperfusionsschaden. Wohingegen die Hochregulation von IL-7 und SLA-DQ potentielle Mediatoren der Schädigung darstellen. SLA-DQ mRNA war bereits vor HTK-Perfusion exprimiert. Unmittelbar nach Reperfusion stieg die SLA-DQ mRNA-Expression an und blieb bis zum Ende der Reperfusionsphase erhöht. SLA-DQ mRNA wurde mittels In-situ-Hybridisierung im mukosalen Epithel und in submukosalen Endothelzellen nachgewiesen.

Die alpha-NAC mRNA-Expression wurde nach Reperfusion hochreguliert. AlphaNAC potenziert die Aktivität des homodimeren c-Jun-Aktivators und stabilisiert den AP-1-Komplex, der von c-Jun Homodimeren gebildet wird.

Vier neue differentiell hochregulierte Gene wurden identifiziert und in der GenBank registriert. FAT Tumor-Suppressor-Gen (GenBank: AF255344) ist ein Cadherinverwandter "Tumor-Supressor-Homolog-Precursor". FAT scheint eine wichtige Rolle bei Entwicklungsprozessen und der Zellkommunikation zu besitzen. RPL3 (GenBank: AF203699) ist an der Bildung des Peptidyltransferasezentrums beteiligt und ist für dessen katalytische Aktivität essentiell. Serin/Threonin-Kinase 12 (GenBank: AF244364; synonym: ARK2), welches Proteine der frühen Entzündungsreaktion phosphoryliert, wurde mittels In-situ-Hybridisierung im mukosalen Epithel, in submukosalen Endothelzellen und in Lymphozyten der Submukosa nachgewiesen. Die Funktion des Son-DNA-bindendem-Proteins (GenBank: AY072691) ist bis heute nicht klar. 
Abschließend ist hervorzuheben, dass nicht-immunologische Faktoren in IschämieReperfusionsshaden bedeutsam sind. Die gewonnenen Erkenntnisse können der weiteren Aufklärung der Pathophysiologie des Ischämie-Reperfusionsschadens und als Grundlage für die weitere Untersuchung der Funktion der differentiell regulierten Gene dienen. Insbesondere ist das Schweinemodell hierbei von Interesse, da die gewonnenen Erkenntnisse nicht nur zur weiteren Aufklärung der Pathophysiologie von Ischämie und Reperfusion und der Entwicklung von Interventionsstrategien dienen, sondern auch eine Perspektive für die Xenotransplantation darstellen, bei der das Schwein als geeignetes Spendertiere in Frage kommt. 


\section{LITERATURVERZEICHNIS}

\section{ACKERMAN GA (1971):}

The human neutrophilen myelocyte. A correlated phase and electron microscopic study

Z. Zellforsch. Mikrosk. Anat. 121: 153-170.

AREND WP, GORDON DF, WOOD WM, JANSON RW, JOSLIN FG, JAMEEL S (1989):

IL-1 $\beta$ production in cultured human monocytes is regulated at multiple levels

J. Immunol. 143: 118-126.

ARTHUR MJ (1988):

Reactive oxygen intermediates and liver injury

J. Hepatol. 6: 125-131.

AVLIYAKULOV NK, LUKES J, KAJAVA AV, LIEDBERG B; LUNDSTROM I, SVENSSON SP ( 2000):

Suramin blocks nucleotide triphosphate binding to ribosomal protein L3 from Trypanoplasma borreli

Eur. J. Biochem. 267: 1723-1731.

BAHRAMI S, REDL H, SCHLAG G (1998):

The intestine as the cause of infection and multiple organ failure

Wien. Klin. Wochenschr. Suppl. 1: 2-10.

BAINTON DF, FARQUHAR MG (1966):

Origin of granules in polymorphonuclear leukocytes. Two types derived from opposite faces of the Golgi complex in developing granulocytes

J. Cell. Biol. 28: 277-301.

BARIE PS, MULLINS RJ (1988):

Experimental methods in the pathogenesis of limb ischemia

J. Surg. Res. 44: 284-307.

BASSAM BJ, CAETANO-ANOLL'ES G, GRESSHOFF PM (1991):

Fast and sensitive silver staining of DNA in polyacrylamide gel

Anal. Biochem. 196: 80-83.

BATTEN P, YACOUB MH, ROSE ML (1996):

Effect of human cytokines (IFN-gamma, TNF-alpha, IL-1beta, IL-4) on porcine endothelial cells: induction of $\mathrm{MHC}$ and adhesion molecules and functional significance of these changes

Immunology 87: 127-133.

BELKIN M, LaMORTE WL, WRIGHT JG, HOBSON RW2nd (1989):

The role of leukocytes in the pathophysiology of skeletal muscle ischemic injury J. Vasc. Surg. 10: 14-18. 
BELLMANN K, JAAATTELA M, WISSING D, BURKART V, KOLB H (1996): Heat shock protein hsp70 overexpression confers resistance against nitric oxide FEBS. Lett. 391: 185-188.

BEUK RJ, HEINEMAN E, TANGELDER GJ, QUAEDACKERS JS; MARKS WH; LIEBERMAN JM; OUDE EGBRINK MG (2000):

Total warm ischemia and reperfusion impairs flow in all gut rat layers but increases leukocyte-vessel wall interactions in the submucosa only

Ann. Surg. 231: 96-104.

BEVILACQUA MP, STENGELIN S, GIMBRONE MA, SEED B (1989):

Endothelial leukocyte adhesion molecule 1: an inducible receptor for neutrophiles related to complement regulatory proteins and lectins

Science 243: 1160-1165.

BEVILACQUA MP, NELSON RM (1993):

Endothelial-leukocyte adhesion molecules in inflammation and metastasis. Thromb. Haemost. 70: 152-154.

BIELSKI BH, SHIUE GG (1979):

Reaction rates of superoxide radicals with the essential amino acids

In: Oxygen free radicals and tissue damage from Ciba Foundation New York (ed.) Elsevier, Amsterdam: pp. 43-56.

BIFFL WL, MOORE EE, MOORE FA, PETERSON VM (1996):

Interleukin- 6 in the injured patient. Marker of injury or mediator of inflammation? Ann. Surg. 224: 647-664

BIRNBOIM HC, DOLY J (1979):

rapid alkanine extraction procedure for screening recombinant plasmid DNA Nucleic Acids Res. 1513-1523.

BLISKOVSKII VV, KIRILLOV AV, ZAKHAR' ev VM, CHUMANKOV IM (1992):

[The human son gene: the large and small transcripts contains various $5^{\prime}-$ terminal sequences]

Mol. Biol. (Mosk.) 26: 807-812.

BOEHM U, KLAMP T, GROOT M, HOWARD JC (1997):

Cellular responses to interferon-gamma

Annu. Rev. Immunol. 15: 749-795.

BRAUN F, SCHÜTZ E, LAABS S,HANACK U, SATTLER B, LORF T, WIELAND E, OELLERICH M, RINGE B (1998):

Development of a porcine small bowel ex vivo perfusion model

Transplant. Proc. 30: 2613-2615.

BRAVERY CA, BATTEN P, YACOUB MH, ROSE ML (1995):

Direct recognition of SLA and HLA-like class II antigens on porcine endothelium by human $T$ cells results in $T$ cell activation and release of interleukin-2 Transplantation 60: 1024-1033. 
BROWN MF, ROSS AJ $3^{\text {rd }}$, DASHER J, TURLEY DL, ZIEGLER MM, O'NEILL JA JR (1990):

The role of leukocytes in mediating mucosal injury of intestinal ischemia/reperfusion

J. Pediatr. Surg. 25:214-217.

BURGER RM, BERKOWITZ AR, PEISACH J, HORWITZ SB (1980):

Origin of malodialdehyde from DNA degraded by $\mathrm{Fe}(\mathrm{II}) \mathrm{x}$ belomycin

J. Biol. Chem. 255: 11832-11838.

CARDEN DL, GRANGER DN (2000):

Pathophaysiology of ischemia-reperfusion injury

J. Pathol. 190: 255-266.

CERASOLI F Jr, McKENNA PJ, ROSOLIA DL, ALBERTINE KH, PETERS SP, GEE $\mathrm{MH}$ (1990):

Superoxide anion release from blood and bone marrow neutrophils is altered by endotoxemia

Circ. Res. 67: 154-165.

CHAN SH, PERUSSIA B, GUPTA JW, KOBAYASHI M, POSPISIL M, YOUNG H, WOLF SF, YOUNG D, CLARK SC, TRINCHIERI G (1991):

Induction of interferon gamma production by natural killer cell stimulatory factor:

characterization of the responder cells and synergy with other inducers

J. Exp. Med. 173: 869-879.

CHIU CJ, McARDLE AH, BROWN R, SCOTT HJ, GURD FN (1970):

Intestinal mucosal lesion in low-flow states. I. A morphological, hemodynamic, and metabolic reappraisal

Arch. Surg. 101: 478-483.

CICALESE L, CARACENI P, NALESNIK MA, BORLE AB, SCHRAUT WH (1996):

Oxygen free radical content and neutrophil infiltration are important determinants in mucosal injury after rat small bowel transplantation Transplantation 62: 161-166.

CICALESE L, SILERI P, GREEN M, ABU-ELMAGD K, KOCOSHIS S, REYES J (2001):

Bacterial translocation in clinical intestinal transplantation

Transplantation 71: 1414-1417.

CIPOLLE MD, PASQUALE MD, CERRA FB (1993):

Secondary organ dysfunction. From clinical perspectives to molecular mediators Crit. Care. Clin. 9: 261-298 
COLLINS T, KORMAN AJ, WAKE CT, BOSS JM, KAPPES DJ, FIERS W, AULT KA, GIMBRONE MA Jr, STROMINGER JL, POBER JS (1984):

Immune interferon activates multiple class II major histocompatibility complex genes and the associated invariant chain gene in human endothelial cells and dermal fibroblasts

Proc. Natl. Acad. Sci. USA. 81: 4917-4921.

COLLINS T, READ MA, NEISH AS, WHITLEY MZ, THANOS D, MANIATIS T (1995):

Transcriptional regulation of endothelial cell adhesion molecules: NF-kappa B and cytokine-inducible enhancers

FASEB J. 9: 899-909.

CRAIG EA, GROSS CA (1991):

Is hsp70 the cellular thermometer?

Trends. Biochem. Sci. 16: 135-140.

CURRIE RW, TANGUAY RM, KINGMA JG Jr (1993):

Heat-shock response and limitation of tissue necrosis during occlusion/reperfusion in rabbit hearts

Circulation 87: 963-971.

DAVIS M, WHITELY T, TURNBULL DM, MENDELOW AD (1997):

Selective impairments of mitochondrial respiratory chain activity during aging and ischemic brain damage

Acta Neurochir. Suppl.(Wien.) 70: 56-58.

DUBAYBO BA, CARLSON RW (1988):

Post-infectious ARDS: mechanisms of lung injury and repair

Crit. Care. Clin. 4: 229-243.

DUNNE J, HANBY AM, POULSOM R, JONES TA, SHEER D, CHIN WG,Da SM, ZHAO Q, BEVERLEY PC, OWEN MJ (1995):

Molecular cloning and tissue expression of FAT, the human homologue of the Drosophila fat gene that is located on chromosome 4q34-q35 and encodes a putative adhesion molecule

Genomics 30: 207-223.

FEHRENBACH E, NIESS AM (1999):

Role of heat shock proteins in the exercise response

Exerc. Immunol. Rev. 5: 57-77.

FEINBERG AP, VOGELSTEIN B (1983):

A technique for radiolabeling DNA restriction endonuclease fragments to high specific activity

Anal. Biochem. 132: 6-13.

FEINSTEIN DL, GALEA E, AQUINO DA, LI GC, XU H, REIS DJ (1996):

Heat shock protein 70 suppresses astroglial-inducible nitric-oxide synthase expression by decreasing NFkappaB activation

J. Biol. Chem. 271: 17724-17732. 
FIOCCHI C, FUKUSHIMA K, STRONG SA, INA K (1996):

Pitfalls in cytokine analysis in inflammatory bowel disease

Aliment. Pharmacol. Ther. 10 (2): 63-71.

FIOCCHI C (1992):

Cytokines. In: Mac Dermott R, Stenson W (eds.): Inflammatory bowel disease

New York: Elsevier: pp. 143-148

FOWLER CJ (1997):

The role of phosphoinositide signalling system in the pathogenesis of sporadic Alzheimer's disease: a hypothesis

Brain Res. Rev. 25: 373-380.

FRIEDRICH T (2001):

Comlex I: a chimera of a redox and conformation-driven proton pump?

J. Bioenerg. Biomembr. 33: 169-177.

FROHMAN MA (1994):

On beyond classic RACE (rapid amplification of cDNA ends)

PCR. Methods Appl. 4: 40-58.

FRÜH K, KARLSSON L and YANG Y (1997):

$\gamma$-Interferon in antigen processing and presentation. In $\gamma$-Interferon in Antiviral Defense, G. Karupiah, ed

Springer, Heidelberg: pp. 39-59.

FUJISHIMA S, AIKAWA N (1995):

Neutrophil-mediated tissue injury and its modulation

Intensive Care. Med. 21: 277-285.

FURMAN C, SHORT SM, SUBRAMANIAN RR, ZETTER BR, ROBERTS TM (2002):

DEF-1/ASAP1 is a GTPase-activating protein (GAP) for ARF1 that enhances cell motility through a GAP-dependent mechanism

J. Biol. Chem. 277: 7962-7969.

GEIGER B, AYALON O (1992):

Cadherins

Annu. Rev. Cell. Biol. 8: 307-332.

GIUILI G, SCHOLL U, BULLE F, GUELLAEN G (1992):

Molecular cloning of the cDNAs coding for the two subunits of soluble guanyly cyclase from human brain

FEBS Lett. 304: 83-88.

GOLDMAN G, WELBOURN R, KLAUSNER JM, KOBZIK L, VALERI CR, SHEPRO

D, HECHTMAN HB (1992):

Mast cells and leukotrienes mediate neutrophil sequestration and lung edema after remote ischemia in rodents

Surgery 112: $578-586$. 
GRISWOLD J; MAIER RV (1988):

Neutrophil phagocytosis during endotoxin-induced lung-injury

J. Surg. Res. 44: 417-424.

GUBITS RM, BURKE RE, CASEY-McINTOSH G, BANDELE A, MUNELL F (1993): Immediate early gene induction after neonatal hypoxia-ischemia

Brain Res. Mol. Brain Res. 18: 228-238.

HAGLUND U (1994):

Gut ischemia

Gut 35: 73-76.

HANAHAN D (1985):

Technics for transformation of E.coli

In DNA Cloning 1, Glover, D. M (ed.) Oxford: pp.109-135.

HARVEY PR, IU S, Mc KEOWN CMB, PETRUNKA CN, IISON RG, STRASBERG SM (1988):

Adenine nucleotide tissue concentrations and liver allograft viability after cold preservation and warm ischemia

Transplantation. 45: 1016-1020.

HERSHBERG RM, FRAMSON PE, CHO DH, LEE LY, KOVATS S, BEITZ J, BLUM JS, NEPOM GT (1997):

Intestinal epithelial cells use two distinct pathways for HLA class II antigen processing

J. Clin. Invest. 100: 204-215.

HERSHBERG RM, MAYER LF (2000):

Antigen processing and presentation by intestinal epithelial cells- polarity and complexity

Immunology Today 21: 123-128.

HIGHTOWER LE (1991):

Heat Shock, stress proteins, chaperones, and proteotoxicity

Cell 66: 191-197.

HOPFNER R, MOUSLI M, JELTSCH JM, VOULGARIS A, LUTZ Y, MARIN C,

BELLOCQ JP; OUDET P; BRONNER C (2000):

ICBP90, a novel human CCAAT binding protein, involved in the regulation of topoisomerase Ilalpha expression

Cancer Res. 60: 121-128.

HOOVER RL, ROBINSON JM, KARNOVSKY MJ (1987):

Adheasion of polymorphnuclear leucocytes to endothelium enhances the effiency of detoxification of oxygen-free radicals

Am. J. Pathol. 126: 258-268. 
HU GZ, RONNE H (1994):

Yeast BTF3 protein is encoded by duplicated genes and inhibits the expression of some genes in vivo

Nucl. Acids Res. 22: 2740-2743.

HYAMS JS, FITZGERALD JE, TREEM WR, WYZGA N, KREUTZER DL (1993):

Relationship of functional and antigenic interleukin 6 to disease activity in inflammatory bowel disease

Gastroenterology 104: 1285-1292.

IBELGAUFTS H (1992):

Lexikon zytokine

München: Medikon Verlag

ILLYÉS G, HAMMAR J (1992):

Sequence of morphological alteration in a small intestinal ischemia/reperfusion model of the anesthetized rat. A light microscopy study

Int. J. Exp. Pathol. 73: 161-172.

ITOH H, YAGI M, FUSHIDA S, TANI T, HASHIMOTO T, SHIMIZU K, MIWA K (2000):

Activation of immediate early gene, c-fos, and c-jun in the rat small intestine after ischemia/reperfusion

Transplantation 69: 598-604.

JOHN HA, BIRNSTIEL ML, JONES KW (1969):

RNA-DNA hybrids of the cytological level

Natur 223: 582-587.

JOHNSON BA, GEHA M, BLACKWELL TK (2000):

Similar but distinct effects of the tristetraprolin/TIS11 immediate-early proteins on cell survival

Oncogene 19: 1657-1664.

JONAS E, DWENGER A, LUEKEN B, BOEHME U (1991):

Simultaneous measurement of endothelial cell damage, elastase release and chemiluminescence response during interaction between polymorphnuclear leucocytes and endothelial cells. IN: Adult respiratory distress syndrome: an aspect of multiple organ failure; result of a prospective clinical study von J. A. STURM (ed.). Springer Verlag, Berlin: pp. 281-293.

JONES SC, BANKS RE, HAIDAR A, GEARING AJ, HEMINGWAY IK, IBBOTSON SH, DIXON MF, AXON AT (1995):

Adhesion molecules in inflammatory bowel disease

Gut 36: 724-730.

JUNG M, DRAPIER JC, WEIDENBACH H, RENIA L, OLIVERA L, WANG A, BEGER HG, NUSSLER AK (2000):

Effects of intracellular iron imbalance on nitric oxide and reactive oxygen intermediates in a model of sepsis

J. Hepatol. 33: 387-394. 
KAI N, MISHINA M, YAGI T (1997):

Molecular cloning of Fyn-associated molekules in the mouse central nervous system

J. Neurosci. Res. 48: 407-424.

KAISERLIAN D, VIDAL K, REVILLARD JP (1989):

Murine enterocytes can present soluble antigen to specific class II-restricted CD4+ T cells

Eur. J. Immunol. 19: 1513-1516.

KAZUI M, ANDREONI KA, WILLIAMS GM, PERLER BA, BULKLEY GB, BEATTIE C, DONHAM RT, SEHNERT SS, BURDICK JF, RISBY TH (1994):

Visceral lipid peroxidation occurs at reperfusion after supraceliac aortic crossclamping

J. Vasc. Surg. 19: 473-477.

KIMURA M, MATSUDA Y, YOSHIOKA T, SUMI N, OKANO Y (1998):

Identification and characterization of STK12/Aik2: a human gene related to aurora of Drosophila and yeast IPL1

Cytogenet. Cell Genet. 82: 147-152.

KINDT GC, GADEK JE, WEILAND JE (1991):

Initial recruitment of neutrophils to alveolar structures in acute lung injury

J. Appl. Physiol. 70: 1575-1585.

KLAUSNER JM, ANNER H, PATERSON IS, KOBZIK L, VALERI CR, SHEPRO D, HECHTMAN HB (1988):

Lower torso ischemia-induced lung injury is leukocyte dependent

Ann. Surg. 208: 761-767.

KNOWLTON AA, BRECHER P, APSTEIN CS (1991):

Rapid expression of heat shock protein in the rabbit after brief cardiac ischemia J. Clin. Invest. 87: 139-147

KONG SE, BLENNERHASSETT LR, HEEL KA, McCAULY RD, HALL JC (1998): Ischemia-reperfusion injury to the intestine

Aust. NZJ. Surg. 68: 554-561.

KORTHUIS RJ, SMITH JK, CARDEN DL (1989):

Hypoxic reperfusion attenuates postischemic microvascular injury

Am. J. Physiol. 256: H315-H319.

KORTHUIS RJ, GRISHAM MB, GRANGER DN (1988):

Leukocyte depletion attenuates vascular injury in postischemic skeletal muscle Am. J. Physiol. 254: H823-H827.

KREGEL KC, MOSELEY PL (1996):

Differential effects of exercise and heat stress on liver HSP70 accumulation with aging

J. Appl. Physiol. 80: 547-551. 
KRISTIAN T, SIESJÖ BK (1998):

Calcium in ischemic cell death

Stroke 29: 705-718.

KUKIELKA GL, YOUKER KA, HAWKINS HK, PERRARD JL, MICHAEL LH,

BALLANTYNE CM, SMITH CW, ENTMAN ML (1994):

Regulation of ICAM-1 and IL-6 in myocardial ischemia: effect of reperfusion Ann. NY Acad. Sci. 723: 258-270.

KUSUGAMI K, MATSUURA T, WEST GA, YOUNGMAN KR, RACHMILEWITZ D, FIOCCHI C (1991):

Loss of interleukin-2-producing intestinal $\mathrm{CD}^{+} \mathrm{T}$ cells in inflammatory bowel disease

Gastroenterology 101: 1594-1605.

LEE JI, BURCKART GJ (1998):

Nuclear factor kappa B: Important transcription factor and therapeutic target

J. Clin. Pharmacol. 38: 981-993.

LEE JW, CHOI HS, GYURIS J, BRENT R, MOORE DD (1995):

Two classes of proteins dependent on either the presence or absence of thyroid hormone for interaction with the thyroid hormone receptor

Mol. Endocrinol. 9: 243-254.

LEVY MN (1959):

Oxygen consumption and blood flow in the hypothermic, perfused Kidney

Am. J. Physiol. 197: 1111-1114.

LIANG P, PARDEE AB (1998):

Differential display. A general protocol

Mol. Biotechnol. 10: 261-267.

LIANG P, PARDEE AB (1992):

Differential display of eukaryotic messenger RNA by means of the polymerase chain reaction

Science 257: 967-971.

LOCKE M, TANGUAY RM (1996):

Increased HSF activation in muscles with a high constitutive Hsp70 expression

Cell Stress Chaperones 1: 189-196.

MANIATIS T, FRITSCHE EF, SAMBROOK J (1989):

Molecular cloning: A laboratory manual $2^{\text {nd }}$ Ed. Cold Spring Harbor Laboratory, Cold Spring Harbor, New York.

MARBER MS, MESTRIL R, CHI SH, SAYEN R, YELLON DM, DILLMANN WH (1995):

Overexpression of the rat inducible $70-\mathrm{kD}$ heat stress protein in a transgenic mouse increases the resistance of the heart to ischemic injury

J. Clin. Invest. 95: 1446-1456. 
MARTIN DR, SCOTT DF, DOWNES GL, BELZER FO (1972):

Primary cause of unsuccessful liver and heart preservation: cold sensitivity of the ATPase system

Ann. Surg. 175: 111-117.

MARUO N, MORITA I, SHIRAO M, MUROTA SI (1992):

IL-6 increases endothelial permeability in vitro

Endocrinology 131: 710-714.

MASUDA K, SHIMA H, WATANABE M, KIKUCHI K (2001):

MKP-7, a novel mitogen-activated protein kinase phosphatase, functions as a shuttle protein

J. Biol. Chem. 276: 39002-39011.

MATTIONI T, HUME CR, KONIGORSKI S, HAYES P, OSTERWEIL Z, LEE JS (1992):

A cDNA clone for a novel nuclear protein with DNA binding activity

Chromosoma 101: 618-624.

MEYERS JA, SANCHEZ D, ELWELL LP, FALKOW S (1976):

Simple agarose gel electrophoretic method for the identification and characterization of plasmid deoxyribonucleic acid

J. Bacteriol. 127: 1529-1537.

McEVER RP (1997):

Regulation of expression of E-Selectin and P-Selectin. „The Selectin“

Vestweber d (Ed.) Harwood Academic Publishers, Amsterdam: pp. 31-47.

MCLENDON C, XIN T, ZIANI-CHERIF C, MURPHY MP, FINDLAY KA, LEWIS PA, PINNIX I, SAMBAMURTI K, WANG R, FAUQ A, GOLDE TE. (2000):

Cell-free assays for gamma-secretase activity

FASEB J. 14: 2383-2386.

MOORE EE, MOORE FA, FRANCOISE RJ, KIM FJ, BIFFL WL, BANERJEE A (1994):

The postischemic gut serves as a priming bed for circulating neutrophils that provoke multiple organ failure

J. Trauma 37: 881-887.

MOREAU A, YOTOV WV, GLORIEUX FH, St-ARNAUD R (1998):

Bone-specific expression of the alpha chain of the nascent polypeptideassociated complex, a coactivator potentiating c-Jun-mediated transcription Mol. Cell Biol. 18: 1312-1321.

MORIKAWA Y, NISHIDA H, MISAWA K, NOSAKA T, MIYAJIMA A, SENBA E, KITAMURA T (1998):

Induction of synaptosomal-associated protein-23 kD (SNAP-23) by various cytokines

Blood 92: 129-135. 
MORIMOTO RI (1993):

Cells in stress: transcriptional activation of heat shock genes

Science 259: 1409-1410.

MORIMOTO RI (1991):

Heat shock: the role of transient inducible responses in cell damage, transformation, and differentiation

Cancer Cells 3: 295-301.

MULLIS KB, FALOONA FA (1987):

Specific synthesis of DNA in vitro via a Polymerase-catalyzed chain reaction Methods Enzymol. 155: 335-350.

MURAOKA K, SHIMIZU K, SUN X, ZHANG YK, TANI T, HASHIMOTO T, YAGI M, MIYAZAKI I, YAMAMOTO K (1997):

Hypoxia, but not reoxygenation, induces interleukin 6 gene expression through NF-kappa B activation

Transplantation 63:466-470.

MURRAY AG, KHODADOUST MM, POBER JS, BOTHWELL AL (1994):

Porcine aortic endothelial cells activate human $T$ cells: direct presentation of $\mathrm{MHC}$ antigens and costimulation by ligands for human CD2 and CD28 Immunity 1: $57-63$.

NETZKER R (1985):

Untersuchungen zur Struktur und Organisation der Gene ribosomaler RNA in Rhodospirillum rubrum

Dissertation Universität Göttingen.

NIERS LE, SMEITINK JA, TRIJBELS JM, SENGERS RC, JANSSEN AJ, VAN DEN HEUVEL LP (2001):

Prenatal diagnosis of NADH: ubiquinone oxidoreductase deficiency

Prenat. Diagn. 21: 871-880.

NIKBAKHT-SANGARI M, QAYUMI AK, KEOWN P, DURINO V, HORLEY K (1999):

Platelet-activating factor plays a role in the mechanism of major histocompatibility complex in T lymphocytes

Immunol. Invest. 28: 223-233.

NISHIDA T, SHIBATA H, KOSEKI M, NAKAO K, KAWASHIMA Y, YOSHIDA Y, TAGAWA K (1987):

Peroxidative injury of the mitochondrial respiratory chain during reperfusion of the hypothermic rat liver

Biochim. Biophys. Acta 890: 82-88.

NÜSSLER AK, WITTEL UA NÜSSLER NC, BEGER HG (1999):

Leukocytes, the janus cells in inflammatory disease

Langenbecks Arch. Surg. 384: 222-232. 
OU JH, YEN TS, WANG JF, KAM WK, RUTTER WJ (1987):

Cloning and characterization of a human ribosomal protein gene with enhanced expression in fetal and neoplastic cells

Nucleic Acids Res.15: 8919-8934.

PARDUE M, GALL JC (1969):

Molecular hybridization of radioactive DNA to the DNA of cytological preparations

Proc. Natl. Acad. Sci. USA. 64: 600-604.

PARKS DA, GRANGER DN (1986):

Contribution of ischemia and reperfusion to mucosal lesion formation

Am. J. Physiol. 250: G749-G753.

PARTHUN MR, MANGUS DA, JAEHNING JA (1992):

The EGD1 product, a yeast homolog of human BTF3, may be involved in GAL4 DNA binding

Mol. Cell Biol. 12: 5683-5689.

PEARSON WR, LIPMAN DJ (1988):

Improved tools for biological sequence comparison

Proc. Natl. Acad. Sci. USA. 85: 2444-2448.

PEARSON NJ, FRIED HM, WARNER JR (1982):

Yeast use translational control to compensate for extra copies of a ribosomal protein gene

Cell 29: 347-355.

PEDERSEN BK, OSTROWSKI K, ROHDE T, BRUUNSGAARD H (1998):

The cytokine response to strenuous exercise

Can. J. Physiol. Pharmacol. 76: 505-511.

PESCOVITZ MD, THISTLETHWAITE JR Jr, AUCHINCLOSS H Jr, ILDSTAD ST, SHARP TG, TERRILL R, SACHS DH (1984):

Effects of class II antigen matching on renal allograft survival in miniature swine

J. Exp. Med. 160: 1495-1508.

POGGETTI RS, MOORE FA, MOORE EE, KOEIKE K, BANERJEE A (1992):

Simultaneous liver and lung injury following gut ischemia is mediated by

xanthine oxidase

J. Trauma 32: 723-727.

POST S, MESSMER K (1996):

The role of reperfusion damage

Chirurg 67: 318-323.

PUJIC Z, MATSUMOTO I, YAMATAKA A, MIYANO T, WILCE P (1996):

Induction of immediate-early, ornithine decarboxylase and antizyme gene expression in the rat small intestine after transient ischaemia

Life Sci. 58: 2289-2296. 
RADFORD NB, FINA M, BENJAMIN IJ, MOREADITH RW, GRAVES KH, ZHAO P, GAVVA S, WIETHOFF A, SHERRY AD, MALLOY CR, WILLIAMS RS (1996):

Cardioprotective effects of $70-\mathrm{kD}$ heat shock protein in transgenic mice

Proc. Nat. Acad. Sci. USA. 93: 2339-2342.

RANDAZZO PA, ANDRADE J, MIURA K, BROWN MT, LONG YQ, STAUFFER S, ROLLER P, COOPER JA (2000):

The Arf GTPase-activating protein ASAP1 regulates the actin cytoskeleton Proc. Natl. Acad. Sci. USA. 97: 4011-4016.

RAVICHANDRAN V, CHAWLA A, ROCHE PA (1996):

Identification of a novel syntaxin- and synaptobrevin/VAMP-binding protein, SNAP-23, expressed in non-neuronal tissues

J. Biol. Chem. 271: 13300-13303.

RINALDO JE, GORRY M, STRIETER R, COWAN H, ABDOLRASULNIA R, SHEPHERD V (1990):

Effect of endotoxin-induced cell injury on $70-k D$ heat shock proteins in bovine lung endothelial cells

Am. J. Respir. Cell Mol. Biol. 3: 207-216.

ROOSE J, HULS G, VAN BEEST M, MOERER P, VAN DER HORN K,

GOLDSCHMEDING R, LOGTENBERG T, CLEVERS H (1999):

Synergy between tumor suppressor APC and the beta-catenin-Tcf4 target Tcf1

Science 285: 1923-1926.

ROSA FM, COCHET MM, FELLOUS M (1986):

Interferon and major histocompatibility complex genes: a model to analyse eukaryotic gene regulation?

Interferon 7:47-87.

RUSSELL J, EPSTEIN CJ, GRISHAM MB, ALEXANDER JS, YEH KY, GRANGER DN (2000):

Regulation of E-selectin expression in postischemic intestinal microvasculature Am. J. Physiol. Gastrointest. Liver Physiol. 278: G878-885.

RUTHER U (1982):

pUR 250 allow rapid chemical sequencing of both DNA strands of its insert Nucleic Acid Res. 10: 5765-5772.

SAMBROOK J, FRITSCH EF, MANIATIS T (1989):

Molecular Cloning: A Laboratory Manual. $2^{\text {nd }}$ Edition, Cold Spring Harbor Laboratory Press, Cold Spring Harbor N.Y.

SARTOR RB (1994):

Cytokines in intestinal inflammation: Phatophysiological and clinical considerations

Gastroenterology 106: 533-539. 
SCHÜTZ E, WIELAND E, HEINE L, HENSEL A, SCHMIEDL A, ARMSTRONG VW, RICHTER J, SCHUFF-WERNER P, GÜNTHER E, OELLERICH M (1997):

Acceleration of hepatocellular energy by idebenone during early reperfusion after cold preservation ameliorates heat shock protein 70 gene expression in a pig liver model

Transplantation 64: 901-907.

SEEKAMP A, WARD PA (1993):

Ischemia-reperfusion injury

Agents Actions Suppl. 41: 137-152.

SEEKAMP A, TILL GO, MULLIGAN MS, PAULSON JC, ANDERSON DC, MIYASAKA M, WARD PA (1994):

Role of selectins in local and remote tissue injury following ischemia and reperfusion

Am. J. Pathol. 144: 592-598.

SEIBERT AF, HAYNES J, TAYLOR A (1993):

Ischemia-reperfusion injury in the isolated rat lung: role of flow and endogenous leukocytes

Am. Rev. Respir. Dis. 147: 270-275.

SERRICK C, ADOUMIE R, GIAID A, SHENNIB H (1994):

The early release of interleukin-2, tumor necrosis factor-alpha and interferongamma after ischemia reperfusion injury in the lung allograft

Transplantation 58: 1158-1162.

SCHINDLER U, BAICHWAL VR (1994):

Three NF-kappa B binding sites in the human E-selectin gene required for maximal tumor necrosis factor alpha-induced expression

Mol. Cell Biol. 14: 5820-5831.

SHIFMAN MI, STEIN DG (1995):

A reliable and sensitive method for non-radioactive northern blot analysis of nerve growth factor mRNA from brain tissues

J. Neurosci. Methods 59: 205-208.

SHINDO M, NAKANO H, KUROYANAGI H, SHIRASAWA T, MIHARA M, GILBERT DJ, JENKINS NA, COPELAND NG, YAGITA H, OKUMURA K (1998):

cDNA cloning, expression, subcellular localization, and chromosomal assignment of mammalian aurora homologues, aurora-related kinase (ARK) 1 and 2

Biochem. Biophys. Res. Commun. 244: 285-292.

SIESJÖ BK (1991):

"The role of calcium in cell death."In: Neurodegenerative Disorders:

Mechanisms and prospects for Therapy, Price DL, Thoenen $\mathrm{H}$, Aguayo Aj (eds.)

John Wiley \& Sns Ltd.: pp 35-59. 
SIGURDSSON GH, CHRISTENSON JT, EL-RAKSHY MB, SADEK S (1992): Intestinal platelte trapping after traumatic and septic shock. An early sign of sepsis and multiorgan failure in critically ill patients?

Crit. Care. Med. 20: 458-467.

SILVER IA, ERECINSKA M (1994):

Extracelular glucose concentration in mamalian brain: continous monitoring of changes during increased neuronal activity and upon limitation in oxygen supply in normo-, hypo-, and hyperglycemic animals

J. Neurosci. 14: 5068-5076.

SIMPSON R, ALON R, KOBZIK L, VALERI CR, SHEPRO D, HECHTMAN HB (1993):

Neutrophil and nonneutrophil-mediated injury in intestinal ischemia-reperfusion Ann. Surg. 218: 444-453.

SISLEY AC, DESAI T, HARIG JM, GEWERTZ BL (1994):

Neutrophil depletion attenuates human intestinal reperfusion injury

J. Surg. Res. 57:192-196.

ST-ARNAUD R, QUELO I (1998):

Transcriptional coactivators potentiating AP-1 function in bone

Front. Biosci. 3: D838-848.

STEPHENS KE, ISHIZAKA A, LARRICK JW, RAFFIN TA (1988):

Tumor necrosis factor causes increased pulmonary permeability and edema.

Comparison to septic acute lung injury

Am. Rev. Respir. Dis. 137: 1364-1370.

TAGGART DP, BAKKENIST CJ, BIDDOLPH SC, GRAHAM AK, McGEE JO (1997): Induction of myocardial heat shock protein 70 during cardiac surgery

J. Pathol. 182: 362-366.

TAKEICHI M (1991):

Cadherin cell adhesion receptors as a morphogenetic regulator

Science 251: 1451-1455.

TAKEICHI M (1993):

Cadherins in cancer: Implications for invasion and metastasis

Curr. Opin. Cell Biol. 5: 806-811.

TAKEYOSHI I, ZHANG S, NOMOTO M, ZHU Y, KOKOUDO Y, SUZUKI T, HAMADA N, NEMOTO A, STARZL TE, TODO S (2001):

Mucosal damage and recovery of the intestine after prolonged preservation and transplantation in dog

Transplantation 71:1-7.

TANOUE T, YAMAMOTO T, MAEDA R, NISHIDA E (2001):

A novel MAPK phosphatase MKP-7 acts preferentially on JNK/SAPK and p38 alpha and beta MAPKs

J. Biol. Chem. 276: 26629-26639. 
TRAYHURN P, DUNCAN JS, NESTOR A, THOMAS ME, RAYNER DV (1994):

Chemiluminescent detection of mRNAs on northern blots with digoxygenin endlabeled oligonucleotides

Anal. Biochem. 222: 224-230.

TRIBBLE DL, Aw TY, JONES DP (1987):

The pathophysical significance of lipid peroxidation in oxidative cell injury Hepatology 7: 377-387.

UENISHI H, HIRAIWA H, SAWAZAKI T, KIUCHI S, YASUE H (2001):

Genomic organization and assignment of the interleukin 7 gene (IL7) to porcine chromosome $4 \mathrm{q} 11 \rightarrow \mathrm{q} 13$ by FISH and by analysis of radiation hybrid panels Cytogenet. Cell Genet. 93: 65-72.

ULLRICH A, SHINE J, CHIRGWIN J, PICTET R; TISCHER E, RUTTER WJ, GOODMAN HM (1977):

Rat insulin genes: construction of plasmids containing the coding sequence Science 196: 1313-1319.

VAN ASSCHE G, BARBARA G, DENG Y, LOVATO P, GAULDIE J, COLLINS SM (1999):

Neurotransmitters modulate cytokine-stimulated interleukin 6 secretion in rat intestinal smooth muscle cells

Gastroenterology 116: 346-353.

VAN DE WETERING M, OOSTERWEGEL M, HOLSTEGE F, DOOYES D,

SUIJKERBUIJK R, GEURTS VAN KESSEL A, CLEVERS H (1992):

The human $T$ cell transcription factor-1 gene. structure, localization, and promotor characterization

J. Biol. Chem. 267: 8530-8536.

VAN GRIENSVEN M, STALP, SEEKAMP A (1999):

Ischemia-Reperfusion directly increases pulmonary endothelial permeability in vitro

Shock 11: 259-263.

VEDDER NB, FOUTY BW, WINN RK, HARLAN JM, RICE CL (1989):

Role of neutrophils in generalized reperfusion injury associated with resuscitation from shock

Surgery 106: 509-516.

WAN JS, SHARP SJ, POIRIER GM, WAGAMAN PC, CHAMBERS J, PYATI J, HOM YL, GALINDO JE, HUVAR A, PETERSON PA, JAKSON MR, ERLANDER MG (1996):

Cloning differentially expressed mRNAs

Nat. Biotechnol. 14:1685-1691.

WARD PA, MULLIGAN MS (1991):

New insights into mechanisms of oxyradical and neutrophil mediated lung injury Klin. Wochensch. 69: 1009-1011. 
WARREN JS, YABROFF KR, REMICK DG, KUNKEL SL, CHENSUE SW, KUNKEL RG, JOHNSON KJ, WARD PA (1989):

Tumor necrosis factor participates in the pathogenesis of acute immune complex alveolitis in the rat

J. Clin. Invest. 84: 1873-1882.

WATANABE M, UENO Y, YAJIMA T, IWAO Y, TSUCHIYA M, ISHIKAWA H, AISO S, HIBI H (1995):

Interleukin 7 is produced by human intestinal epithelial cells and regulates the proliferation of intestinal mucosal lymphocytes

J. Clin. Invest. 95: 2945-2953.

WATANABE F, KAMIIKE W, NISHIMURA T, HASHIMOTO T, TAGAWA K (1983):

Decrease in mitochondrial levels of adenine nucleotides and concomitant mitochondrial dysfunction in ischemic rat liver

J. Biochem. (Tokyo) 94: 493-499.

WAUD WR, RAJAGOPALAN KV (1976):

"The mechanism of conversion of rat liver xanthine dehydrogenase from an $\mathrm{NAD}^{+}$-dependent from (typ D) to an $\mathrm{O}_{2}$-dependent from (typ O)"

Arch. Biochem. Biophys. 172: 365-379.

WEIXIONG H, ANEMAN A, NILSSON U, LUNDGREN O (1994):

Quantification of tissue damage in the feline small intestine during ischemiareperfusion: the importance of free radicals

Acta. Physiol. Scand. 150: 241-250.

WENZEL RP (1993):

"Prevention and control of nosocomial infection"

$2^{\text {nd }}$ edition.Williams and Wilins. Baltimore, Hong-Kong, London, Munich,

Philadelphia, Sydney, Tokyo.

WHEELOCK EF (1965):

Interferon-like virus-inhibitor induced in human leukocytes by phyto-

hemagglutinin

Science 149: 310-311.

WIEDMANN B, SAKAI H, DAVIS TA, WIEDMANN M (1994):

$A$ protein complex required for signal-sequence-specific sorting and translocation

Nature 370: 434-440.

WYBLE CW, DESAI TR, CLARK ET, HYNES KL, GEWERTZ BL (1996):

Physiologic concentrations of TNFalpha and IL-1beta released from reperfused human intestine upregulate E-selectin and ICAM-1

J. Surg. Res. 63: 333-338.

YEH KY, YEH M, GLASS J, GRANGER DN (2000):

Rapid activation of NF-kappaB and AP-1 and target gene expression in postischemic rat intestine

Gastroenterology 118: 525-534. 
YOTOV WV, MOREAU A, ST-ARNAUD R (1998):

The alpha chain of the nascent polypeptide-associated complex functions as a transcriptional coactivator

Mol. Cell Biol. 18: 1303-1311.

ZEITZ M, QUINN TC, GRAEFF AS, JAMES SP (1988):

Mucosal T cells provide helper function but do not proliferate when stimulated by specific antigen in lymphogranuloma venererum proctitis in nonhuman primates

Gastroenterology 94: 353-366.

ZHENG XM, BLACK D, CHAMBON P, EGLY JM (1990):

Sequencing and expression of complementary DNA for the general transcription factor BTF3

Nature 344: 556-559.

ZHU WM, ROMA P,PELLEGATTA F, CATAPANO AL (1994):

Oxidized-LDL induces the expression of heat shock protein 70 in human endothelial cells

Biochem. Biophys. Res. Commun. 200: 389-394.

ZHU WM, ROMA P, PIRILLO A, PELLEGATTA F, CATAPANO AL (1995):

Oxidized LDL induces hsp70 eypression in human smooth muscle cells

FEBS-Lett. 372: 1-5.

ZUND G, NELSON DP, NEUFELD EJ, DZUS AL, BISCHOFF J, MAYER JE, COLGAN SP (1996):

Hypoxia enhances stimulus-dependent induction of E-selectin on aortic endothelial cells

Proc. Natl. Acad. Sci. USA. 93: 7075-7080. 
Aus dieser Promotionsarbeit sind folgende Veröffentlichungen hervorgegangen:

\section{Publications}

1. Braun F, Hosseini M, Laabs S, Bothur P, Sattler B, Elias K, Ringe B.

Kinetics of inflammatory parameters after intestinal ischemia reperfusion injury.

Acta Gastro-Ent Belg 1999; 62 (2): 226-228

2. Braun F, Quondamatteo F, Bothur P, Hosseini M, Laabs S, Sattler B, Ringe B.

Determination of intestinal $\alpha$-glutathione S-transferase after ischemia-reperfusion injury.

Acta Gastro-Ent Belg 1999; 62 (2): 229-233

3. Braun F, Hosseini S, Lorf T, Laabs S, Ringe B.

Differential gene expression during intestinal ischemia-reperfusion injury.

Transplant Proc 2002; 34(6): 2301

\section{Abstracts}

1. Braun F, Schütz E, Christians U, Shipkova M, Hosseini M, Laabs S, Bothur P, Elias K, Ringe B. Effects of Tacrolimus/MMF on swine small bowel perfusion after ischemia-reperfusion.

Eur Surg Res 1999 (31): 58

2. Braun F, Hosseini $\mathbf{M}$, Laabs $S$, Bothur $P$, Ringe $B$.

Differential gene expression during ischemia/reperfusion.

Transplantation 2000; 69 (8): 354

3. Hosseini M, Braun F, Sattler B, Laabs S, Ringe B.

Inflammatory mediators from non-immune cells after intestinal ischemia-reperfusion injury in swine.

Eur Surg Res 2000; 32 (Suppl. 1): 95

4. Laabs S, Braun F, Hosseini M, Sattler B, Schütz E, Oellerich M, Ringe B.

Einfluß der Konservierungszeit auf den Sauerstoffverbrauch im Gewebe und mukosale Schädigung nach Reperfusion des Dünndarms beim Schwein.

TxMed 2000; Suppl.: 170

5. Hosseini M, Braun F, Laabs S, Wieland E, Ringe B.

A hypoxia related gene detected by $m R N A$ differential display after isolated intestinal reperfusion and intestinal transplantation in pigs.

Am J Transplant 2001; Suppl.: 463

6. Braun F, Hosseini M, Laabs S, Sattler B, Wieland E, Ringe B.

Localization and kinetics of interleukin-6 (IL-6) during ischemia-reperfusion (IRI) of porcine intestine.

Am J Transplant 2001; Suppl.: 238

7. Hosseini M, Braun F, Kruse R, Laabs S, Ringe B.

Differentielle Genexpression während intestinaler Ischämie und Reperfusion beim Schwein. Transplantationsmedizin 2001; Suppl.: S-39 


\section{Poster presentations}

1. Braun F, Hosseini M, Laabs S, Bothur P, Sattler B, Hanack U, Castro-Machguth R, Ringe B. Kinetics of inflammatory parameters after intestinal ischemia reperfusion injury.

$7^{\text {th }}$ meeting of the European Intestinal Transplantation Study Group, Brussels (Belgien) 31.10.1998

2. Braun F, Hosseini M, Sattler B, Schütz E, Castro-Machguth R, Ringe B.

Source of inflammatory parameters in non-immune cells during intestinal ischemia reperfusion injury in swine.

European meeting on Biomarkers of Organ Damage and Dysfunction (EMBODY),

Cambridge (England) 03.-07.04.2000

3. Braun F, Hosseini M, Laabs S, Bothur P, Ringe B.

Differential gene expression during ischemia/reperfusion.

American Society of Transplant Surgeons (ASTS) and American Society of Transplantation (AST), Transplant 2000 Joint Meeting,

Chicago (USA) 13.-17.05.2000

4. Hosseini M, Braun F, Sattler B, Laabs S, Ringe B.

Inflammatory mediators from non-immune cells after intestinal ischemia-reperfusion injury in swine.

$X X X V^{\text {th }}$ European Society for Surgical Research,

Malmö (Schweden) 01.-03.06.2000

5. Laabs S, Braun F, Hosseini M, Sattler B, Schütz E, Oellerich M, Ringe B.

Einfluß der Konservierungszeit auf den Sauerstoffverbrauch im Gewebe und mukosale

Schädigung nach Reperfusion des Dünndarms beim Schwein.

9. Jahrestagung der Deutschen Transplantationsgesellschaft,

Regensburg (Deutschland), 26.-28.10.2000

6. Braun F, Hosseini M, Laabs S, Sattler B, Wieland E, Ringe B.

Localization and kinetics of interleukin-6 (IL-6) during intestinal ischemia-reperfusion injury (IRI) of porcine intestine.

Transplant 2001, The Joint American Transplant Meeting (AST and ASTS),

Chicago (USA), 11.-16.05.2001

7. Hosseini M, Braun F, Kruse R, Laabs S, Ringe B.

Differentielle Genexpression während intestinaler Ischämie und Reperfusion beim Schwein.

10. Jahrestagung der Deutschen Transplantationsgesellschaft (DTG),

Heidelberg (Deutschland), 22.-24.11.2001

\section{Oral presentations}

1. Braun F, Quondamatteo F, Bothur P, Hosseini M, Laabs S, Sattler B, Ringe B.

Determination of intestinal $\alpha$ - and $\mu$-glutathione S-transferase after ischemia-reperfusion injury.

$7^{\text {th }}$ meeting of the European Intestinal Transplantation Study Group,

Brüssel (Belgien) 31.10.1998

2. Braun F, Schütz E, Christians U, Shipkova M, Hosseini M, Laabs S, Bothur P, Elias K, Ringe B. Effects of Tacrolimus/MMF on swine small bowel perfusion after ischemia-reperfusion.

European Society of Surgical Research (ESSR),

Bern (Schweiz) 24.04.1999

3. Braun F, Hosseini M, Laabs S, Sattler B, Ringe B.

Kinetics and source of interleukin-6 after intestinal ischemia-reperfusion injury.

$6^{\text {th }}$ International Symposium on Small Bowel Transplantation,

Omaha (USA) 06.-08.10.1999 
4. Braun F, Laabs S, Hosseini M, Schütz E, Ringe B. An ex vivo model to study intestinal ischemia-reperfusion in pigs.

$1^{\text {st }}$ European Transplant Fellow Workshop (ETFW),

Groningen (Niederlande), 20.-22.09.2000

5. Hosseini M, Braun F, Laabs S, Wieland E, Ringe B.

A hypoxia related gene detected by $m R N A$ Differential display after isolated intestinal perfusion and intestinal transplantation in pigs.

American Society of Transplantation (AST),

Chicago (USA), 11.-16.05.2001

6. Braun F, Hosseini M, Laabs S, Sattler B, Wieland E, Ringe B.

Localization and kinetics of interleukin-6 (IL-6) during ischemia-reperfusion injury (IRI) of porcine intestine.

American Society of Transplantation (AST),

Chicago (USA), 11.-16.05.2001

\section{Sequenzen in Genbanken}

$\begin{array}{llcc}\text { mRNA: Sus scrofa, Serine-Threonine kinase (STK); partial CDS } & \underline{\text { Länge(bp) }} & & \text { GenBank } \\ \text { mRNA: Sus scrofa, ribosomales protein L3 (RPL3); partial CDS } & 133 & \text { AF244364 } \\ \text { mRNA: Sus scrofa, FAT tumor suppressor gene (SFAT); partial CDS } & 587 & \text { AF203699 } \\ \text { mRNA: Sus scrofa, Son3 protein mRNA; partial CDS } & 525 & \text { AF255344 }\end{array}$




\section{DANKSAGUNG}

Diese Arbeit wurde im Rahmen des SFB402 Teilprojektes D1 (01.01.199831.12.2000) und des German Israeli Foundation (G.I.F.) Grant (2013-1079.2/2000) (01.10.2001-30.09.2002) in der Klinik für Transplantationschirurgie im Zentrum Chirurgie der Georg-August-Universität zu Göttingen von März 1998 bis Februar 2002 erstellt.

Herrn Professor Dr. B. Ringe (bis 31.03.2002 Direktor der Klinik für Transplantationschirurgie und Teilprojektleiter im SFB402 D1) danke ich für die Überlassung des Themas und die fachliche Beratung bei der Erstellung meiner Dissertation.

Ebenso danke ich Herrn Professor Dr. Hardeland und Herrn Professor Dr. Engel für ihre Bereitschaft, als Referent und Korreferent für meine Arbeit zur Verfügung zu stehen, und die konstruktiven Vorschläge und die fachliche Beratung bei der Erstellung meiner Promotion.

Ferner danke ich Herrn Professor Dr. E. Wieland für die sehr hilfreichen Gespräche und seine guten Anregungen.

Mein besonderer Dank gilt Dr. F. Braun (damaliger Assistent der Klinik für Transplantationschirurgie, Teilprojektleiter im SFB402 D1 und Leiter des G.I.F.Projektes), der mir jederzeit mit Rat und Tat bei der Durchführung des Projektes zur Seite stand.

Für zahlreiche, anregende Diskussionen danke ich außerdem meinem Bruder, Herrn Dr. Dr. H. Hosseini.

Dr. K. Nebendahl und Dr. O. Schunck aus der Zentralen Tierexperimentellen Einrichtung danke ich für die Durchführung der Narkosen bei den Organentnahmen.

Den medizinisch-technischen Assistentinnen des Zentrums Chirurgie danke ich für die Unterstützung bei der Durchführung der Versuche während der Erstellung meiner Promotion.

Den Mitarbeitern der Abteilung Klinische Chemie und der Abteilung Kardiologie danke ich für die Bereitstellung von Geräten und Räumlichkeiten (S1-Labor) zur Durchführung meiner Arbeit. Schließlich danke ich meiner Frau, Violaine Eymard, für ihr Verständnis und ihre stetige Ermutigung. 


\section{LEBENSLAUF}

Am 07.11.1960 wurde ich in Teheran (Iran) als fünftes von neun Kindern meiner Eltern geboren. Die Grundschule, Mittelschule und das Gymnasium habe ich in Teheran besucht. Im Jahre 1979 habe ich das iranische Abitur mit dem Schwerpunkt Naturwissenschaften abgelegt. Von 1980 bis 1982 habe ich meinen Militärdienst im Iran abgeleistet. Danach habe ich als selbstständiger Kaufmann in Teheran gearbeitet. Ich habe 1985 den Iran verlassen und bin in die Bundesrepublik Deutschland eingereist. Nach einem Intensivsprachkurs in Deutsch an der GFBA in Hannover habe ich von 1988 bis 1989 das dortige Studienkolleg besucht und die allgemeine Hochschulreife erworben. Am 15.04.1990 habe ich mit dem Studium des Faches Chemie an der Universität Göttingen begonnen und bin im Wintersemester 1991 zum Studium der Biologie gewechselt. Am 01.05.1996 habe ich die Diplomprüfung im Studiengang Biologie mit der Note "gut“ bestanden. Meine Diplomarbeit habe ich im Max-Planck-Institut für experimentelle Medizin in der Abteilung für molekulare Genetik angefertigt. Das Thema der Diplomarbeit war die zelluläre Lokalisation des Cdc6-EGFP-Fusions-proteins in Saccharomyces cerevisiae. Die Diplomarbeit wurde mit der Note „sehr gut“ bewertet. Vom 01.03.1998 bis 31.03.2002 war ich wissenschaftlicher Mitarbeiter der Klinik für Transplantationschirurgie der Universität Göttingen. Anschließend war ich vom 01.04.2002 bis 31.07.2002 als wissenschaftlicher Mitarbeiter in der Abteilung Allgemeinchirurgie des Göttinger Universitätsklinikums beschäftigt. Während dieser Zeit habe ich u. a. die molekularbiologischen Untersuchungen zur Pathophysiologie des Ischämie-Reperfusionsschadens durchgeführt, welche Thema dieser Arbeit sind. Dieser Forschungsschwerpunkt wurde im Teilprojekt D1 „Mechanismen des Konservierungs-/Reperfusionsschadens und dessen Bedeutung für den Funktionserhalt von Leber und Dünndarm des Schweins“ des SFB402 „Molekulare und zelluläre Hepatogastroenterologie“ vom 01.01.1998 bis zum 31.12.2000 gefördert. Die Förderung wurde seit dem 01.10.2001 durch das Projekt der German Israeli Foundation (G.I.F.) Grant (2013-1079.2/2000) fortgesetzt.

Seit dem 01.08.2002 bin ich wissenschaftlicher Mitarbeiter in der Abteilung Kardiologie und Pneumologie der Universität Göttingen.

Am 30.07.1993 habe ich Violaine Eymard geheiratet. Wir haben zwei Kinder. Seit dem 12.03.2000 bin ich deutscher Staatsbürger. 


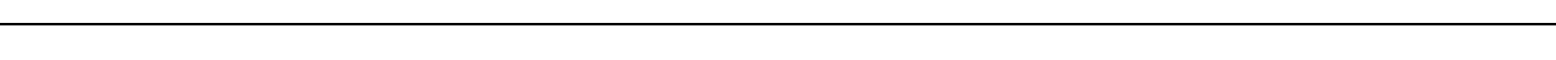

